US Arm y Corps

neers

LIBRARY Irways Experiment JSE ONLY

US-CE-C Property of the

United States Government

\title{
A Finite-Element Model for the Olmsted Wicket
}

by Mostafiz R. Chowdhury, Sharon Garner,

Yazmin Seda-Sanabria, Robert L. Hall

Approved For Public Release; Distribution Is Unlimited Prepared for Headquarters, U.S. Army Corps of Engineers
and U.S. Army Engineer District, Louisville

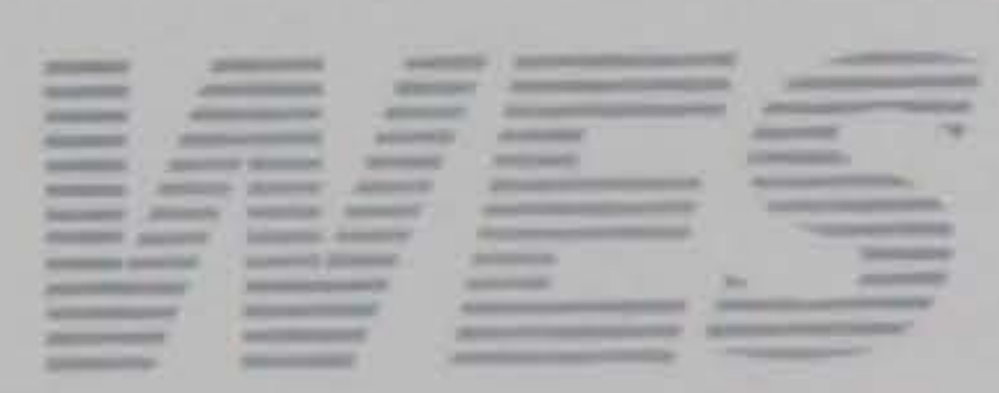

Research Library

US Army Engineer Waterways

Experiment Station

Vicksburg. Mississippi 
The contents of this report are not to be used for advertising, publication, or promotional purposes. Citation of trade names does not constitute an official endorsement or approval of the use of such commercial products.

The findings of this report are not to be construed as an official Department of the Army position, unless so designated by other authorized documents. 


\section{A Finite-Element Model for the OImsted Wicket}

by Mostafiz R. Chowdhury, Sharon Garner, Yazmin Seda-Sanabria, Robert L. Hall

U.S. Army Corps of Engineers

Waterways Experiment Station

3909 Halls Ferry Road

Vicksburg, MS 39180-6199

Final report

Approved for public release; distribution is unlimited 


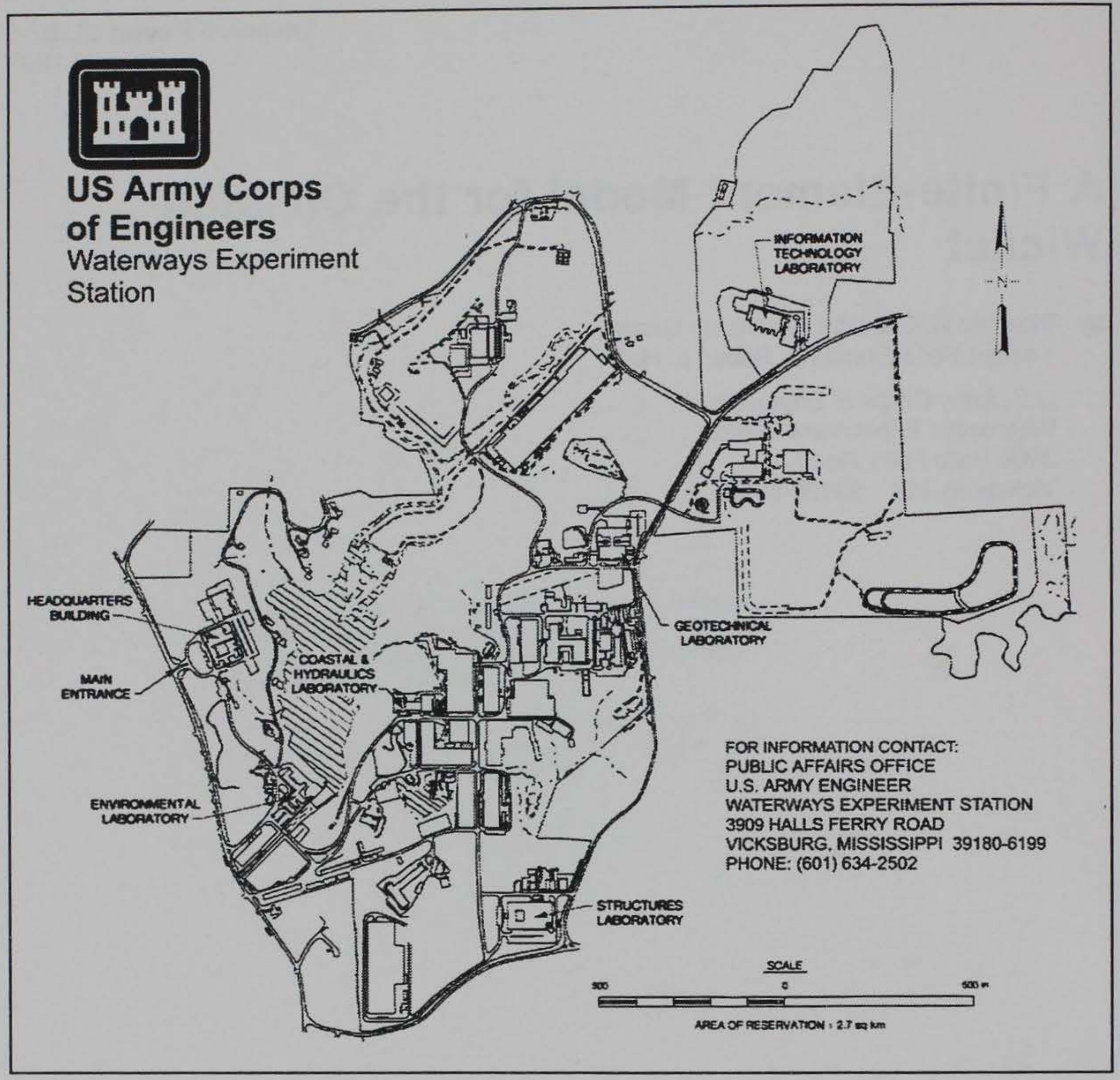

Waterways Experiment Station Cataloging-in-Publication Data

A finite-element model for the Olmsted wicket / by Mostafiz R. Chowdhury ... [et al.]; prepared for U.S. Army Corps of Engineers and U.S. Army Engineer District, Louisville.

108 p. : ill. ; $28 \mathrm{~cm}$. - (Technical report ; SL-97-6)

Includes bibliographic references.

1. Finite element method - Computer programs. 2. Hydraulic gates. 3. Locks (Hydraulic engineering) - Ohio River - Mathematical models. 4. Olmsted Locks and Dam Project -Ohio River. I. Chowdhury, Mostafiz R. II. United States. Army. Corps of Engineers. Louisville District. III. U.S. Army Engineer Waterways Experiment Station. IV. Structures Laboratory (U.S. Army Engineer Waterways Experiment Station) V. Series: Technical report (U.S. Army Engineer Waterways Experiment Station) ; SL-97-6.

TA7 W34 no.SL-97-6 


\section{Contents}

Preface

Conversion Factors, Non-SI to SI Units of Measurement $\quad \mathrm{x}$

1-Introduction 1

Background

Olmsted Navigational Pass 2

Physical Model Studies 5

Objectives

Scope 7

2-Finite-Element (FE) Model- Development Phases 8

Background $\quad 8$

Physical Model $\quad 9$

Model descriptions 9

Physical and material properties $\quad 10$

Preliminary FE Model 12

Verification of Preliminary Model 13

Dry gate modal parameters $\quad 15$

Static response $\quad 19$

Revised FE Model 21

Modeling of supports $\quad 22$

Added fluid masses $\quad 25$

Damping 26

Verification of the Revised FE Model 27

Response spectrum results $\quad 28$

Time-domain dynamic response 35

3-FE Model-Applications $\quad 56$

Background $\quad 56$

Sensitivity Study $\quad 56$

Physical parameters $\quad 58$

Pre-experiment Investigation $\quad 62$

Fatigue Analysis $\quad 62$

Critical Response Simulation $\quad 64$

Idealized loading 64

Frequency analyses $\quad 67$

Time-history analysis $\quad 68$ 
4 -Results and Conclusions $\quad 77$

$\begin{array}{ll}\text { Results and Conclusions } & 77\end{array}$

$\begin{array}{ll}\text { References } & 81\end{array}$

Appendix A: Selected Prototype Design Sheets A1

\section{List of Figures}

Figure 1. Olmsted L\&D location 3

Figure 2. Locks and dam \#52 4

$\begin{array}{lll}\text { Figure } 3 \text { Olmsted 1:5-scale model } & 6\end{array}$

$\begin{array}{ll}\text { Figure 4. Views of connection details } & 10\end{array}$

Figure 5. Equilibrium experiment on the physical wicket model 12

$\begin{array}{lll}\text { Figure 6. Finite-element grid } & 14\end{array}$

Figure 7. Frequency response function for upstream and downstream scanning of the physical gate $\quad 16$

Figure 8. Calculated mode shapes for the initial FE model 18

Figure 9. Location of distributed loading and displacement gauges for static experiment 19

Figure 10. Revised FE model with reference axes for tests and analyses 22

Figure 11. An illustrations of boundary conditions in the FE model 23

Figure 12. Analytical simulation of base hinge-pin connection 24

Figure 13. Analytical simulation of prop-rod and gate connection 24

$\begin{array}{lll}\text { Figure 14. Experimental modal setup schematic diagram } & 27\end{array}$

Figure 15. A three-gate gap flow configuration 28

iv 
Figure 16. Mode shapes, dry condition, prop-rod end restrained in $\mathrm{x}, \mathrm{y}$, and $\mathrm{z}$ directions

Figure 17. Mode shapes, dry condition, prop-rod end restrained

in $\mathrm{x}$ and $\mathrm{y}$ directions only

Figure 18. Experimental mode shapes for the prop-supported physical model 32

Figure 19. Location of FE nodes and accelerometers

Figure 20. Pressure gauge locations and column lines for displaying pressure readings

Figure 21. $\mathrm{Z}$ accelerations, node 9581 and gauge 1

Figure 22. $\mathrm{Z}$ accelerations, node 9728 and gauge 2

Figure 23. $\mathrm{Z}$ accelerations, node 8877 and gauge 3

Figure 24. $\mathrm{Z}$ accelerations, node 7188 and gauge 4

Figure 25. $\mathrm{Z}$ accelerations, node 7145 and gauge 6

Figure 26. $\mathrm{Z}$ accelerations, node 2813 and gauge 7

Figure 27. $\mathrm{Z}$ accelerations, node 2858 and gauge 8

Figure 28. $\mathrm{Z}$ accelerations, node 2769 and gauge 9

Figure 29. FFT of ABAQUS and test records, gauge 8 and node 2858

Figure 30. Frequency response function for prop rod

Figure 31. FFT plots of 21-ft head test $\mathrm{z}$ accelerations, accelerometers 1 through 9

Figure 32. FFT plots of ABAQUS $\mathrm{z}$ acceleration records corresponding to gauges 1 through 9

Figure 33. ABAQUS versus test amplitudes, gauges 1 through 4 and 6 through 9

Figure 34. $\mathrm{Z}$ acceleration, node 9581 and gauge 1, analysis 2

Figure 35. $Z$ acceleration, node 7188 and gauge 4, analysis 2 
Figure 36. $\mathrm{Z}$ acceleration, node 2813 and gauge 7 , analysis 2

Figure 37. Frequency content of $Z$ acceleration records for 3 nodes, analysis 2

Figure 38. Measured and calculated hinge reactions

Figure 39. Calculated prop-rod reactions

Figure 40. $\mathrm{ABAQUS}$ total reactions, $\mathrm{AB} 1$ and $\mathrm{AB} 2$

Figure 41. Locations and direction of reactions, ABAQUS analyses

Figure 42. Typical maximum principal stress, gate top plate

Figure 43. Typical maximum principal stress, gate-hinge surfaces

Figure 44. Variation of deflection at gauge locations due to changes in span length ( $E=32,213 \mathrm{ksi}$, and roller model)

Figure 45. Variation of deflection at gauge locations due to changes in modulus of elasticity ( $\mathrm{Y}=21.4 \mathrm{in}$. and roller model)

Figure 46. Variation of deflection at gauge locations due to changes in component thickness ( $\mathrm{E}=32,213 \mathrm{ksi}, \mathrm{Y}=21.4$ in., and spring model)

Figure 47. Variation of deflection at gauge locations due to changes in support conditions $(\mathrm{E}=32,213 \mathrm{psi}, \mathrm{Y}=21.4$ in.)

Figure 48. Gate frame hinge assembly

Figure 49. Average maximum pressure distribution at critical configuration ( $24 \mathrm{deg})$

Figure 50. Normalized random acceleration (ratio) record for the critical configuration

Figure 51. Auto spectra comparison for the full and partial time record

Figure 52. Modes 1 through 5 , gate at $24 \mathrm{deg}$

Figure 53. Accelerations at nodes near hinges, at center of gate, and near the top of the gate

Figure 54. Displacements at top corner nodes

vi 
Figure 55. Displaced shape at $2.787 \mathrm{sec}$, magnification factor 20

Figure 56. Maximum principal stress, gate top and bottom surfaces, $\mathrm{t}=2.787 \mathrm{sec}$

Figure 57. Maximum principal stresses on end plate, $\mathrm{t}=2.787 \mathrm{sec}$

Figure 58. Maximum principal stresses at center support stiffeners, $\mathrm{t}=2.787 \mathrm{sec}$

Figure 59. Maximum principal stresses in gate hinges, $\mathrm{t}=2.787 \mathrm{sec}$

Figure 60. Maximum principal stresses at support-rod hinges, $\mathrm{t}=2.787 \mathrm{sec}$

Figure 61. Von-Mises stresses at end plate

Figure 62. Von-Mises stresses at gate hinges 76

\section{List of Tables}

Table 1. Material Properties for the 1:5-scale Wicket Model

Table 2. Physical Properties for the Experimental and Analytical Model

Table 3. Analytical and Experimental Modal Frequencies

Table 4. Experimental and ABAQUS results for Static Test 1

Table 5. Gate Hinge Reactions, Static Analysis

Table 6. Experimental Dynamic Characteristics, Dry and 21-ft

Head Conditions for the Prop-Supported Wicket

Table 7. Response Spectrum Modes, Dry Analyses

Table 8. Response Spectrum Modes, Wet Analyses

Table 9. Correlation Matrix for the Prop-Supported Dry Wicket Modes Obtained from an Analytical (no Z-Restraint Case) and the Experimental Sources 
Table 10. Correlation Matrix for the Prop-Supported Wet Wicket Modes Obtained from an Analytical (no Z-Restraint Case) and the Experimental Sources

Table 11. Modal Participation Factors, "Wet" Analysis, Z Restraint

Table 12. Modal Participation Factors, "Wet" Analysis, No Z Restraint

Table 13. Measured Deflection in inches

Table 14. Spring Stiffness for Boundary Condition (Spring) at $\mathrm{Y}=21.4$ in.

Table 15. Thickness Variation in the Major Gate Components

Table 16. Adjusted Results for Modified Thicknesses and Boundary Condition (Spring) set at $\mathrm{Y}=21.4$ in. 


\section{Preface}

The research reported herein was sponsored by the U.S. Army Engineer District, Louisville, in support of the Olmsted Navigational Model Study program. Mrs. Anjana Chudgar was the technical monitor for the structural performance evaluation of the Olmsted wickets.

All work was carried out by Dr. Mostafiz R. Chowdhury and Robert L. Hall, Ms. Sharon Garner, and Ms. Yazmin Seda-Sanabria, Structural Mechanics Division (SMD), Structures Laboratory (SL), U.S. Army Engineer Waterways Experiment Station (WES), under the general supervision of Mr. Bryant Mather, Director, SL; Mr. John Ehrgott, Assistant Director; and Dr. Reed Mosher, Chief, SMD. The work was conducted during the period May 1993 through January 1996 under the direct supervision of Dr. Chowdhury.

The contribution of Mr. William $\mathrm{Li}$, graduate student from the Virginia Polytechnic Institute and State University, in analyzing modal data used in this report to update the finite-element model is gratefully acknowledged. Mr. Billy Benson, SMD, assisted during the static tests. Mr. Joe Ables, Information Technology laboratory (ITL), was responsible for instrumentation and operation of the model during tests. Mr. Terry Warren, ITL, wrote the program for data acquisition, and Mr. Homer Greer, ITL, was responsible for coordinating instrumentation and data acquisition tasks. The efforts of Editorial Section and Visual Production Center, ITL, staff members who participated in the preparation of the report are appreciated.

At the time of publication of this report, Director of WES was Dr. Robert W. Whalin. Commander was COL Bruce K. Howard, EN.

The contents of this report are not to be used for advertising, publication, or promotional purposes. Citation of trade names does not constitute an official endorsement or approval of the use of such commercial products. 


\section{Conversion Factors, Non-SI to SI Units of Measurements}

Non SI units of measurement used in this report can be converted to SI units using the conversion factors listed below.

\begin{tabular}{|l|l|l|}
\hline Multiply & By & To Obtain \\
\hline degrees (angle) & 0.01745329 & radians \\
\hline feet & 0.3048 & metres \\
\hline inches & 0.0254 & metres \\
\hline $\begin{array}{l}\text { inches per second } \\
\text { squared }\end{array}$ & 0.0254 & $\begin{array}{l}\text { metres per second } \\
\text { squared }\end{array}$ \\
\hline ksi (kips per square in.) & 6.894757 & megapascals \\
\hline pounds (force) & 4.4484 & newtons \\
\hline pounds (mass) & 0.4535924 & kilograms \\
\hline $\begin{array}{l}\text { pounds (force) per } \\
\text { square inch }\end{array}$ & 0.006894757 & megapascals \\
\hline $\begin{array}{l}\text { g (standard acceleration } \\
\text { of free fall) }\end{array}$ & 9.80665 & $\begin{array}{l}\text { metres per second } \\
\text { squared }\end{array}$ \\
\hline \hline
\end{tabular}




\section{Introduction}

\section{Background}

Olmsted Locks and Dam (L\&D) is one of the largest civil works projects undertaken by the U. S. Army Corps of Engineers to lead the modernization of Corps navigational facilities for the twenty-first century. Maintaining a robust navigational infrastructure to facilitate the water transportation and to meet the demand for the ever-increasing barge-traffic flows through our nation's inland waterways is vital to our economy. Transportation of bulk commodities through our vast inland waterways provides the most economic mode of conveyance and it conserves natural energy resources. In this complex global economy, increasing productivity by making efficient and effective use of resources has become increasingly important. In this regard, the Corps continuing effort to improve the navigation facilities using the latest technology is exemplary.

An experimental and analytical investigation was initiated by the U. S. Army Engineer (USAE) Division, Ohio River (ORD) and the USAE District, Louisville (LRL) to study the flow-induced characteristics of the wicket gates proposed for the Olmsted navigation dam. Several research and development phases were initiated and coordinated by the LRL, to accomplish this navigational project on the Ohio River. The principal focus of this research scheme was to determine the most appropriate design of wickets for the new Olmsted L\&D project. Scale models based on hydraulic and structural similitude relationships have been studied to understand the flow-induced dynamic characteristics of Olmsted wicket installed in the Olmsted Prototype Wicket Dam, Smithland facility. These models have provided researchers with necessary tools for the structural performance evaluation of hydraulically actuated wickets (March and Elder 1992, Seda-Sanabria 1994, and Chowdhury, Hall, and Pesantes 1997). Such evaluation requires the development of complex analytical models capable of properly simulating the interaction between the 
structure and the fluid flow-fields. For this purpose, the ABAQUS/Standard FE module was used to develop a numerical model of the Olmsted wicket.

The inability of the physical models to address broad boundaries of enquiry for numerous operating conditions demanded the development of an analytical model at WES. This report presents the step-by-step updating procedures used for developing an FE model based on dry and wet experimental modal analyses and flow-induced dynamic experimental results. An updated model would enable the researchers to study the effect of future modifications, if any, in obtaining an efficient and optimum design for the proposed wicket. This model can be used to measure the sensitivity of different parameters influencing the dynamics of the wicket and to evaluate the structural dynamic performance during critical operation.

\section{Olmsted Navigational Pass}

The Olmsted L\&D project is to be constructed on the Ohio River, 16 miles upstream from the confluence of the Ohio and the Mississippi Rivers. This new L\&D project will replace L\&D 52 and 53 on the lower Ohio River. This facility will facilitate navigation at Paducah, Kentucky, with a capacity sufficient to meet projected demands for tow traffic through the year 2025 . Construction of the Olmsted L\&D Project was authorized by the United States Congress on 17 November 1988, by the passage of the Water Resources Development Act of 1988 (Public Law 100-676). The cost of this project is being equally shared with the navigation industry. Tariffs paid by the navigational traffics on diesel fuel are used to form an Inland Waterways Trust Fund which will provide 50 percent of the project cost. Estimated total project cost is over $\$ 1$ billion.

Wicket gates have been used as part of lock-and-dam systems by the Corps of Engineers since 1909 (Soast 1994). Originally, 220 remotely-operated hydraulic actuators were proposed to raise and lower the wickets. However, the current plan calls for a 1,400-ft section with boat-operated steel gates in combination with six tainter gates and a fixed weir. At 10-ft wide, $26-\mathrm{ft}$ long, 
and with a design lift of $21-\mathrm{ft}$, these wickets will be the largest hydraulicallyactuated wickets in the world. The LRL gate design team has designed the prototype model for the Olmsted wickets built in the Smithland Dam on the Ohio River. The project will include twin $1,200-\mathrm{ft}$ by $110-\mathrm{ft}$ lock chambers with a design lift of $21-\mathrm{ft}$ and a 1,400-ft long navigation pass and $660 \mathrm{ft}$ of tainter gates. In the raised position, the wicket gates will be used to regulate the level of the navigable pool. In the lowered position, the gates will provide a navigable pass (Lance 1992). The remaining 140-foot dam will include a fixed-weir section which will tie into the Kentucky shore.

The Olmsted navigation pass is one of the busiest barge traffic route in the nation. The new L\&D project will be constructed near the community of Olmsted, IL, at Ohio River Mile 964.4. Figure 1 shows the relative location of the Olmsted Dam, the navigational routes, and the old L\&D 52 and 53. As shown in the figure, this reach of the Ohio River is particularly strategic in that it provides a connection between the Ohio, Tennessee, Cumberland, and Mississippi Rivers. The area has been described as the "hub" of the Ohio and Mississippi Rivers waterways system. Barge traffic moving between the Mississippi River system and the Ohio, Tennessee, and Cumberland Rivers must pass through this stretch of river. More tonnage passes this point than any other place in the inland navigation system. In 1991 alone, 100 million tons of goods were shipped through this junction of the Ohio River. Clearly, this is a critical reach of water from a commercial navigation perspective.

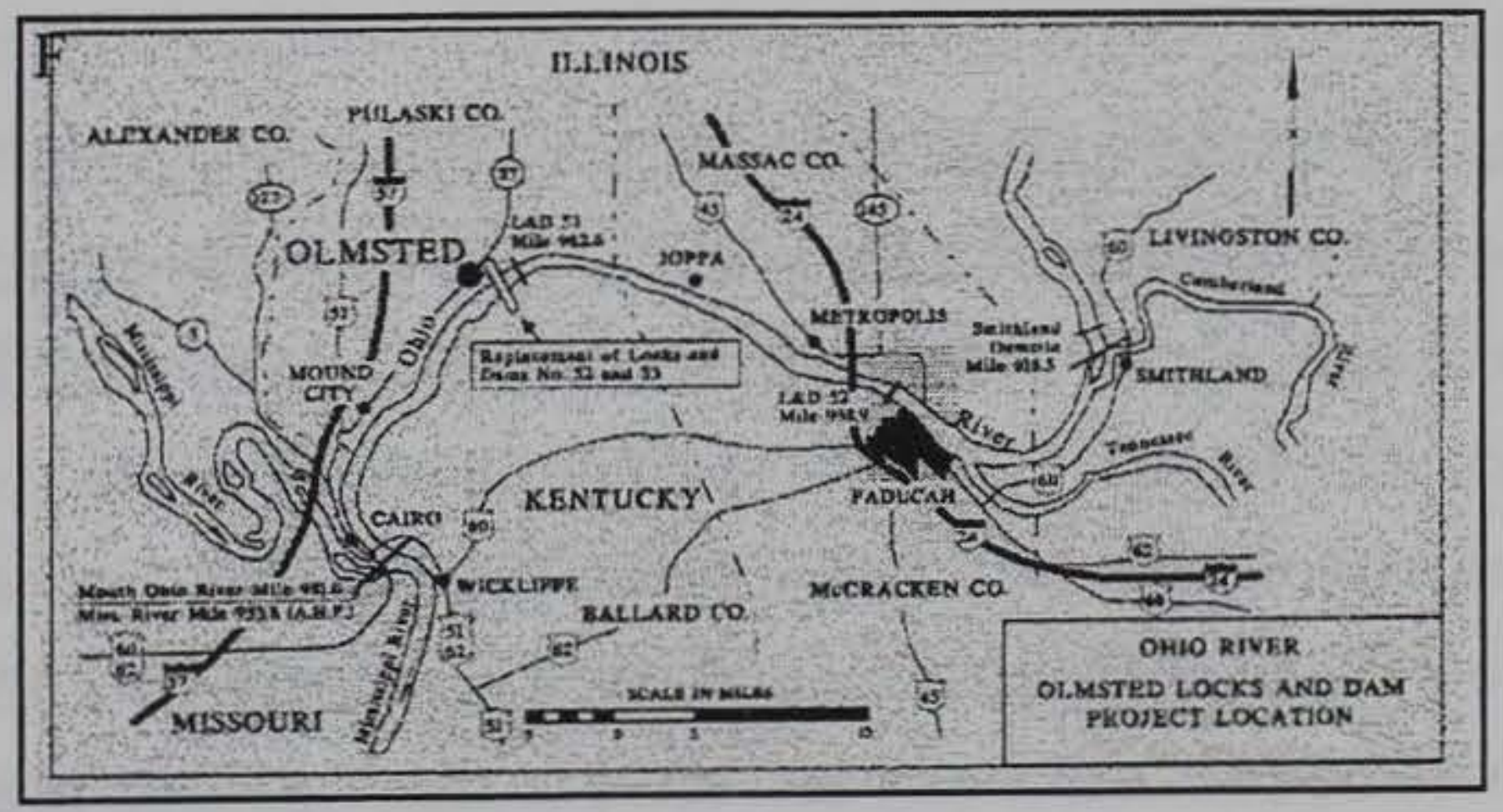

Figure 1. Olmsted L\&D location 
The original dams consisted of wooden wickets that were manually raised to hold back water during periods of low flow and dropped to the river bottom during high water. A view across the Ohio River at L\&D No. 52 , showing the operational condition of the wooden wickets is displayed in Figure 2. Built in 1929, these aged L\&D were renovated to meet traffic demands in 1970's by adding temporary, 1200-ft new lock chamber. The present facility, however, is inadequate to handle the current traffic volume without significant delays. The continuing growth in barge traffic on the Ohio River and, more importantly, deterioration of these aging structures demand a replacement of the L\&D in this strategic hub of the waterways.

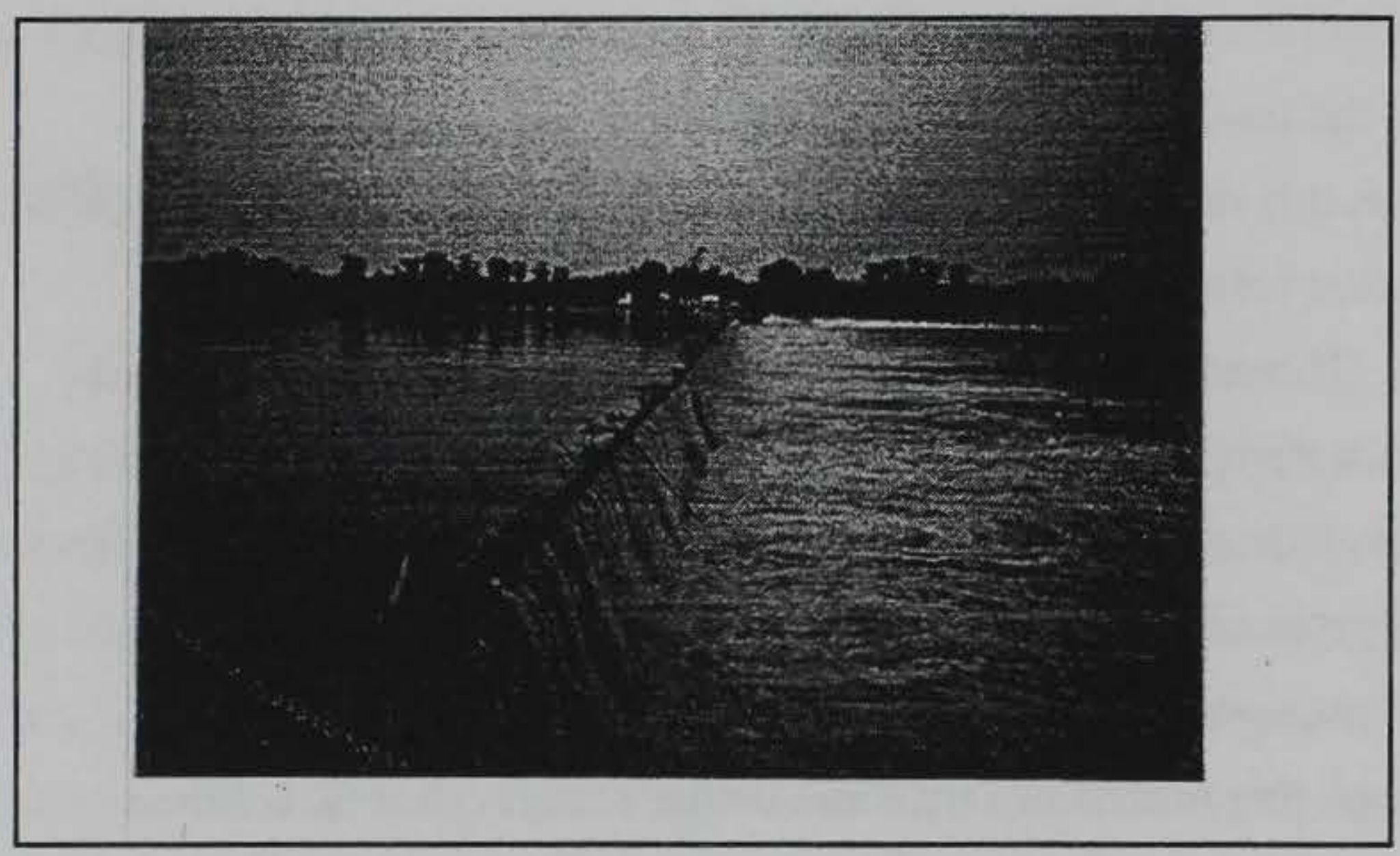

Figure 2. Locks and dam \#52

The current operating proposal calls for the wicket gates to be raised in groups of five with five-gate gaps until all 110 gates are raised. Flow over the top of any gate is not anticipated except during its raising or lowering operation. The five-gate gaps will then be closed by raising two gates simultaneously or one gate at a time. In each case, the end gate or gates will be moved. To maintain a uniform flow pattern in the river, as many as 44 gates will be simultaneously and continuously operated in a manner that subjects the gates to uneven hydraulic loading that may produce flow-induced gate vibrations. In addition, the raising or lowering 
operations could also induce gate vibrations. A large amount of gate manipulation is expected during low-flow periods due to powerhousecontrolled inflows into Olmsted Reservoir from the Tennessee and Cumberland Rivers (Elder 1992).

An updated FE model capable of simulating the flow-induced vibrational response will enable the LRL to evaluate the gate performance for a variety of channel and flow configurations. The analytical capability saves time and cost by reducing experimental simulation of numerous test cases. Most importantly the long term performance of operational wickets can be evaluated with this FE model without much additional cost. Gate component performances and the impact of individual components on the overall survivability of the wicket would enable the district to measure the reliability of the system as well. The findings obtained from these analyses will help in the support of an effective design procedure for hydraulically lifted wickets.

\section{Physical Model Studies}

The Olmsted Wicket Model studies began in January 1990 when the LRL tasked the WES with the development of a 1:25-scale curved gate model of the Olmsted L\&D. Since then, two additional models were developed: 1:25- and 1:5-scale flat gates. These physical models have been used to investigate the flow-induced vibrational response of Olmsted Wicket, and have also helped researchers to better understand the complexities involved in the fluid-structure interaction problem affecting them. The Olmsted Wicket Models studies also included a prototype test facility in the Smithland Dam on the Ohio River (Chowdhury, Ross, and Hall 1997). This facility examined the physical performances of various mechanical/electrical/hydraulic systems proposed for the Olmsted Dam. Although the prototype facility and the 1:25-scale models provided the necessary information about wicket gate vibrational behavior, both of these models had limitations. The prototype model was limited in the flow conditions that it can simulate, and the 1:25-scale models were not 
true similitude structural models. The 1:25-scale models and the prototype test facility and their limitations are further discussed by Chowdhury, Hall and Davis (technical report (TR) in preparation).

Considering the limitations involved in the construction of a prototype facility (i.e., operational inconveniences, excessive modification costs, etc.), and the inadequacy of the 1:25-scale flat gate model in representing the structural similarity of the prototype wicket, it was imperative to study the behavior of an intermediate-scale wicket in an easily controlled environment. Thus, a moderate-scale of $1: 5$ of the prototype geometry was considered for further investigation. The 1:5scale flat gate model was capable of simulating the structural as well as the hydraulic responses of the prototype gate. The 1:5-scale flat gate model, shown in Figure 3, was geometrically and dynamically a similitude model. In contrast to the previous 1:25-scale model, its geometrical characteristics simulated those found on the prototype structure.

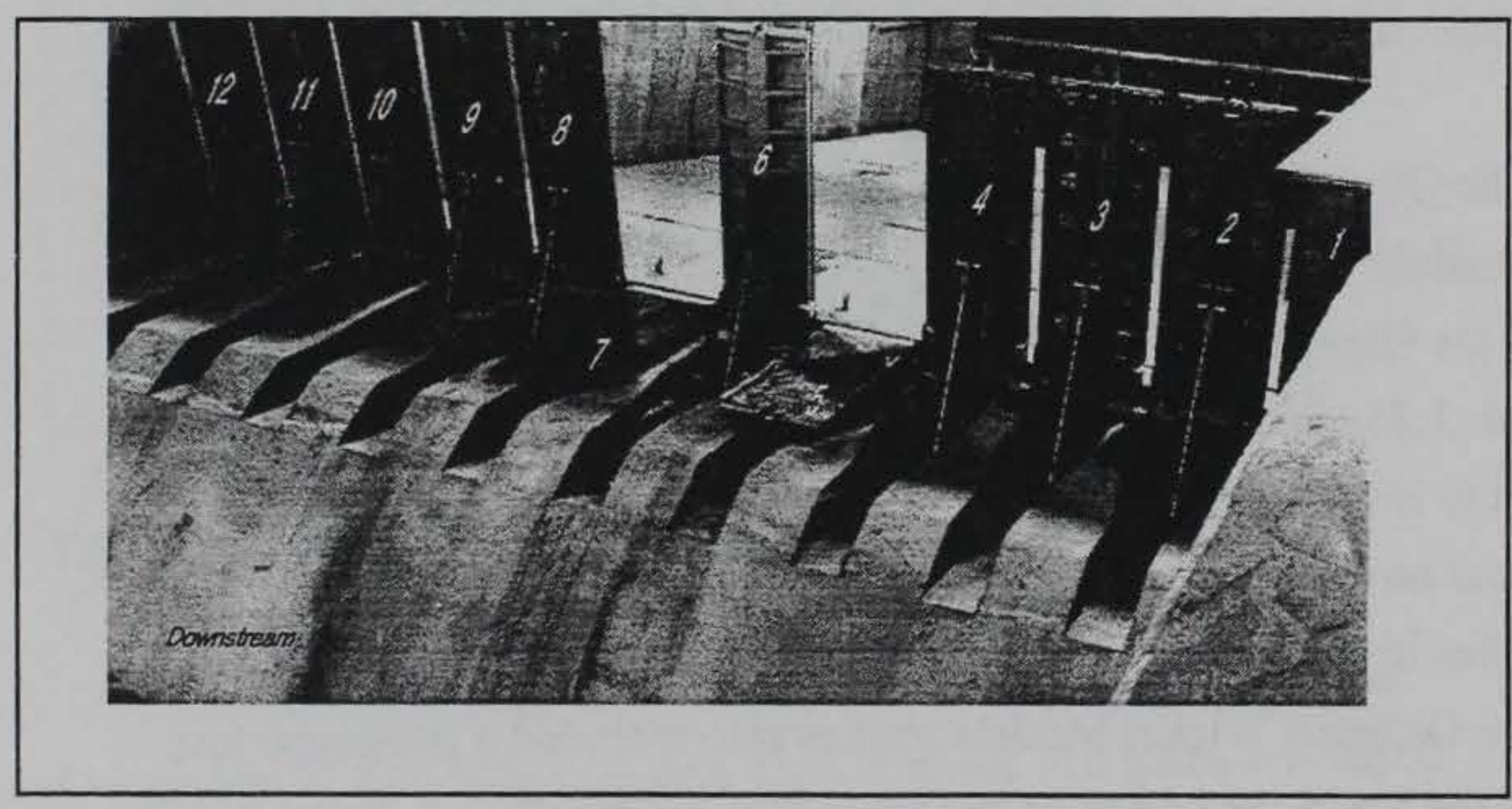

Figure 3. Olmsted 1:5-scale model

Experimental results obtained from the 1:5-scale model have been used for updating the FE model presented in this report. These included the static and dynamic parameters indicative of the actual performance of the operating wicket. 


\section{Objectives}

The objectives of the 1:5-scale flat gate model investigation in support of the Olmsted Model studies program were to:

a. Develop an analytical finite-element (FE) model for predicting the flow-induced vibrational response of Olmsted wicket gates using analytical- experimental correlation.

b. Validate design of the wickets by evaluating the FE model.

c. Investigate the gate behavior using the FE model.

\section{Scope}

An experimental and analytical investigation was initiated to study the flow-induced characteristics of the wickets proposed for the Olmsted navigation dam. Scale models based on hydraulic and structural similitude relationships have been studied to understand the flow-induced dynamic characteristics of Olmsted wicket installed in the Smithland prototype facility. These models have provided sufficient experimental data for developing analytical models capable of properly simulating the interaction between the structure and the fluid flowfields. For this purpose, the ABAQUS/Standard FE module was used to develop a numerical model of the Olmsted wicket. The FE model was validated using results obtained from both dry and wet experimental modal analyses, and static and flow-induced dynamic experiments (Chowdhury, Hall, and Davis TR in preparation). Geometric dimensions, physical properties, and experimental modal data were correlated with the analytical model to ensure the correct distribution of mass and stiffness of the model. Wet modal parameters were used to define the added mass distribution of the operational gate. Flow-induced operational test pressures on the gate surfaces were used to define the loading function and its history for the FE model. The final product of these studies is an updated FE model based on these correlations that adequately predicts the structural response of the Olmsted wickets for various operational and flow configurations. This report is a review of the step-by -step updating process used to develop the final FE model. It also describes the uses of the model for evaluating the dynamic performance of the operational wicket. 


\section{Finite-Element (FE) Model- Development Phases}

\section{Background}

The ABAQUS general purpose FE code had been used to develop a numerical model for the Olmsted wicket structure presented in this report. The general purpose of the model was to simulate the flow-induced structural motion of the wicket due to various operating conditions. This required a comprehensive modeling of the fluid-structure interaction of the system using experimental results so that a Lagrengian based FE code could be used for dynamic response prediction of an operational gate. Experimentally determined Lagrangian displacement based fluid elements could be readily incorporated into a general purpose computer code for structural analysis (Calayir and Dumanoglu 1993). Experimental results have been extensively used by the researchers to compute a virtual added mass representing the fluid-structure interaction of major navigational structures (Daniell and Taylor 1994; Ishii and Knisely 1992; and Thang 1982). An equivalent added mass is computed such that the free vibrational natural characteristics of the wet system are preserved in the model.

In the Lagrangian approach, the displacement variables in both the fluid and the structure are identical. Thus by simulating the water as a mass added to the dry structure the compatibility and equilibrium are automatically satisfied at the nodes along the interfaces between the fluid and the structures.

Experimental data for the Olmsted 1:5-scale model were used to obtain the added mass of the wicket for different operating conditions. Experimentally recorded known pressure fields provided the input forcing functions for the operational wicket. This completed the modeling of the operational wicket in three major steps. In the first step, the geometric model was developed to match the mass and stiffness of the dry wicket. In the second step, added masses were distributed in the geometry to simulate the wet natural characteristics of the operational gate, and finally, the forcing functions were applied to the FE model to measure the dynamic response of the operating gate.

Static and dynamic modal updating were used to calibrate the mass and stiffness of the FE model with those of the experimental wicket. Experimental modal data have been extensively used by researchers to correct the FE model for vibration analysis (Okuma 1993; Niedbal 1985; Touhei and Ohmachi 1994; Dascotte 1991; Petrick 1993; Brillhart et al. 1991; and Ewins 1984). All of these researchers except Touhei and Ohmachi (1994) used experimental data for updating their FE model. Touhi and Ohmachi (1994) used a finite element- 
boundary element method in the time-domain to determine the modal characteristics of dam-foundation system. Updating techniques used by these researchers included the modal assurance criteria (MAC) and crossorthogonality check (COC). MAC is used to check the consistency of the extracted modal parameters by measuring the correlation between analytical and experimental modal vectors. The $\mathrm{COC}$ determines the orthogonality of analytical and experimental modal parameters based on the property of orthogonality with respect to the analytical mass matrix.

An updated FE model is most often an approximate analysis tool which tends to minimize the deviation between the analytical and experimental responses. In reality, this deviation widens due to the uncertainty and randomness of the geometry and material properties of the structure, and loading and boundary conditions (Chang 1993). This is due to the fact that in most FE analysis, the geometric and material properties, and loading conditions are treated as deterministic despite the fact that they are variant. Difficulty of modeling of boundary conditions becomes one of the most troubled area in most $\mathrm{FE}$ analysis. Such an inherent limitation prompted researchers to study the sensitivity of major design parameters to determine the structural modification effects in the analysis for many decades (Lin Du and Ong 1993; and Bretl 1992). A sensitivity based study could correctly identify the controlling parameters which could be used with greater confidence to measure the bounds of vibrational responses. In this research, a sensitivity study was conducted to determine the major influential parameters and the bounds of wicket responses were computed using the most probable limits of boundary and loading conditions.

\section{Physical Model}

\section{Model description}

Test gate \#6, shown in Figure 3, was used to extract the experimental data for the FE model updating. General dimensions and the structural components used for fabricating the wicket are presented in Appendix A. A hydraulic lifting cylinder was used to raise and lower the gate, and the prop rod supported the gate when the dam was in service. Lugs mounted on the sill bearing frame provided base-hinge mounting connections for the gate. Base hinges restrained the translational movement of the gate with free rotational capabilities. The hydraulic system consisted of a primary and an alignment cylinder. A cup on the end of the primary cylinder piston rod provided a nonrigid bearing connection (roller) to the gate through a ball mounted to the back of the gate. This roller attachment allowed the retraction of the piston rod when the gate was being supported by the prop rod.

One end of the prop rod was pin connected to the gate and the other end 
rested on the hurter as shown in Figure 4. The bottom end of the prop blade provided "no-tension" mechanism such that the prop blade was restrained only against sliding away from the gate. Top end of the clevis connection to the ball mounting plate provided no rotational restraint. As a result, the top end of the prop rod randomly shifted its position during the operation of the gate. Such uncertain behaviors of the prop ends introduced nonlinearity into the system along with time-invariant modal responses (Chowdhury, Hall, and Davis in preparation). There are two one-way tracks in the hurter (see appendix A and Fig $4 \mathrm{~b}$ ) which provide the sliding paths for the prop rod end-blade during raising and lowering cycles.

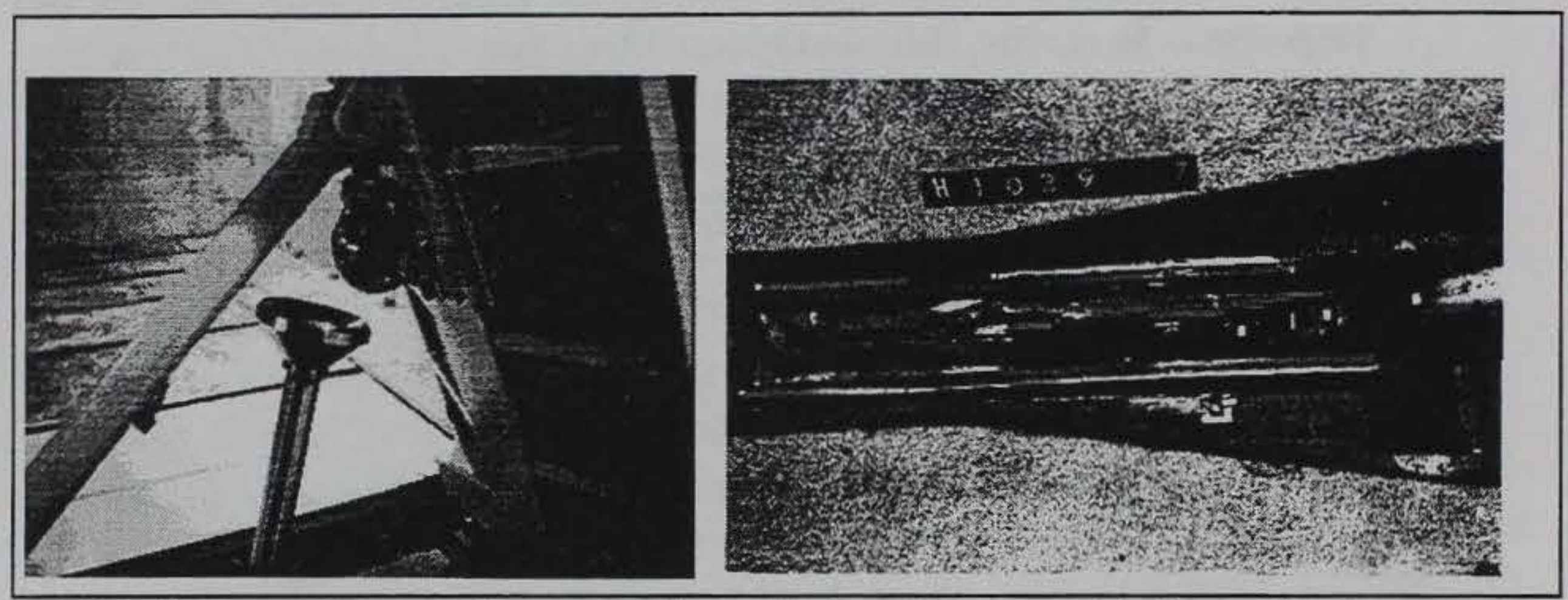

a. Ball-cup and prop-pin connections b. In-place prop-blade on the hurter recess

Figure 4. Views of connection details

During a raising cycle, the primary cylinder was extended, thereby rotating the gate through an arc from -3 to $68 \mathrm{deg}$, then stopped and retracted and the load from the gate was transferred to the prop rod at the 65-deg position where the prop rod locks in the hurter. During a lowering cycle, the primary cylinder was extended while the alignment cylinder was used to rotate the primary cylinder to match the cylinder cup with the ball mounted to the back of the gate, the gate was then rotated from 65 to $70 \mathrm{deg}$ where the prop rod was disengaged and the primary cylinder was retracted until the gate came to rest at a -3 deg position.

\section{Physical and material properties}

Prototype physical dimensions shown in appendix A were used to construct the FE model presented in this report. Table 1 shows the elastic properties of major structural components used for the scaled physical model. In this table, column two presents the design-drawing reference sheet numbers corresponding to each component mentioned in the first column. Tensile strength experiments were conducted for each batch of materials procured for the scaled physical model. Tensile strength results for each component are also shown in the table. All material experiments were conducted in the Structures Laboratory, SL, using the ASTM E8 Test Methods (ASTM 1995). As seen in 
the table, material properties differed from components to components and even within the group the material properties varied randomly. An average of three specimen results were used to obtain the elastic properties presented in this table.

\begin{tabular}{|c|c|c|c|c|}
\hline \multicolumn{5}{|c|}{$\begin{array}{l}\text { Table } 1 \\
\text { Material Properties for the 1:5-Scale Wicket Model }\end{array}$} \\
\hline $\begin{array}{l}\text { Component } \\
\text { Description }\end{array}$ & $\begin{array}{l}\text { Reference } \\
\text { Sheet \# }\end{array}$ & Material Type & $\begin{array}{l}\text { Young's } \\
\text { Modulus, ksi }\end{array}$ & Yield Strength, psi \\
\hline Skin Plate & S-24, S-25 & A 606 & 40,974 & 64,521 \\
\hline Beam & S-24, S-25 & A 588 Grade 50 & 34,287 & 55,956 \\
\hline Channel & S-24 & A 588 Grade 50 & 32,213 & 55,956 \\
\hline $\begin{array}{l}\text { Stiffener } \\
\text { Plates }\end{array}$ & S-24 & A 514 Grade 70 & 42,083 & 61,216 \\
\hline $\begin{array}{l}\text { Web } \\
\text { Stiffener }\end{array}$ & S-24 & A 514 Grade 70 & 32,480 & 65,469 \\
\hline $\begin{array}{l}\text { Gate Frame } \\
\text { Hinge pins }\end{array}$ & M-8 & $\begin{array}{l}\text { A } 276 \text { Stainless } \\
\text { Steel }\end{array}$ & 30,850 & 50,676 \\
\hline $\begin{array}{l}\text { Gate Frame } \\
\text { Hinge }\end{array}$ & $M-8$ & A 588 Grade 50 & 35,658 & 52,128 \\
\hline $\begin{array}{l}\text { Ball } \\
\text { Mounting } \\
\text { Plate }\end{array}$ & M-15 & $\begin{array}{l}\text { A } 276 \text { Stainless } \\
\text { Steel }\end{array}$ & 30,850 & 50,676 \\
\hline Prop Rod & M-18 & A 588 Grade 50 & 30,737 & 64,940 \\
\hline
\end{tabular}

Using the Archimedes principle of buoyancy, the density of the wicket was measured by submerging the gate in a water-filled tank and measuring the volume of water displaced. The density for the wicket gate shown in Figure 5 was $421.98 \mathrm{lb} / \mathrm{ft}^{3}$. The center of gravity (CG) of the wicket was also determined by balancing the gate over a roller as shown in Figure 5 . The CG for the wicket was 24.875 in. away from the base of the gate. 


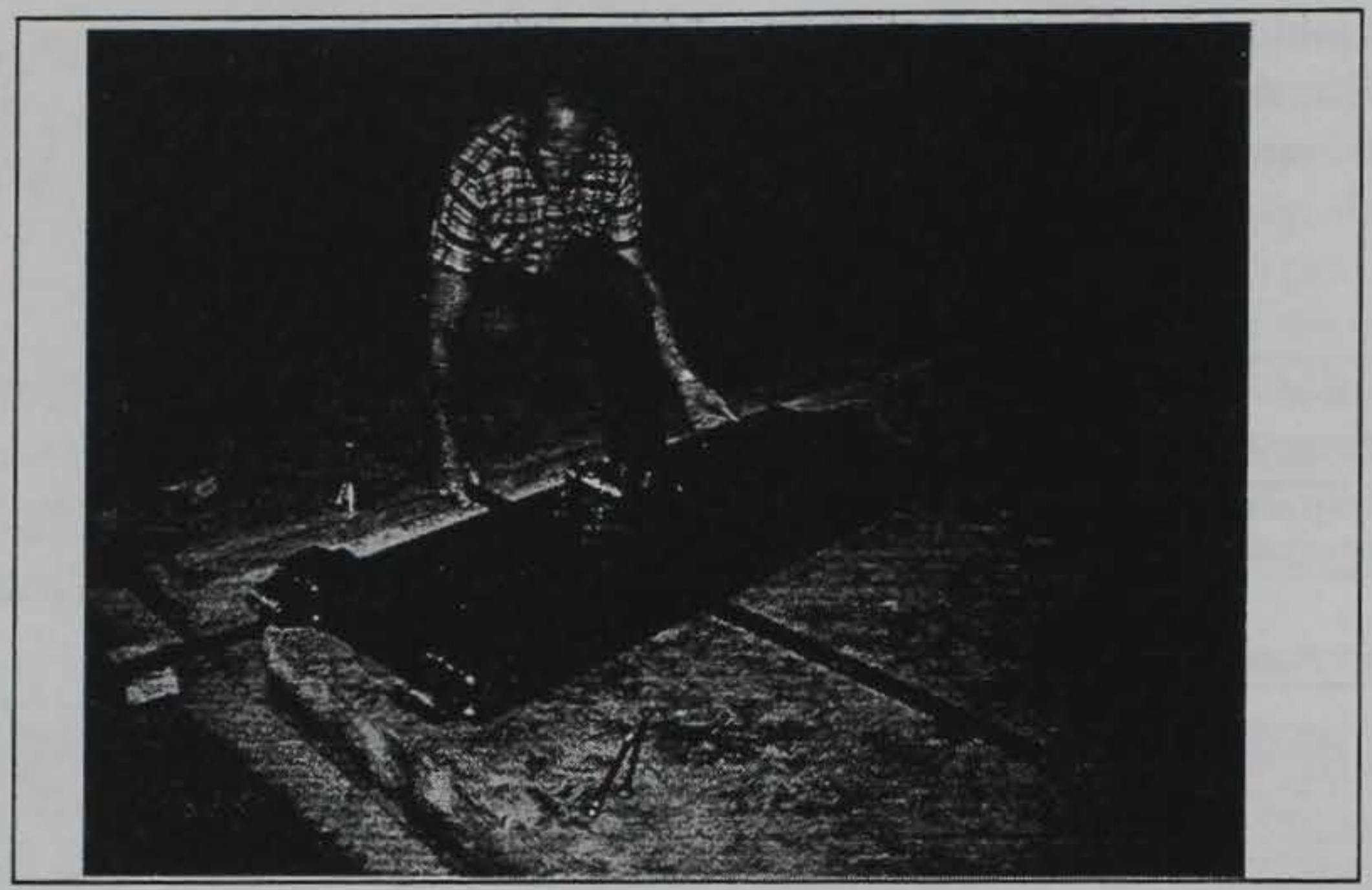

Figure 5. Equilibrium experiment on the physical wicket model

\section{Preliminary FE Model}

The preliminary FE model of the test wicket was developed from construction drawings and observation of the 1:5 scale structure. This initial model represented the wicket geometry independent of its supporting devices as shown in Figure 6. Detailed modeling of the supporting mechanisms was accomplished in a subsequent study presented in the later part of this report. This FE model included 11,763 nodes with a total of 3,179 elements. Most of the structural components of the wicket have been modeled using eight-noded shell elements (S8R5). These are second-order quadrilateral shells with five degrees-of-freedom (DOF) per node. Six-noded triangular shell elements (STRI65) were used as transitional elements to provide connectivity of dissimilar intersecting elements in the model; these elements also have five DOF per node. A few of the four-noded quadrilateral shell elements (S4R5) were also used as a transitional element to provide continuity of the nodal pattern. Twonoded linear beam elements (B31) were used to model steel rod supporting hanger and the instrumentation cable routing pipes. Lumped mass elements were used to model the mass of both bearing brackets and the connecting supports of the hydraulic cylinder (see Appendix A and Fig 4).

Gate hinges were modeled as pinned supports and the prop rod was simulated by a spring applied to the gate bottom surface. Nodes connecting the gate to the hinge assemblies were restrained at both hinges. For these nodes, only the translational DOF, about the $Z$ direction were restrained. Two nodes at the hinges were also used to restrain the translational movement of the hinge assemblies about the $\mathrm{X}$-and $\mathrm{Y}$-directions. These allowed the rotational freedom of the hinge assembly and restraint about the $\mathrm{Z}$-direction. For the pin-connected hoisting mechanism, translational DOF about Z-direction were restrained for two nodes on the ball-mounting plate at the pillow-block locations. 
The spring coefficient was calculated based on the dimensions of the prop rod and the elastic modulus of steel and was 1,822,974 lbf/in. Since the support elements, which included the gate and prop rod hinges and the pillow block and ball assembly, contributed significantly to the mass of the gate, the mass contribution of these elements was calculated and applied to the FE model at the appropriate nodes. The initial FE model is shown in Figure 6.

\section{Verification of Preliminary Model}

Initial verification of the FE model included physical properties comparison of both analytical and experimental results. The total mass and the center of gravity for both analytical and experimental models are compared in Table 2. A close agreement between the predicted and actual parameters indicates that the mass distribution for both cases were identical.

Further correlation of the preliminary FE model consisted of comparing results of modal dynamic response and static deflection analysis with experimental results. Experimentally measured modal parameters for the propsupported gate were compared with that of the analytically computed data. Experimental modal testing using the state-of-the-art Scanning Laser Doppler Vibrometer (SLDV) system was conducted to extract the dry and wet vibrational characteristics of the 1:5-scale physical wicket model. Modal testing was conducted by exciting the wicket gate with a shaker and scanning the downstream surface of the gate using the SLDV system. Detailed information on data acquisition and analysis techniques are summarized in Chowdhury, Hall, and Davis (in preparation).

\begin{tabular}{||l|r|r|r||}
\hline \multicolumn{4}{||l||}{$\begin{array}{l}\text { Table } 2 \\
\text { Physical Properties for the Experiment and Analytical Models }\end{array}$} \\
\hline $\begin{array}{l}\text { Descriptions } \\
\text { Center of mass } \\
\text { measured from } \\
\text { the base of the } \\
\text { gate, y-dir }\end{array}$ & 24.84 in. & FE Model & Percent Error \\
\hline Total mass & $182.75 \mathrm{lb}$ & $182.38 \mathrm{lb}$ & \\
\hline
\end{tabular}




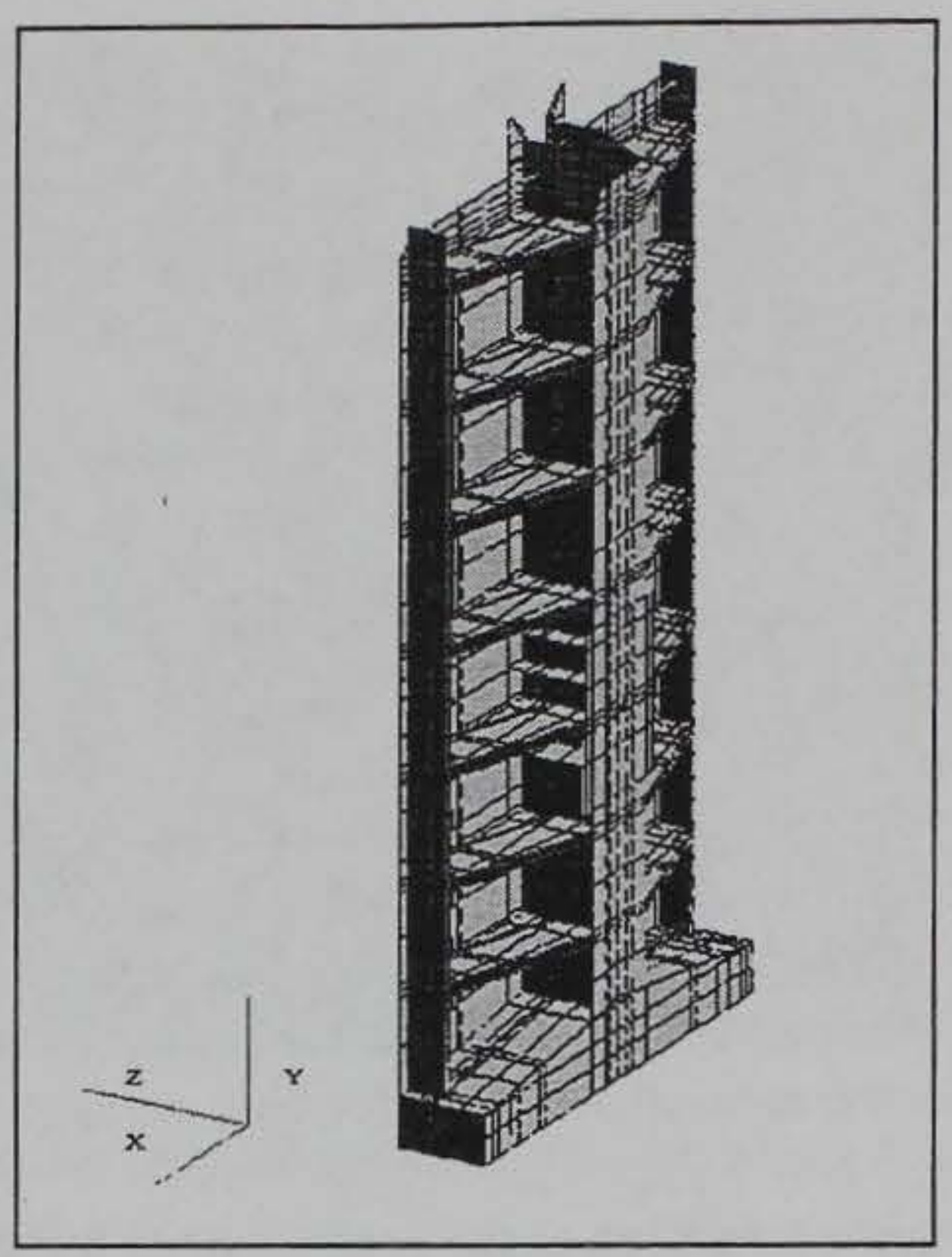

Figure 6. Finite element grid

A good correlation of the free-vibrational characteristics of both analytical and experimental models would indicate a dynamic similarity of the models which in turn would validate that the mass and stiffness of the actual gate are properly modeled. In addition to the dynamic similarity verification of the models, a static load-deflection test was also used to calibrate the static stiffness of the wicket.

In the static tests, the gate was placed in the horizontal position resting on the supporting hydraulic cylinder. Various loadings were applied to the top surface of the gate and displacements near the hinges, at the center and near the top of the gate were measured for each loading condition. In the dynamic flow experiments, a single gate near the center of the model was instrumented with a number of displacement gauges, pressure gauges, load cells, and accelerometers. Pressures on the gate surfaces, reaction forces, and gate accelerations were measured for different flow and channel configurations. Experimental data recording and analysis are further discussed by Chowdhury, Hall, and Davis (in preparation). Flow- induced operating responses for the scaled physical model were measured for different gate configurations with appropriate head of pool elevations. 


\section{Dry gate modal parameters}

A linear-elastic technique for extraction of eigenvalue data for the structural system was used to compute the natural frequencies of the FE model. A detailed formulation for the ABAQUS eigenvalue and other dynamic response analyses methodologies is presented in the literature (HKS 1994). The response spectrum analysis of the initial FE gate model for the "dry" condition extracted 10 modes of vibration. Table 3 presents the analytically computed modal frequencies for the wicket model for two different types of boundary conditions. Different boundary conditions were examined to measure the sensitivity of supporting mechanisms on the natural dynamics of the wicket. A free-free supporting condition represented the unsupported gate while a hinge-pin connection simulated the translational restraint of the base hinges and prop connection. Analytical results shown in Table 3 clearly show the increasing sensitivity of the higher modes to the boundary conditions of the wicket. An unchanged first bending mode, however, indicates its independence of the boundary conditions. Modeling of boundary conditions was thus recognized as one of the most critical tasks during the development phase of this model study.

Sensitivities of the boundary conditions, on the global modes of the wicket, were throughly examined during the experimental investigation of the 1:5scale physical model (Chowdhury, Hall, and Davis in preparation). Experimental results indicated that vibrational modes above $100 \mathrm{~Hz}$ were closely interacted with the prop dynamics and were most sensitive to the prop-rod connection mechanisms. Figure 7 shows the variation in the modal peaks for the wicket when scanned from upstream and downstream sides of the flume. A change in the frequency-response function (FRF) indicates that the system response for the gate was sensitive to the direction of the driving force. Such a change in the peak resonant frequency resulted primarily due to the nonlinear behavior of the "notension" supporting mechanisms of the prop rod during the excitation of the wicket. Also the uncertain orientation of the clevis connection at the top end of the prop rod introduced non-linearity into the system performance. Experimental modal resonant frequencies for upstream and downstream scanning are also presented with the analytical results in Table 3. 


\begin{tabular}{|c|c|c|c|c|}
\hline \multicolumn{5}{|c|}{$\begin{array}{l}\text { Table } 3 \\
\text { Analytical and Experimental Modal Frequencies }\end{array}$} \\
\hline \multirow{4}{*}{$\begin{array}{l}\text { Mode } \\
\text { Description }\end{array}$} & \multicolumn{4}{|c|}{ Frequency $(\mathrm{Hz})$} \\
\hline & \multicolumn{2}{|c|}{ Analytical } & \multicolumn{2}{|c|}{ Experimental } \\
\hline & \multicolumn{2}{|c|}{$\begin{array}{l}\text { Boundary } \\
\text { Conditions }\end{array}$} & \multicolumn{2}{|c|}{ Scanning Laser Positions } \\
\hline & $\begin{array}{l}\text { Free- } \\
\text { free }\end{array}$ & $\begin{array}{l}\text { Hinge- } \\
\text { pin }\end{array}$ & $\begin{array}{l}\text { Up-stream } \\
\text { face scanned }\end{array}$ & $\begin{array}{l}\text { Down-stream } \\
\text { face scanned }\end{array}$ \\
\hline Mode 1 & & & 49.11 & 43.11 \\
\hline $\begin{array}{l}\text { Mode } 2 \\
\text { (bending) }\end{array}$ & 57.74 & 57.74 & 62.26 & 58.00 \\
\hline $\begin{array}{l}\text { Mode } 3 \\
\text { (torsion) }\end{array}$ & 149.09 & 97.99 & 95.57 & 91.40 \\
\hline $\begin{array}{l}\text { Mode } 4 \\
\text { (bending) }\end{array}$ & 251.25 & 113.91 & 171.70 & 141.20 \\
\hline $\begin{array}{l}\text { Mode } 5 \\
\text { (torsion) }\end{array}$ & 314.82 & 133.50 & 202.01 & 232.60 \\
\hline
\end{tabular}

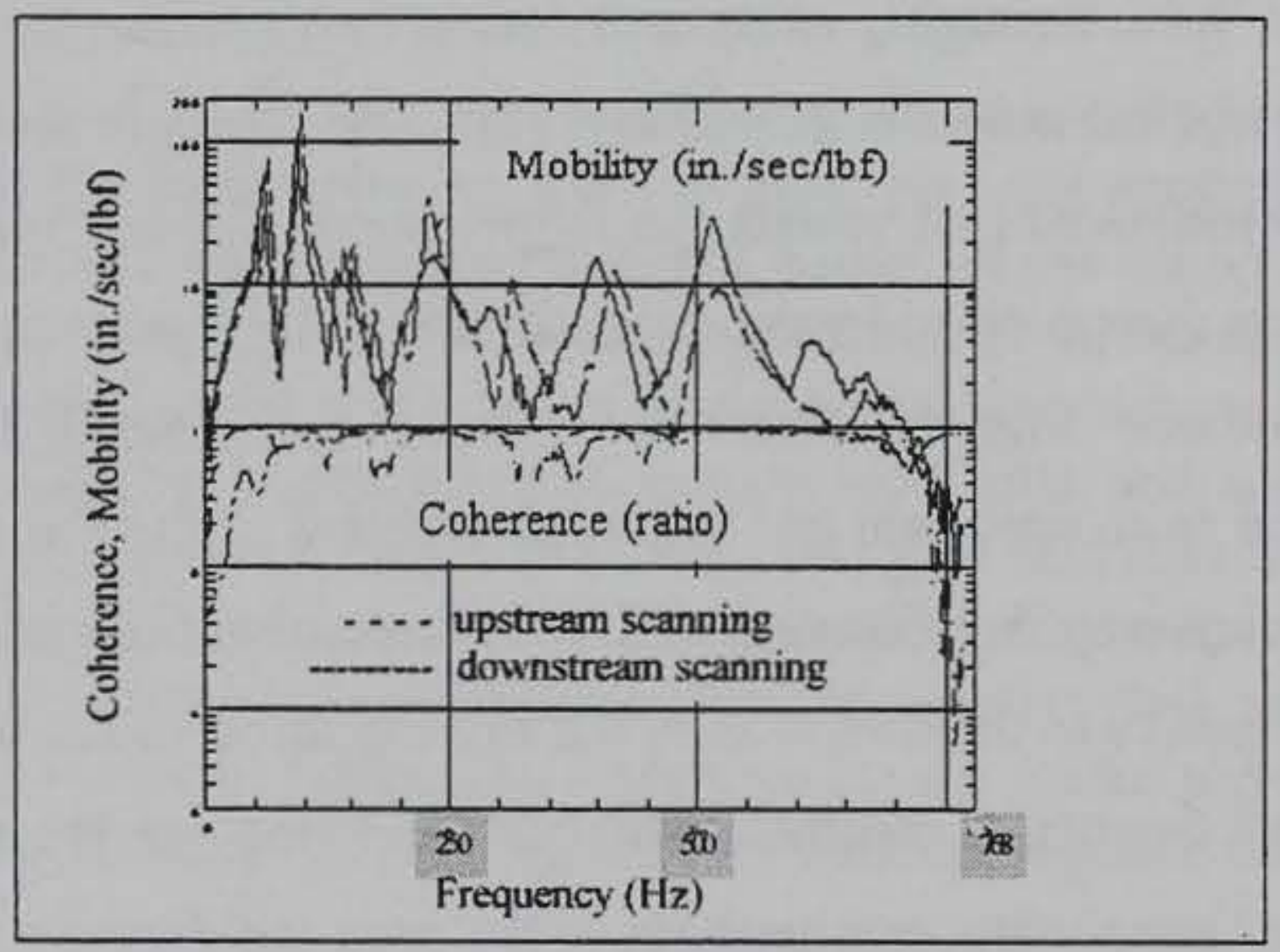

Figure 7. Frequency response functions for upstream and downstream scanning of the physical gate 
Analytically computed first bending and torsional modes occurred at frequencies of $57.74 \mathrm{~Hz}$ and $97.99 \mathrm{~Hz}$, respectively, and second bending and torsional modes occurred at $113.91 \mathrm{~Hz}$ and $133.50 \mathrm{~Hz}$, when the supports were modeled as hinge-pin. Vibrational shapes for these modes are shown in Figure 8. These frequencies are compared with experimental results in Table 3. A comparison of the analytical and experimental modal frequencies indicates that the first elastic mode below $100 \mathrm{~Hz}$, for the hinge-pin condition, approached the experimental result despite the fact that these modes were not absolutely timeinvariant. However, predicted frequencies for the other structural modes did not quite match the experimental results.

As indicated in the experimental results, the higher modes over $100 \mathrm{~Hz}$ would be very difficult to match during the modal updating due to the intrinsic uncertainty and non-linearity of the system. A number of higher unstable wicket modes varied greatly due to their interaction with the localized prop modes. Although the peak frequencies differed, the first five mode shapes were found most stable and repeatable during the experiments. For these modes, mode shapes did not differ, however, the modal frequencies changed during the experiments. Modal assurance criteria (MAC) matrix for the first five mode shapes obtained from different experiments showed a very good agreement between the identical modes. Therefore, for the remaining of the study only the first five global modes considered to be most stable, repeatable, and reliable, were used during the modal correlation and updating process.

Modeling of the uncertain orientation of the clevis connection at the top of the prop rod is beyond the scope of the present research. Such an intrinsic uncertain random behavior could be modeled using the stochastic FE method (Chang 1993). The bottom end of the prop rod in its locked position, provides restraint only along a direction away from the gate. 


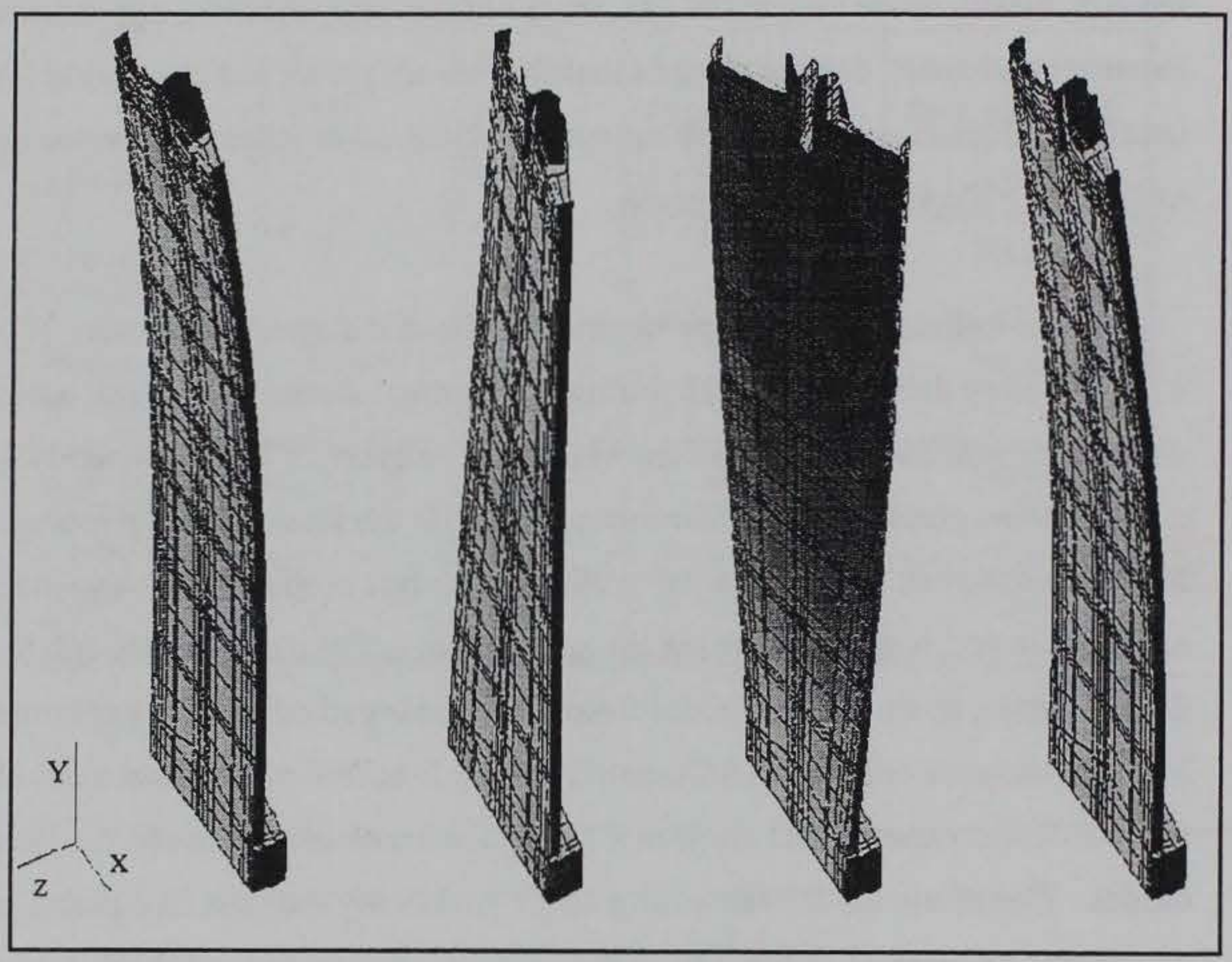

Figure 8. Calculated mode shapes for the initial FE model 


\section{Static response}

A preliminary comparison of the static test results with that of the analytical results was conducted to measure the adequacy of the static stiffness used for the analytical model. The static analysis modeled the test in which a 500lbf static load was distributed across the top surface of the gate as shown in Figure 9. This loading condition corresponded to test load case 1 . In which a cylindrical disk mounted on a 12 -in. by 4.56 -in. steel plate was placed on the top edge of the skin plate. Test load case 1 applied a 500 -lbf load on a center-line axis passing through the top two gauge locations. Five extensometers attached to the gate were used to record the linear deflection at gauge locations. Displacement gauge locations and FE model nodes at those locations are also shown in Figure 9. The test gate was supported by the lifting cylinder at -1.1-deg down from the horizontal axis. At its resting position, the gate lies at -3.3-deg down the horizontal axis.

Two values of spring stiffness were used for the hydraulic cylinder. Analysis 1 used the initial value of $94,035 \mathrm{lbf} / \mathrm{in}$. based on the stiffness of the oil column. A second value, 15,1761.6 lbf/in., was determined by calculating the reaction at the ball support for zero vertical displacement and dividing this value by the test displacement of 0.008 in. at this point. The second case will be identified as Analysis 2. Calculated reactions using the unyielding cylinder support for this preliminary analysis were $-714 \mathrm{lbf}$ at the gate hinges and 1,214 lbf at the ball support. Note that the stiffness of the mid-point support, provided by the hydraulic cylinder, was time-dependent and caused the gate to deflect independent of the loading situation. A time-depended deformation of the hydraulic cylinder was possible due to relaxation of the uncertain amount of airpockets trapped inside the hydraulic chamber. As a result of such experimental shortcomings it was impossible to measure the true deflection of the gauge locations during the static test.

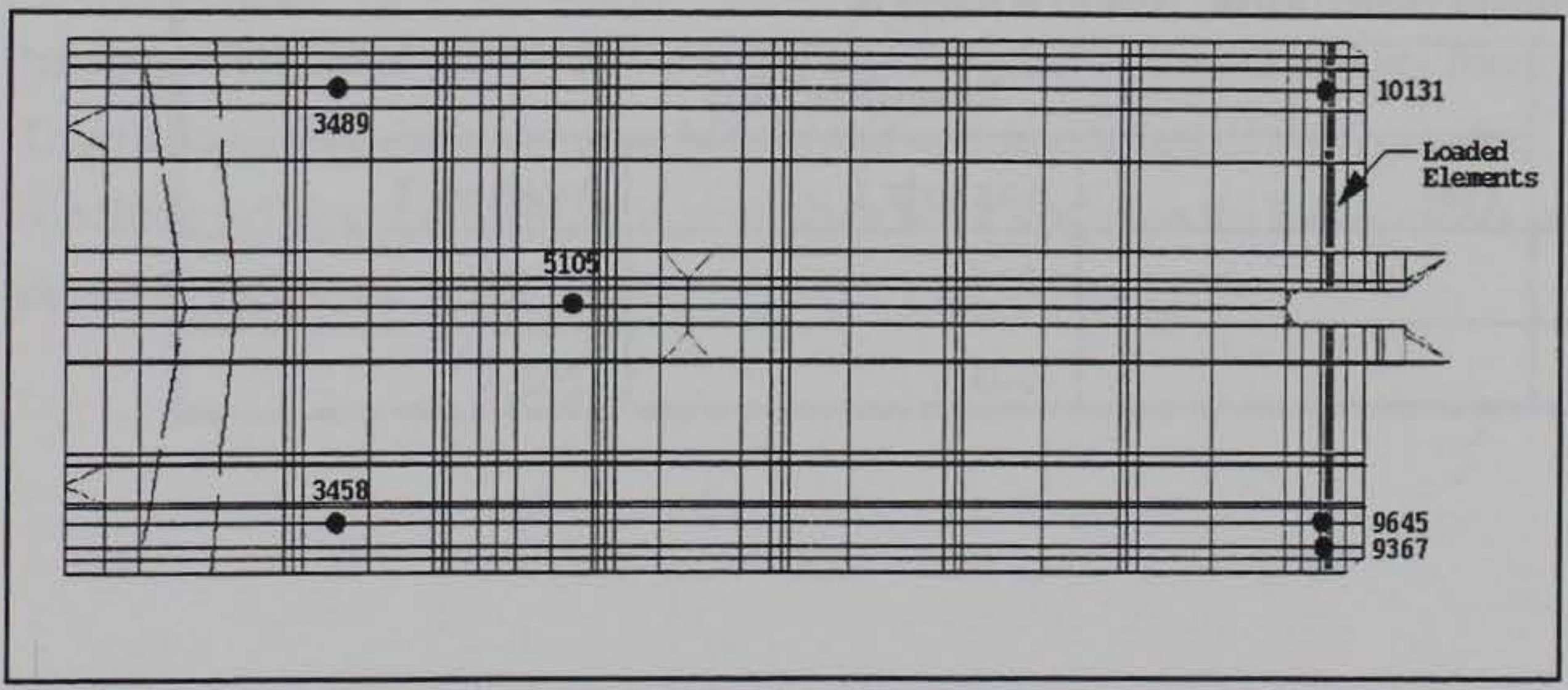

Figure 9. Location of distributed loading and displacement gagues for static experiment 
In the analysis using the $94,035 \mathrm{lbf} / \mathrm{in}$. spring stiffness, displacements at nodes at the center and base of the gate, corresponding to gauges 3 through 5 , were greater than test displacements, indicating that the spring stiffness was too low. Displacements at these locations in the second analysis were close to test displacements, indicating a more nearly correct spring stiffness. However, displacements at the top of the gate in the second analysis were only about 77 percent of the test displacements. These differences could be attributed to the shortcomings of the experimental results mentioned earlier. Test displacements and displacements for the two analyses are compared in Table 4. Reactions at the gate hinges for each analysis are shown in Table 5 .

\begin{tabular}{|c|c|c|c|c|}
\hline \multicolumn{5}{|c|}{$\begin{array}{l}\text { Table } 4 \\
\text { Experimental and ABAQUS Results for Static Test } 1\end{array}$} \\
\hline \multirow[t]{3}{*}{ Gauge No. } & \multirow[t]{3}{*}{ Node } & \multicolumn{3}{|c|}{ Displacements (in.) } \\
\hline & & \multirow[t]{2}{*}{ Test } & Analysis 1 & Analysis 2 \\
\hline & & & Results & Results \\
\hline 1 & 10131 & 0.048 & 0.0448 & 0.03707 \\
\hline 2 & 9367 & 0.048 & 0.0448 & 0.03705 \\
\hline 3 & 5105 & 0.008 & 0.0112 & 0.00797 \\
\hline 4 & 3489 & 0.003 & 0.0049 & 0.00313 \\
\hline 5 & 3458 & 0.003 & 0.0048 & 0.00308 \\
\hline
\end{tabular}

\begin{tabular}{||l|l|l|l||}
\hline \multicolumn{2}{|l||}{\begin{tabular}{l} 
Table $\mathbf{5}$ \\
Gate Hinge Reactions, Static Analysis \\
\hline \multirow{2}{*}{ Node }
\end{tabular}} & \multicolumn{3}{|c||}{ Reactions (lbf) } \\
\cline { 2 - 4 } & Test & Analysis 1 & Analysis 2 \\
\hline 428 & & -218.2 & -275.9 \\
\hline 453 & & -203.1 & -262.8 \\
\hline
\end{tabular}




\section{Revised FE Model}

Since the FE model duplicated the 1:5 test gate model materials, densities, and sections, a high degree of confidence could be placed in the accuracy of the model. Mass in the FE model was verified by comparison between the ABAQUS and actual values. The good correlation between the ABAQUS static test predictions and the experimental data confirmed that the gate stiffness was reasonably accurate.

However, the accuracy of the predicted vibrational characteristics of an elastic FE model is dependent on three factors: stiffness, mass, and boundary conditions. In an attempt to more accurately model the 1:5-scale physical wicket's support conditions, a detailed modeling of the supports was undertaken. Additional modifications were made to simulate the surrounding water for operating condition response spectrum analyses and to provide damping coefficients for a time-domain dynamic analysis. The revised FE model is shown in Figure 10. This figure shows a side view of the prop-supported wicket model along with the global directional axes. As shown in the figure, the physical details of the wicket geometry were explicitly discretized in the FE model. A more detailed isometric view of the FE model is shown in Figure 11. This figure illustrates the idealized boundary conditions for the base-hinges and the prop bottom end connection for the wicket assembly. Translational restraints with rotational flexibility at the mid-point of the hinge pins represented the actual holding of the hinge pins within the rigid lugs mounted on the sill bearing frame. Translational restraint at the prop-bottom end was used to model the fixed-gate condition (65-deg position) of the prop blade while seated on the hurter recess as shown in Figure $4 \mathrm{~b}$. 


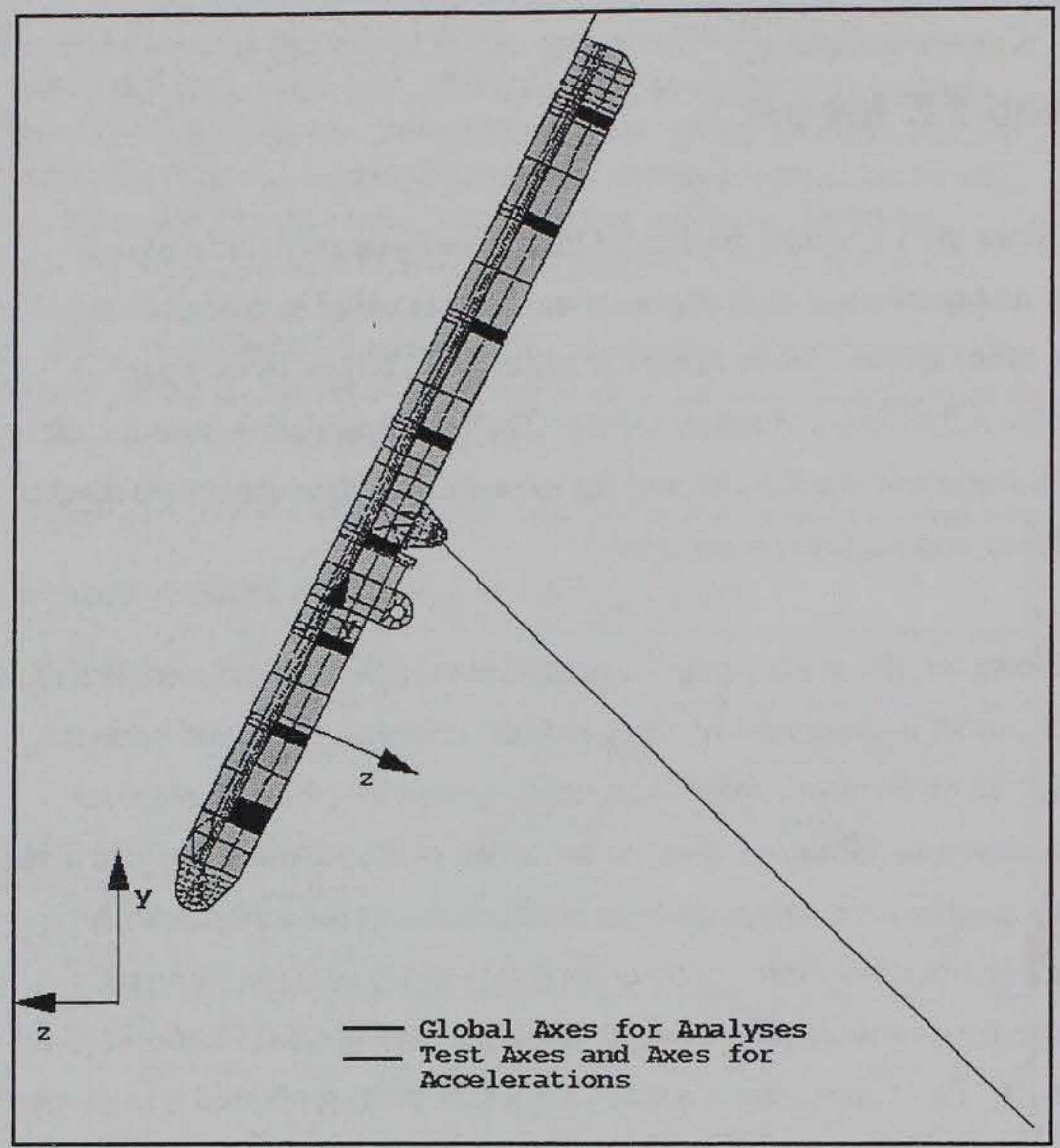

Figure 10. Revised FE model with reference axes for tests and analyses

\section{Modeling of supports}

The gate base-hinges, support-rod hinge and the pillow-block were modeled using approximately 300 additional 20 -node brick and 15 -node wedge elements. Solid elements with no mass were used to model hinge openings. The prop-rod and hinge pins were modeled with 2-node beam elements. Continuity between the $3 \mathrm{DOF}$ solid elements and the $6 \mathrm{DOF}$ shell elements used to model the gate was imposed by the use of multipoint constraints (MPC's) at element interfaces. Such an MPC ensures proper moment transferring from the shell to the interconnected solid elements (Ridlon 1987). The shell-solid intersection was constrained 
such that the rotational DOF at the intersecting nodes were compatible. The kinematic constraints, MPC types SS LINEAR and SS BILINEAR, were used depending upon the location of nodes and the type of elements intersecting each other. At the prop-rod hinge, separate nodes were used for the prop-pin beam elements and the no-mass solid elements at the openings, and by pinned supports at the hinge-pin centers. Figure 12 and 13 illustrate the FE idealization of the base-hinge and prop-end connections, respectively. The prop-rod congruent nodes were tied with pintype MPC's to allow rotation between the beam elements and the solid elements. At the gate hinges, rotation was allowed but the end was restrained in the $y$-direction shown in Figure 10 and in the $x$-direction, along the width of the gate. For the response spectrum calculations, two conditions were simulated for the restraint in the $\mathrm{z}$-direction: full restraint and no restraint. To simulate the slotted connection used at the prop-rod end in the 1:5 physical model, only negative z-direction displacements were restrained in the dynamic time-history analysis.

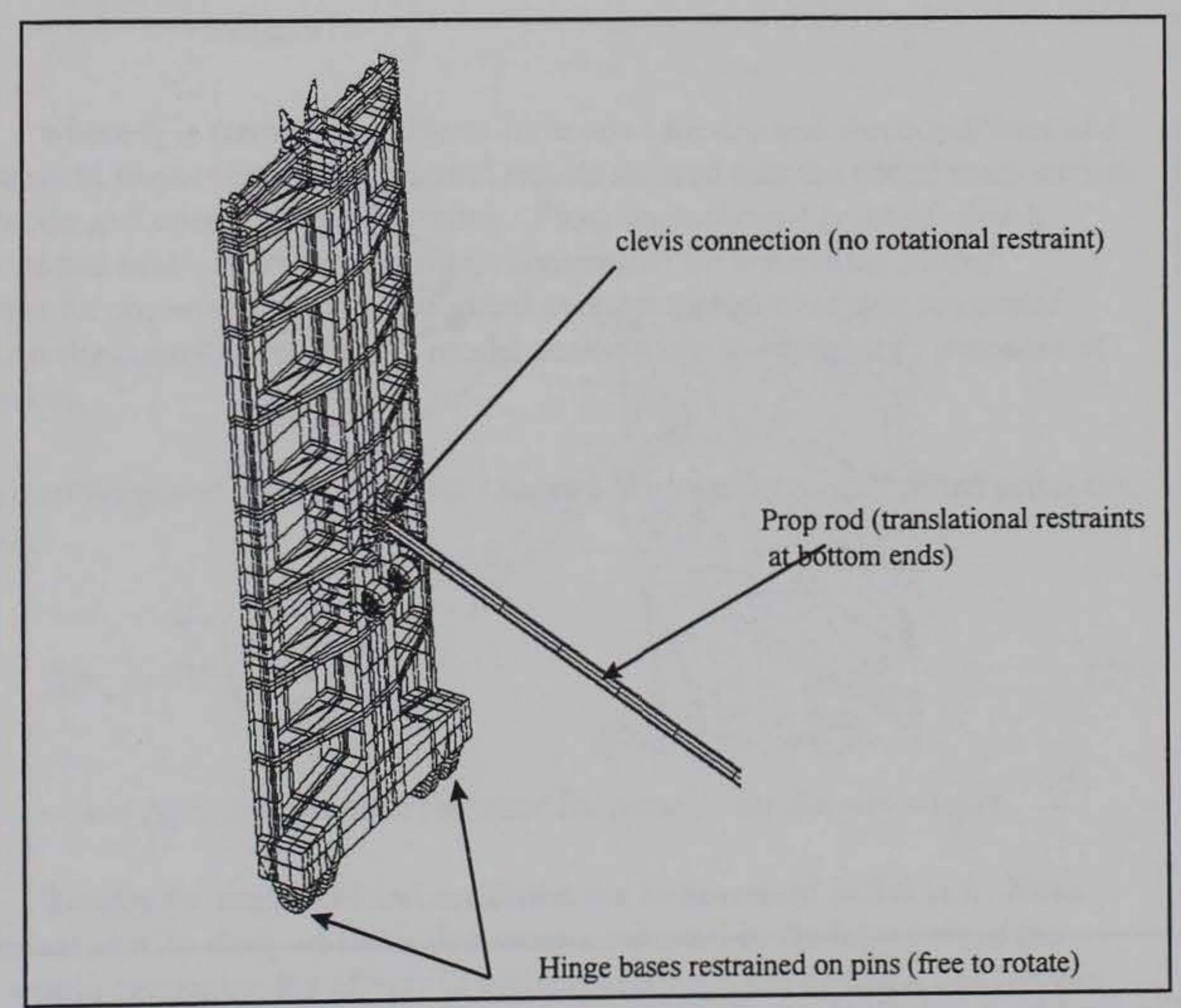

Figure 11. An illustration of boundary conditions in the FE model 


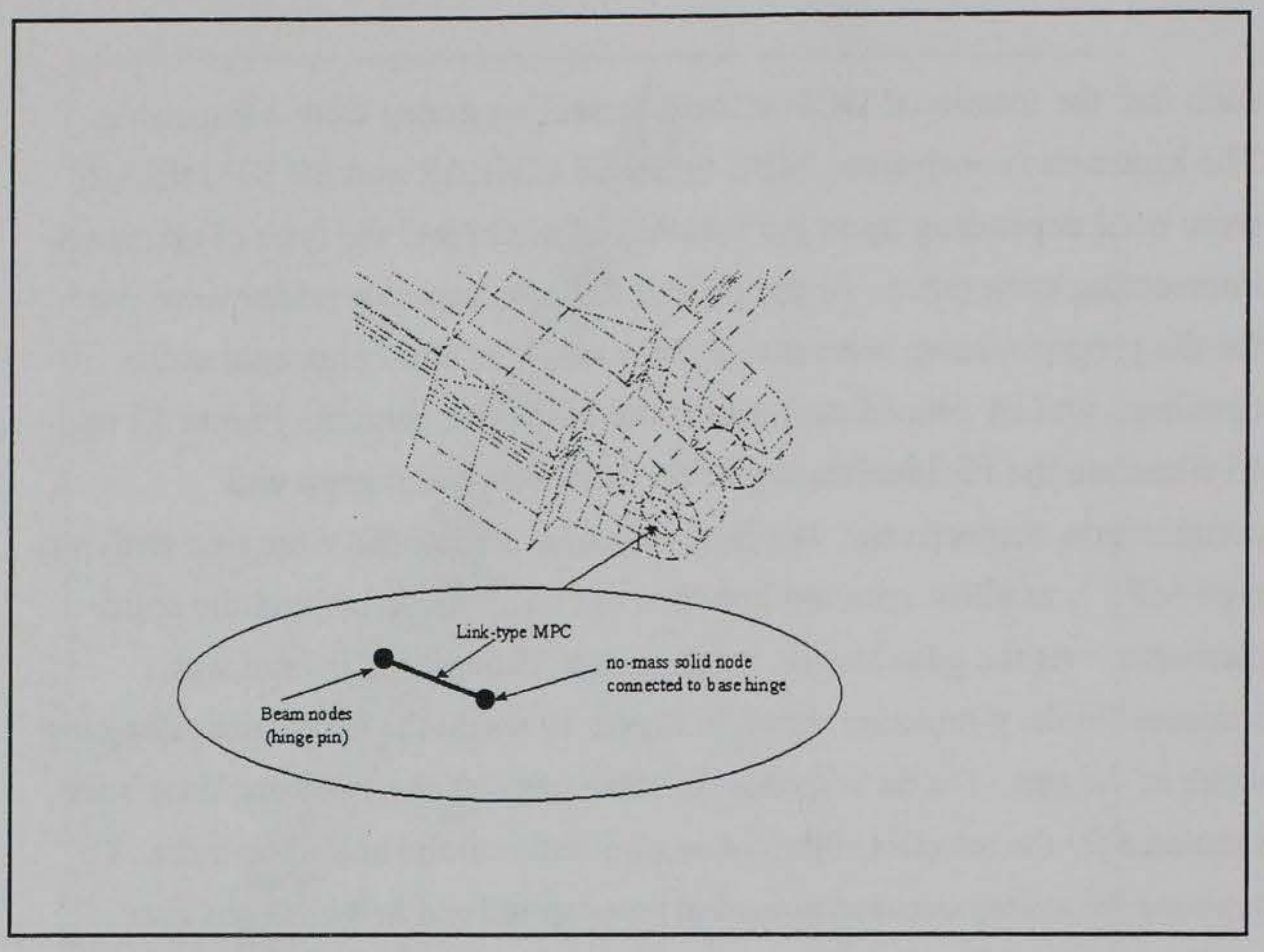

Figure 12. Analytical simulation of base hinge-pin connection

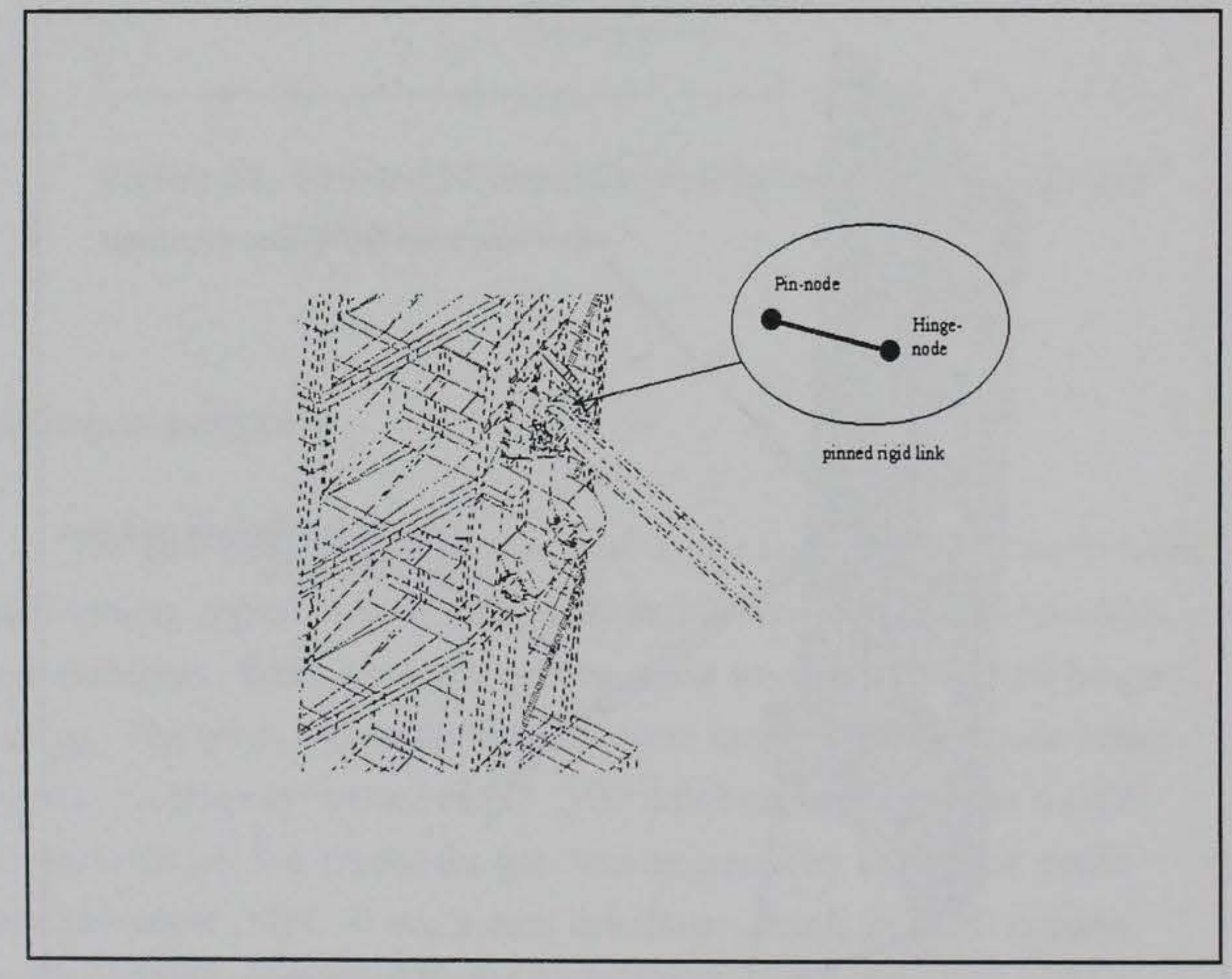

Figure 13. Analytical simulation of prop-rod and gate connection 


\section{Added fluid masses}

Physical parameters obtained from the experimental results provided the most valuable information for updating the FE model of the proposed wicket. These included the static and dynamic parameters indicative of the actual performance of the operating wicket. Dynamic parameters included the dry and wet gate modal parameters and the physical input loading and output response history from the actual flow measurements. Wet gate natural characteristics were synthesized to determine the added-mass contribution representing the effects of water upon the dynamics of the wicket.

To account for the effects of fluid on the elastic response of the structure under operating conditions, fluid added masses were distributed across the top surface of the FE model. Experimental vibrational characteristics for the dry gate and for the gate subjected to various operating conditions were obtained from modal experiments using the SLDV system. Using the plate vibration theory, the added masses for different pool configurations were computed for the operational wicket (Chowdhury, Hall, and Davis in preparation). The added mass $(\Delta \mathrm{m})$ for each mode was calculated from experimental modal frequencies and amplitudes using the formula shown below.

$$
\Delta m_{i}=m\left[\left(\frac{f_{i, d r y}}{f_{i, \text { wet }}}\right)^{2}-1\right]
$$

where $\mathrm{f}_{i}$ is frequency in Hertz for mode i for dry and wet conditions and $\mathrm{m}$ is mass in $\mathrm{lb}-\mathrm{sec}^{2} / \mathrm{in}$. Experimental results showed that the added mass varied with mode and operating configuration. From an analytical point of view a single added-mass, however, would be convenient for computing global response for the wet wicket. A weighted average added-mass was suggested based on the contribution of each modal peaks in the wet frequency response of the wicket.

Combined weighted mass, $\Delta m_{w}$, for modes 1 through 5 was calculated using the formula:

$$
\Delta m_{w}=\frac{\sum\left(A_{i} \cdot \Delta m_{i}\right)}{\sum A_{i}}
$$

where $\mathrm{A}_{i}$ is amplitude at resonant frequency $i$ for the wet wicket.

Results for the 21-ft head condition are summarized in Table 6. Note that the sensitivity study of the added-mass conducted in the later part of the study would determine the effects of added-mass upon the dynamics of the wet gate. Neglecting the contribution of second mode, in Table 6 , the weighted 
average added-mass could be estimated as $0.4366 \mathrm{lb}-\mathrm{sec}^{2} /$ in.

\section{Damping}

Damping has little effect on predicted modal shapes and frequencies, but can affect results in a dynamic time-domain analysis. In many situation, however, damping has only small effects on the predicted response, so that approximate damping formulations are sufficient in the FE analysis (Meyer and Will 1987). Rayleigh damping is one of the widely used models for damping characteristics of an FE system. Rayleigh damping coefficients $\alpha$ and $\beta$ used in the dynamic analysis were calculated from experimental data using the formula below.

$$
c_{i}=\frac{1}{\left[2 \omega_{i}\left(\alpha+\beta \omega_{i}^{2}\right)\right]}
$$

where $c_{i}$ is damping for mode $\mathrm{i}$,

$\omega_{i}$ is $2 \pi / T_{i}$ and

$\mathrm{T}_{i}$ is period for mode $\mathrm{i}$ in sec.

Coefficients for the 21 - $\mathrm{ft}$ head operating condition, calculated from modes 1 and 3, were used in the time-history analysis. Experimental results for the modal damping in the wet case are presented in Table 6.

\begin{tabular}{|c|c|c|c|c|}
\hline Mode & $f_{d r y}(H z)$ & $\begin{array}{l}f_{\text {wet }}(\mathrm{Hz}) \text {, } \\
\text { (percent damping ) }\end{array}$ & $\begin{array}{l}A_{\text {wet }} \\
\text { (in./s/lbf) }\end{array}$ & $\begin{array}{l}\Delta \mathrm{m}_{\mathrm{i}} \\
\text { (lb-sec}{ }^{2} \text { /in.) }\end{array}$ \\
\hline 1 & 43.1 & $38.7 \quad(2.6)$ & 56.3 & 0.118168 \\
\hline 2 & 58.0 & $58.6 \quad(1.9)$ & 460.4 & 0.0 \\
\hline 3 & 91.4 & $68.6 \quad(3.0)$ & 477.8 & 0.38174 \\
\hline 4 & 141.2 & $96.8 \quad(3.1)$ & 147.4 & 0.55453 \\
\hline 5 & 231.6 & $148.47 \quad(2.9)$ & 203.7 & 0.49855 \\
\hline $\begin{array}{l}\text { weighted } \\
\text { average }\end{array}$ & & & $\Delta \mathrm{m}_{\mathrm{w}}=$ & 0.3090 \\
\hline
\end{tabular}




\section{Verification of the Revised FE Model}

Modal and dynamic flow experiments provided experimental data for verification of the FE model:

1) The results of modal testing under "dry" and operating conditions for the prop-supported wicket were compared with the results of response spectrum calculations. Figure 14 shows a schematic diagram of a typical experimental setup for the modal experiment using the SLDV system. Wet modal experimental data for the operating conditions of a 21 -ft head difference, and a three-gate gap ( $3 \mathrm{GG}$ ) flow configuration were used for updating the FE model. A $3 \mathrm{GG}$ flow condition for the prop supported gate is shown in Figure 15 .

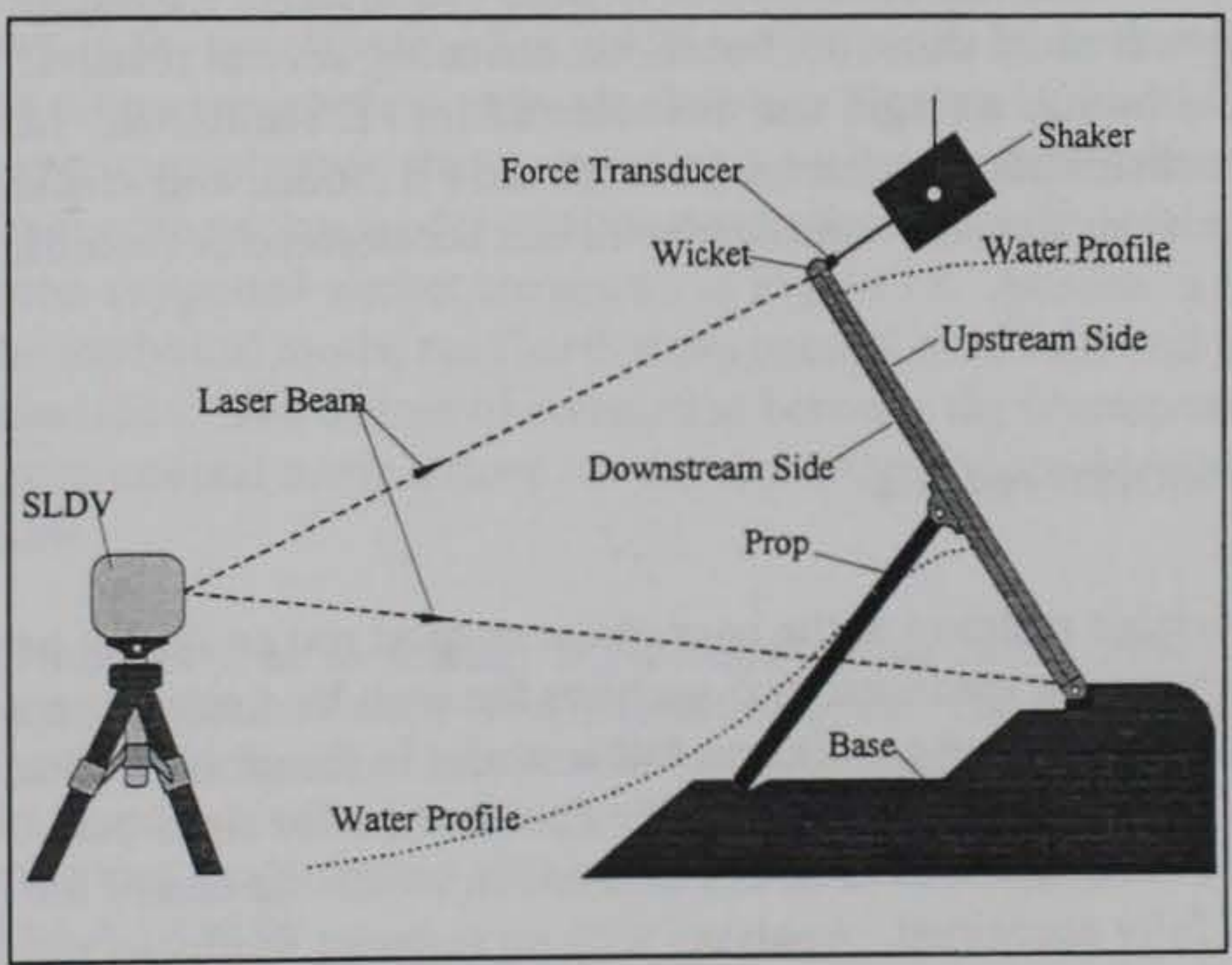

Figure 14. Experimental modal setup schematic diagram 


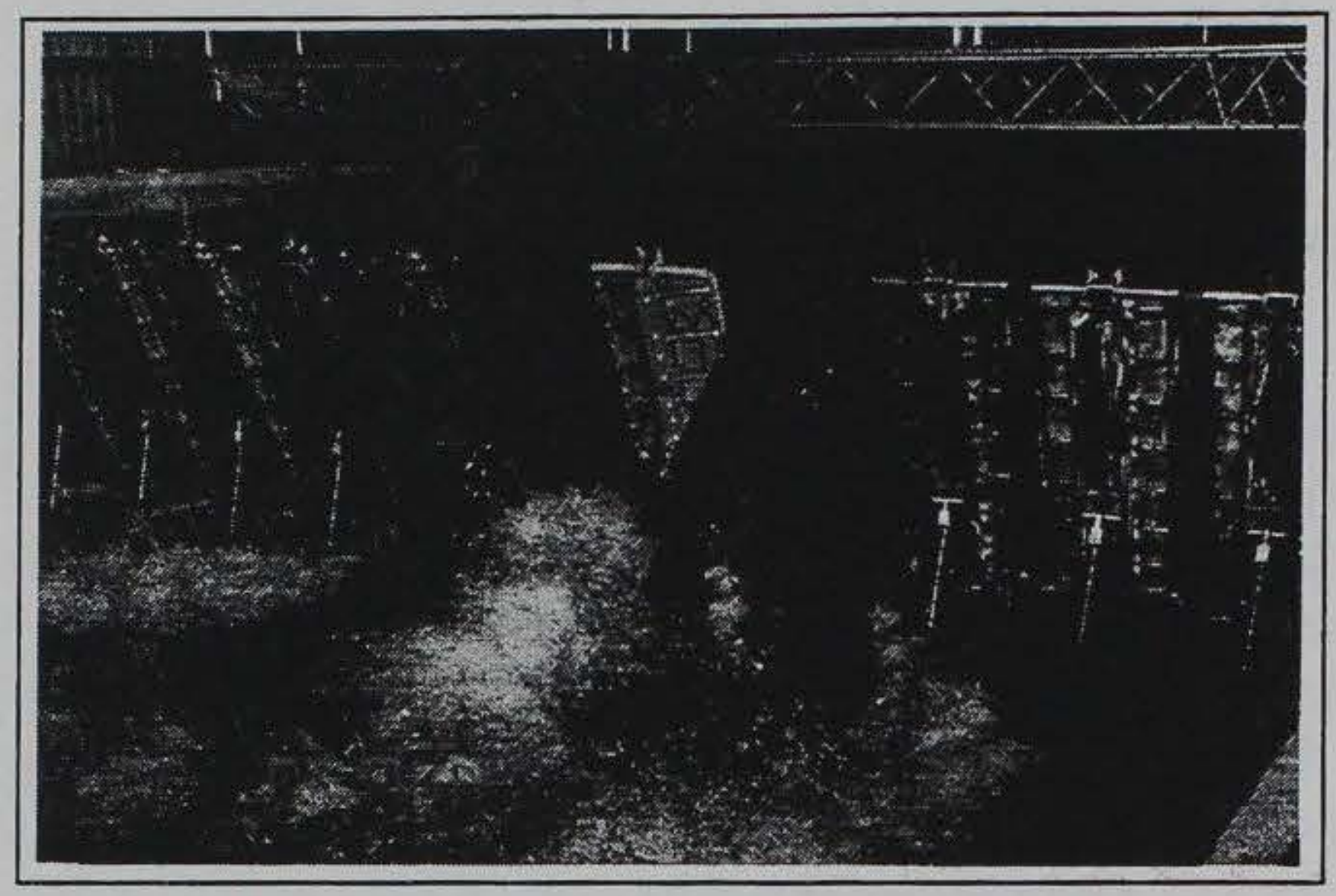

Figure 15. A three-gate gap flow configuration

2) Dynamic flow tests were conducted to simulate various operational conditions, including varying heads of water and gate positions.

Dynamic flow tests are discussed by Chowdhury, Hall, and Davis (in preparation). Although a wealth of experimental data was available from the various tests, the estimated $\mathrm{CPU}$ time required for a dynamic FE analysis was more than 100 hours, necessitating several restarts. Due to time constraints, a single test was selected for FE simulation. Measured pressure distributions were used to load the FE model, and accelerations from the analysis were compared with test accelerometer records.

\section{Response spectrum results}

Since variable restraint at the base of the support rod could not be modeled in the response spectrum, two analyses for each load condition were run for the dry and 21-ft head conditions: full restraint in the global $\mathrm{z}$ direction and no restraint in the global $\mathrm{z}$ direction. The first test mode, rigid-body vibration, could not be reproduced in any analysis in which the end of the support rod was fully restrained. Analyses with no restraint produced rigid-body modes at somewhat lower frequencies than the test frequencies and produced second bending modes at significantly higher frequencies than the analyses with restraint. The frequencies of the first bending and torsional modes and the second torsional mode were not affected by support rod restraint conditions.

Predicted frequencies for the higher modes (above $100 \mathrm{~Hz}$ ) did not agree well with experimental results. For the wet condition, the experimental second bending mode occurred at a frequency of $96.8 \mathrm{~Hz}$. ABAQUS predicted 
frequencies for the second bending mode in the wet condition were $80.035 \mathrm{~Hz}$ for restraint in 3 directions at the end of the support rod, and $157.2 \mathrm{~Hz}$ for restraint in the global $\mathrm{x}$ and $\mathrm{y}$ directions only. Two factors account for the inaccuracy of the ABAQUS predictions. These are:

a. The actual test condition, in which $\mathrm{z}$ displacement in the direction of water flow was restrained, lies somewhere between the two modeled conditions.

b. The added masses are much larger for the second bending and torsional modes than for the first 3 modes.

An additional analysis was run for the wet condition without $\mathrm{z}$ restraint at the end of the support rod and using an added mass of $0.5 \mathrm{lb}-\mathrm{sec}^{2} / \mathrm{in}$. to reflect the higher added mass of the fourth and fifth modes. This analysis produced a second bending mode at $138 \mathrm{~Hz}$. Obviously the addition of mass does lower the frequency of the second bending mode if all other variables remain equal. However, the inability to model the actual support conditions in a linear elastic analysis seems to be a larger contributor to inaccuracies at the higher modes.

Frequencies calculated for the analytical model are presented in Tables 7 and 8 . In these tables, the sequential modal order for the physical and analytical models are shown in the parenthesis. Analytical mode shapes for both restraint conditions of the prop-supported dry gate are shown in Figures 16 and 17. All but the fourth experimental mode shape agreed very well with that of the analytical results for the wicket model with no z-restraint. Experimental mode shapes for the prop-supported wicket are shown in Figure 18. As seen in this figure, unlike the analytical mode, the fourth experimental mode showed weak torsional characteristics. The degree of correlation between the corresponding analytical and experimental mode shapes were computed using the MAC matrix as discussed below.

A MAC number is an indication of the degree of statistical correlation between mode shapes obtained from two different sources. The MAC matrix provides a measure of the least-squares deviation of the points of mode shape from the straight line correlation (Allemang and Brown 1982). The MAC matrix between corresponding mode shapes obtained from source $\mathrm{A},\left\{\phi_{A i}\right\}$, and source $\mathrm{B},\left\{\phi_{B j}\right\}$ could be defined by:

$\operatorname{MAC}\left(\phi_{A i} \phi_{B j}\right)=\frac{\left|\left\{\phi_{A}\right\}_{i}^{T}\left\{\phi_{B}\right\}_{j}\right|^{2}}{\left\{\phi_{A}\right\}_{i}^{T}\left\{\phi_{A}\right\}_{i}\left\{\phi_{B}\right\}_{j}^{T}\left\{\phi_{B}\right\}_{j}}$. 


\begin{tabular}{|c|c|c|c|}
\hline \multicolumn{4}{|c|}{$\begin{array}{l}\text { Table } 7 \\
\text { Response Spectrum Modes, Dry Analyses }\end{array}$} \\
\hline \multirow{2}{*}{$\begin{array}{l}\text { Mode } \\
\text { Description }\end{array}$} & \multicolumn{3}{|c|}{$f_{d y y}(H z)$} \\
\hline & $Z$ Restraint & No Z Restraint & Experimental \\
\hline rigid body & & 30.227 & $43.1 \quad$ (1) \\
\hline bending & 57.742 (1) & $57.742 \quad$ (2) & $58.0 \quad$ (2) \\
\hline torsional & 93.963 (2) & $93.963 \quad$ (3) & $91.4 \quad$ (3) \\
\hline torsional & & $128.02 \quad(4)$ & $136.2 \quad(4)$ \\
\hline bending & 104.7 & $205.94 \quad(5)$ & $141.2 \quad(5)$ \\
\hline torsional & $128.02 \quad(4)$ & & $231.6 \quad(6)$ \\
\hline
\end{tabular}

\begin{tabular}{|c|c|c|c|c|}
\hline \multicolumn{5}{|c|}{$\begin{array}{l}\text { Table } 8 \\
\text { Response Spectrum Modes, Wet Analyses }\end{array}$} \\
\hline \multirow{2}{*}{$\begin{array}{l}\text { Mode } \\
\text { Description }\end{array}$} & \multicolumn{4}{|c|}{$f_{\text {wet }}(\mathrm{Hz})$ - order of modes are shown in parenthesis } \\
\hline & Z Restraint & $\begin{array}{l}\text { No Z } \\
\text { Restraint }\end{array}$ & $\begin{array}{l}\Delta \mathrm{m}=0.5 \mathrm{lb}-\mathrm{sec}^{2} / \mathrm{in} . \\
\text { (No Z Restraint) }\end{array}$ & Experimental \\
\hline rigid body & & $22.94(1)$ & 22.745 (1) & $38.9 \quad$ (1) \\
\hline bending & $57.742(1)$ & $57.74 \quad(2)$ & $57.742(2)$ & 58.6 \\
\hline torsional & $72.763 \quad(2)$ & $72.76 \quad(3)$ & $64.542 \quad(3)$ & $68.6 \quad$ (3) \\
\hline torsional & & 83.37 (4) & 70.922 (4) & * \\
\hline bending & 80.035 & $157.2 \quad(5)$ & $138.08 \quad(5)$ & $96.8 \quad$ (4) \\
\hline torsional & 83.368 (4) & & & $163.2\left(6^{* *}\right)$ \\
\hline
\end{tabular}

*Shaft supported wicket had a torsional mode at $87.21 \mathrm{~Hz}$

** 5th experimental mode was disregarded because of its inconsistent behavior due to interaction with prop dynamics. 


$$
\frac{|1| \| \mid}{\text { IIIIII }}
$$




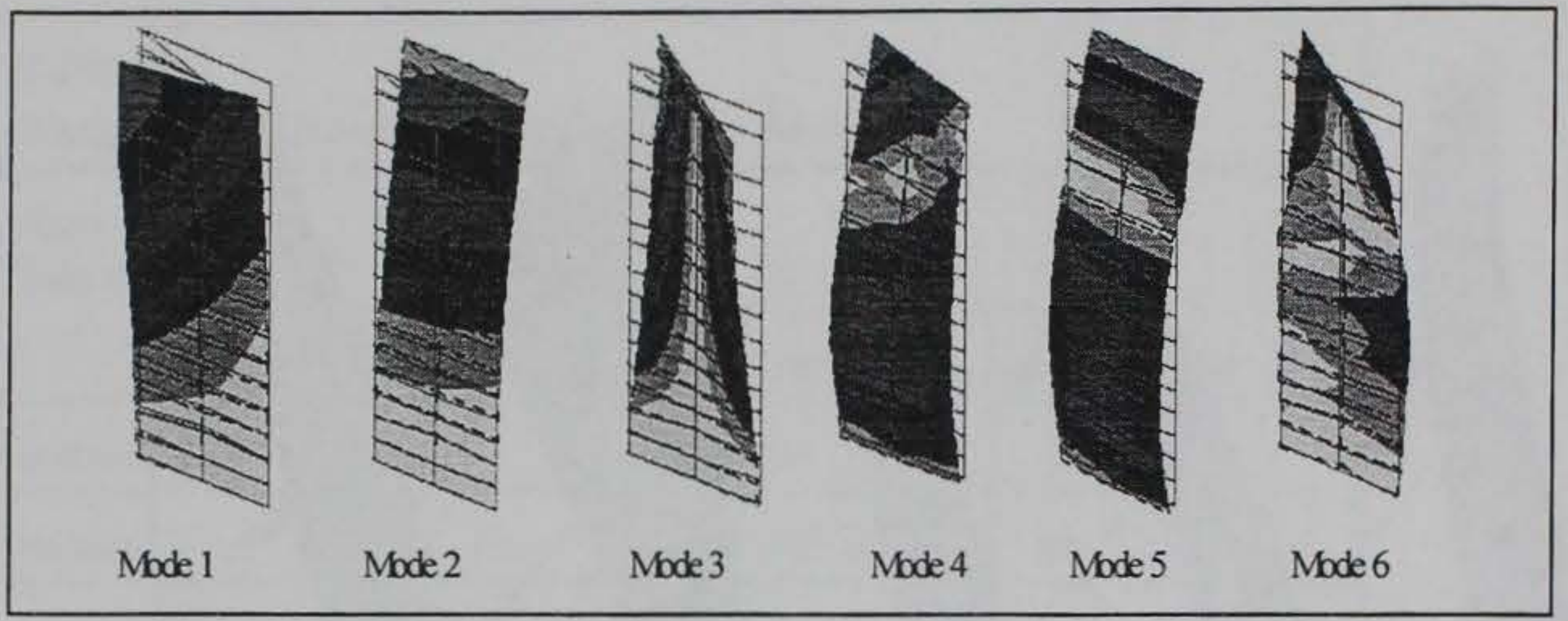

Figure 18. Experimental dry mode shapes for the prop-supported physical model

The MAC matrix for the dry-gate mode shapes obtained from the analytical (no $Z$ restraint) and experimental sources is presented in Table 9. These results indicate that a high degree of correlation existed between the modes compared in this table. Similarity of multiple modes, particularly the first two, is evident from this analysis. Experimental investigation indicated that coupled modes in the frequency range 100 to $200 \mathrm{~Hz}$ are time variant and highly dependent upon the prop dynamics. It is, thus, highly unlikely that the correlation between the analytical and experimental results will be enhanced without incorporating stochastic $\mathrm{FE}$ analysis or nonlinear system identification techniques into the current approach. Moreover, the participation factor obtained from the analytical results indicated that the most influential mode (mode \# 5) that contributed significantly to the dynamics of the dry gate had a quite high correlation between the experimental and analytical shapes. A participation factor indicates how strongly motion in the global directions is represented in the eigenvector of that mode (HKS 1994). For all practical purposes the analytical model is considered satisfactory to represent the physical dry modal behavior of the wicket model.

The MAC relations between the corresponding wet experimental and analytical mode shapes are shown in Table 10. This table confirms the similarity of the identical modes presented in Table 8 . The physical model showed a number of deceptive modes that did not exist in the analytical model. Mode numbers 4 and 5 in the experimental model, for instance, were the biased modes due to nonlinear interaction of the prop dynamics. A relatively higher 
correlation value for the 6 th mode was regarded as the distinguishing criteria for selecting the most probable similar mode that existed between the analytical and experimental models.

\begin{tabular}{|c|c|c|c|c|c|c|}
\hline $\begin{array}{l}\text { Table } 9 \\
\text { Correlation } \\
\text { Obtained Fr } \\
\text { Experiment: }\end{array}$ & $\begin{array}{l}\text { Matrix } f \\
\text { m the } \\
\text { I Sourc }\end{array}$ & $\begin{array}{l}\text { the } \mathrm{Pr} \\
\text { alytica }\end{array}$ & $\begin{array}{l}\text { p-Supp } \\
\text { (No Z-R }\end{array}$ & $\begin{array}{l}\text { rted Dry } \\
\text { straint C }\end{array}$ & $\begin{array}{l}\text { Wicket } \mathbb{N} \\
\text { ase) and }\end{array}$ & $\begin{array}{l}\text { odes } \\
\text { the }\end{array}$ \\
\hline Analytical & & erimental & odal Orde & (Column) & & \\
\hline $\begin{array}{c}\text { Modal Order } \\
\text { (Row) }\end{array}$ & $\begin{array}{c}1 \\
(43.1 \mathrm{~Hz}) \\
\end{array}$ & $\begin{array}{c}2 \\
(58 \mathrm{~Hz})\end{array}$ & $\begin{array}{c}3 \\
(91.4 \mathrm{~Hz})\end{array}$ & $\begin{array}{c}4 \\
(136.2 \mathrm{~Hz})\end{array}$ & $\begin{array}{c}5 \\
(141.2 \mathrm{~Hz})\end{array}$ & $\begin{array}{c}6 \\
(231.6 \mathrm{~Hz})\end{array}$ \\
\hline $\begin{array}{c}1 \\
(30.2 \mathrm{~Hz}) \\
\end{array}$ & 0.873 & 0.959 & & & & \\
\hline $\begin{array}{c}2 \\
(57.7 \mathrm{~Hz}) \\
\end{array}$ & 0.794 & 0.853 & & & & \\
\hline $\begin{array}{c}3 \\
(93.9 \mathrm{~Hz}) \\
\end{array}$ & & & 0.989 & & & \\
\hline $\begin{array}{c}4 \\
(128.0 \mathrm{~Hz}) \\
\end{array}$ & & & 0.977 & 0.214 & & \\
\hline $\begin{array}{c}5 \\
(205.9 \mathrm{~Hz}) \\
\end{array}$ & & & & 0.789 & 0.984 & \\
\hline $\begin{array}{c}6 \\
(212.8 \mathrm{~Hz}) \\
\end{array}$ & & & & & & 0.887 \\
\hline
\end{tabular}

Row Source: Laser_down, Column Source: NEW_6512

Unlike the 1st rotational experimental mode, the 1st analytical mode had a bouncing pattern as indicated in the MAC relation table. Such a change in the lst rigid body mode from bouncing to rotation could be attributed to the boundary effects on the physical model. Experimental results indicated that the actual pattern of the 1st mode depended primarily upon the orientation of the prop-rod bearing housing connection (top-end) with respect to the propconnection pin that was mounted tangential to the gate transverse axis. A slight tilting of the bearing housing, which is quite obvious during the wet experiment, could definitely change the resistance mechanisms of the prop-supported gate. Experimental modal results for the wet and dry wicket indicated a bouncing 1 st mode for a shaft supported wicket rather than the rotational pattern obtained for 
the prop-supported gate. A one-gate gap wet condition also showed 1st bouncing mode instead of rotational one for the prop-supported wicket. These results support the above conclusion that the interchangeability of the 1st mode is dependent upon the instantaneous boundary condition of the prop top-end connection and the uneven water mass distribution, if any, on the submerged surface of the wicket. Realistically, however, a nonuniform added mass distribution from a uniform flow pattern is nonobvious. Considering such a strenuous boundary incompatibility between the physical and analytical models, reasonably good MAC numbers between the corresponding most contributory modes indicate a good analytical representation of the wet physical model. As discussed below, the strong modes that are most contributory to the dynamics of the wet wicket are identified from the modal participation factor obtained from the $\mathrm{FE}$ analysis. In the wet analysis, the 5 th mode is the most active mode that has the largest modal participation in excitation along the $\mathrm{z}$-direction (normal to the gate surface).

\begin{tabular}{|c|c|c|c|c|c|c|}
\hline \multicolumn{7}{|c|}{$\begin{array}{l}\text { Table } 10 \\
\text { Correlation Matrix for the Prop-Supported Wet Wicket Modes } \\
\text { Obtained From the Analytical (No-Z Restraint Case) and the } \\
\text { Experimental Sources }\end{array}$} \\
\hline \multirow{2}{*}{$\begin{array}{l}\text { Analytical } \\
\text { ( no } Z \text { restraint) } \\
\text { Modal Order } \\
\text { (Row) }\end{array}$} & \multicolumn{6}{|c|}{ Experimental Modal Order (Column) for 21-ft, 3GG configuration } \\
\hline & $\begin{array}{c}1 \\
(38.9 \mathrm{~Hz}) \\
\end{array}$ & $\begin{array}{c}2 \\
(58.6 \mathrm{~Hz}) \\
\end{array}$ & $\begin{array}{c}3 \\
(68.6 \mathrm{~Hz}) \\
\end{array}$ & $\begin{array}{c}4 \\
(96.8 \mathrm{~Hz}) \\
\end{array}$ & $\begin{array}{c}5 \\
(148.4 \mathrm{~Hz}) \\
\end{array}$ & $\begin{array}{c}6 \\
(163.2 \mathrm{~Hz}) \\
\end{array}$ \\
\hline $\begin{array}{c}1 \\
(22.9 \mathrm{~Hz}) \\
\end{array}$ & & 0.890 & & & & \\
\hline $\begin{array}{c}2 \\
(57.7 \mathrm{~Hz}) \\
\end{array}$ & & 0.59 & & & & \\
\hline $\begin{array}{c}3 \\
(72.7 \mathrm{~Hz}) \\
\end{array}$ & 0.930 & & 0.981 & & 0.506 & \\
\hline $\begin{array}{c}4 \\
(83.3 \mathrm{~Hz}) \\
\end{array}$ & 0.924 & & 0.979 & & 0.533 & \\
\hline $\begin{array}{c}5 \\
(157.2 \mathrm{~Hz}) \\
\end{array}$ & & & & 0.826 & & \\
\hline $\begin{array}{c}6 \\
(200.0 \mathrm{~Hz})\end{array}$ & & & & & 0.477 & 0.699 \\
\hline
\end{tabular}

Row Source: Laser_21_ft_2_gt_dn, Column Source: NEW_6512w 
Modal participation factors for the wet analyses show that in the analysis with $\mathrm{z}$ restraint, mode 2 , the first torsional mode, is the largest contributor to gate behavior. Mode 6, a third bending mode that occurs at $218.77 \mathrm{~Hz}$, is also a large contributor. In the analysis without $\mathrm{z}$ restraint, the first torsional mode, mode 3 , is again the largest contributor to gate behavior, but the third bending mode disappears. In both analyses, the first bending modes contribute little to gate behavior. Participation factors for the first 5 modes for the wet condition analyses are given in Tables 11 and 12 .

The analytically computed modal effective mass also indicated that the first five modes could adequately represent the actual dynamics of the dry and wet wicket assembly. This conclusion was based on the fact that the sum of the modal effective masses for the first five modes along the $\mathrm{z}$-kinematic directions was about 70 percent of the total mass. This suggests that the first five modes have significant participation in excitation along the $\mathrm{z}$-direction, normal to the gate surface. The higher modes contribution (modes 6 through 10) was very insignificant, in the order of $10^{-11}$, which could easily be neglected for determining the total response of the wicket system. The sum total of modal effective masses and the contribution along the kinematically restrained degrees of freedom should provide the total mass of the model (HKS 1994). In this case, 30 percent of total mass remained fixed along the $\mathrm{z}$-direction due to the kinematic restraints at the supports.

\section{Time-domain dynamic response}

Response spectrum analyses indicated that gate behavior was well modeled for the first bending and torsional modes, but higher modes were more directly influenced by prop-rod end conditions and were less well modeled. Based on this, an initial decision was made to attempt to model only frequencies less than $100 \mathrm{~Hz}$ in the dynamic analysis. The maximum time step that can be expected to allow excitation of the structure at a frequency of $100 \mathrm{~Hz}$ is approximately 2.5 times the period, or $0.004 \mathrm{sec}$. Analysis of the frequency content of the acceleration records for the various experiments revealed that for a 
given experiment, the frequency content of each third of the data was similar, and only one-third of the test records were used for loading the model and evaluating resulting accelerations. During the experiment the accelerometer data were filtered at $500 \mathrm{~Hz}$, thus the resampled data used in the analysis, having a third of

\begin{tabular}{||l|l|l|l|l|l||}
\hline \multicolumn{1}{|l|}{$\begin{array}{l}\text { Table 11 } \\
\text { Modal Participation Factors, "Wet" Analysis, Z Restraint }\end{array}$} \\
\hline \multirow{2}{*}{ Mode } & \multicolumn{1}{|l|}{ Participation factors, analysis with z restraint on prop rod } & y-rot \\
\cline { 2 - 6 } & x-comp & y-comp & z-comp & x-rot & - \\
\hline 1 & 0.0005 & 0.01723 & 0.04371 & 2.8714 & - \\
\hline 2 & 438.79 & 3.2717 & -0.48626 & 98.602 & -8005.6 \\
\hline 3 & -0.002 & 0.56161 & 1.4385 & 58.422 & 0.11666 \\
\hline 4 & 245.55 & 0.32975 & -6.3558 & -168.93 & -1675.4 \\
\hline 5 & 0.22362 & 0.01294 & -0.02699 & -0.06653 & -5.6198 \\
\hline & & & & & \\
\hline
\end{tabular}

\begin{tabular}{|c|c|c|c|c|c|}
\hline \multicolumn{6}{|c|}{$\begin{array}{l}\text { Table } 12 \\
\text { Modal Participation Factors, "Wet” Analysis, no Z Restraint }\end{array}$} \\
\hline \multirow[t]{2}{*}{ Mode } & \multicolumn{5}{|c|}{ Participation factors, analysis with no $z$ restraint on prop rod } \\
\hline & $x$-comp & $y$-comp & z-comp & $\mathrm{x}$-rot & $y$-rot \\
\hline 1 & 0.0004 & 0.61672 & 1.3814 & 43.895 & 0.07844 \\
\hline 2 & 0.0008 & -0.01688 & -0.03679 & 0.59786 & -0.01342 \\
\hline 3 & 438.95 & 2.9482 & -1.29 & 67.969 & -8008.5 \\
\hline 4 & 244.57 & 2.097 & -1.7118 & 25.925 & -1668.4 \\
\hline 5 & 2.0897 & 54.913 & 116.78 & -945.3 & -22.216 \\
\hline
\end{tabular}


the total frequency range of the experiments, almost contained the first five wet modes of the physical model. Test accelerometer locations and corresponding nodes are shown in Figure 19. In this figure, the accelerometer locations are designated by the suffix $\mathrm{A} i$, where $i=1$ to 9 .

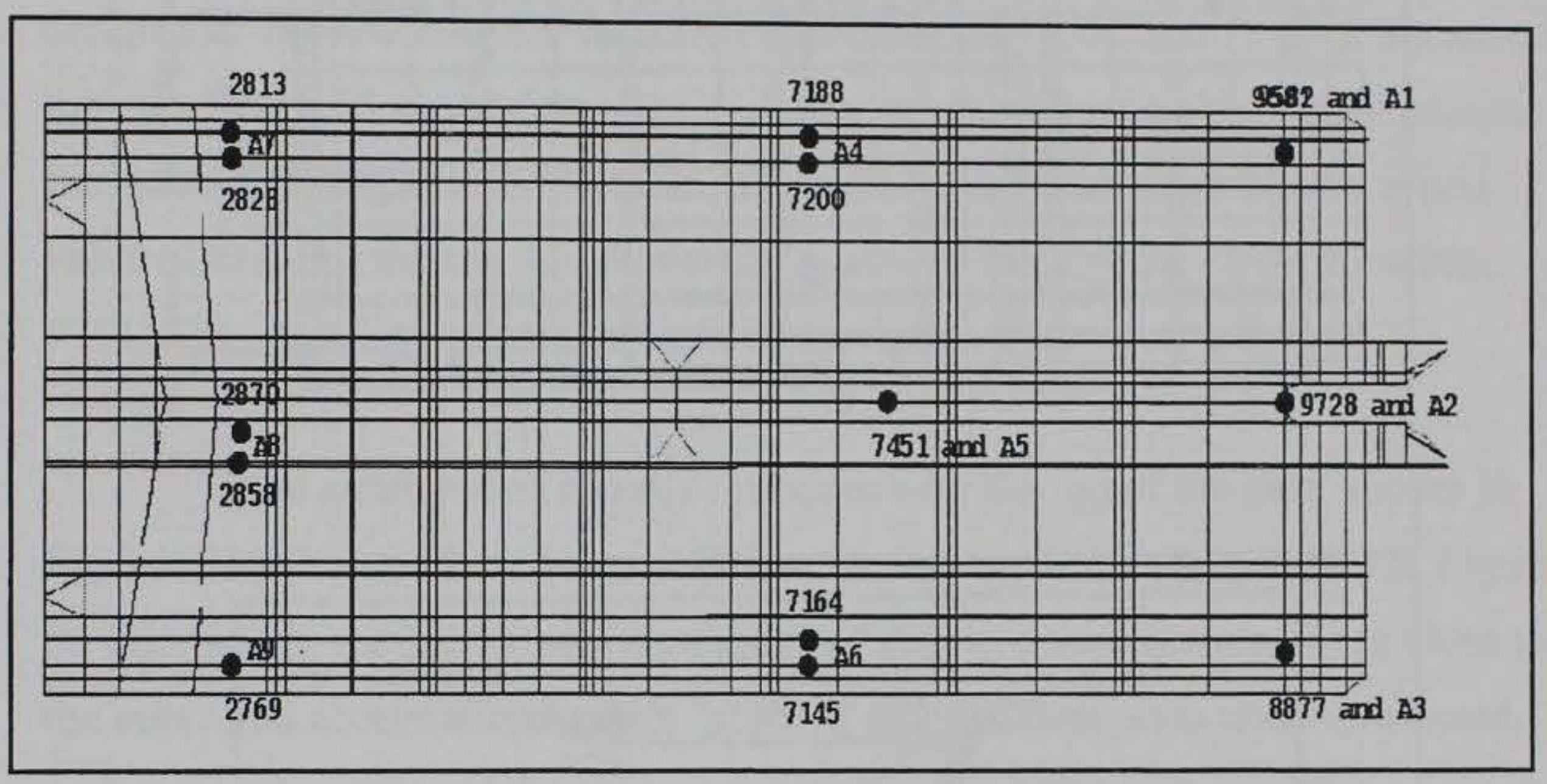

Figure 19. Location of FE nodes and accelerometers

The dynamic analysis modeled experiment number 163 , with the gate in the $65-\mathrm{deg}$ position and a $21-\mathrm{ft}$ head of water. A static loading equal to an average of the test pressure-time histories for the first few load increments was used as in initial loading for the gate. Displacement in the direction opposite the water flow at the base of the support rod was allowed by providing a gap element between the node at the end of the support rod and a fixed node at the same location. This allowed free movement of the support rod end away from the fixed node, but prevented further movement in the direction of flow once the gap was closed. Test downstream pressures were subtracted from upstream pressures to give a net pressure at each gauge location, and pressures for loading the plate surface were calculated by interpolating between test data for the 9 gauge locations, shown in Figure 20. Thus, the net pressure envelope comprising the nine gauge readings provided the flow-induced pressure loads for the analytical model. 


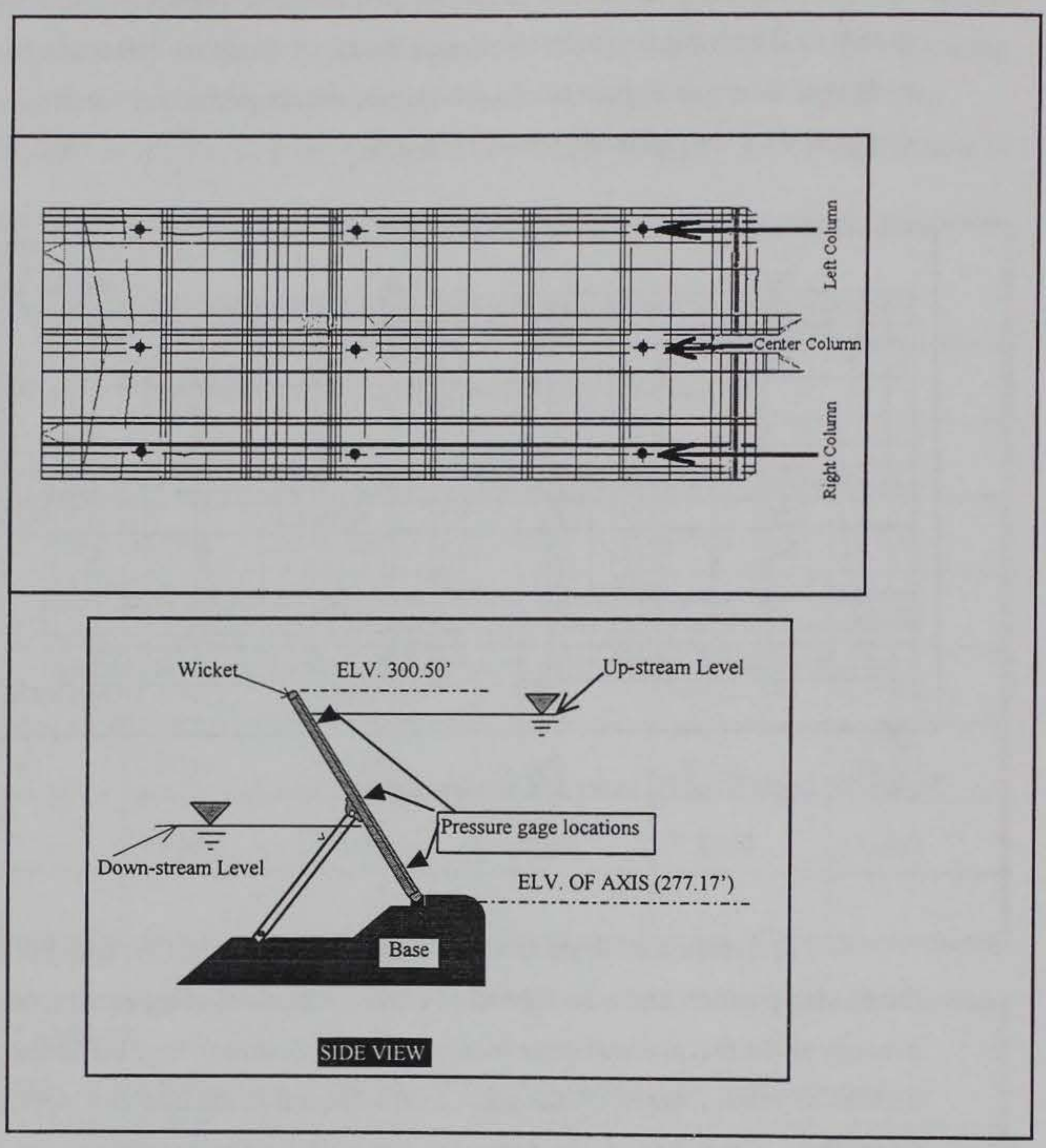

Figure 20. Pressure gauge locations and column lines for displaying pressure readings

An initial analysis using approximately $0.5 \mathrm{sec}$ of the pressure history showed that peak accelerations were calculated at each $0.004 \mathrm{sec}$ increment, and that times for these peaks did not exactly correspond to those in the test acceleration records. This indicated that the $0.004-\mathrm{sec}$ time step was not small enough to capture all of the response, and the analysis was reinitiated with a 0.002 -sec time step. The analysis was then conducted for $5 \mathrm{sec}$, requiring approximately $120 \mathrm{hr}$ of CPU time on the CRAY C-90. Calculated and 
experimental acceleration records are shown for eight locations in Figures 21 through 28. Calculated acceleration records were not saved at node 7451 .

At all of these locations, the abrupt application of dynamic loads to a model with no initial accelerations resulted in large initial accelerations that were damped to more consistent values by approximately 0.05 to $0.15 \mathrm{sec}$. Because of this, the first $0.15 \mathrm{sec}$ of data were deleted prior to evaluating the modal content of the ABAQUS acceleration records. The resulting records shifted to an initial value of zero are the records shown in Figures 21 through 28. Data at nodes 7451 , corresponding to gauge 5 , was not saved.

In the acceleration records for nodes near the top of the gate, shown in Figures 21 through 23, and at nodes near the bottom of the gate, shown in Figures 26 through 28 , the predicted magnitudes of negative accelerations were close to the measured accelerations, while positive accelerations were under predicted. At nodes near the center of the gate, shown in Figures 24 and 25, negative accelerations were under predicted.

Preliminary fast Fourier transforms (FFT) of the calculated and test accelerations at the eight locations are shown in Figures 29,31, and 32. Peak amplitudes at $60 \mathrm{~Hz}, 120 \mathrm{~Hz}$, and $240 \mathrm{~Hz}$, seen in Figures 29 and 31, appear in all of the test record FFTs and are a function of variations in electrical frequency. These frequencies were embedded in the pressure records used to load the analytical model and also appear in the ABAQUS records. Since amplitudes were low except at these peaks, only amplitudes through 0.5 have been plotted on the ordinate in FFT plots shown in Figures 31 and 32. Only frequencies through 150 $\mathrm{Hz}$ are plotted, since the structural frequencies of interest lie in this range. 


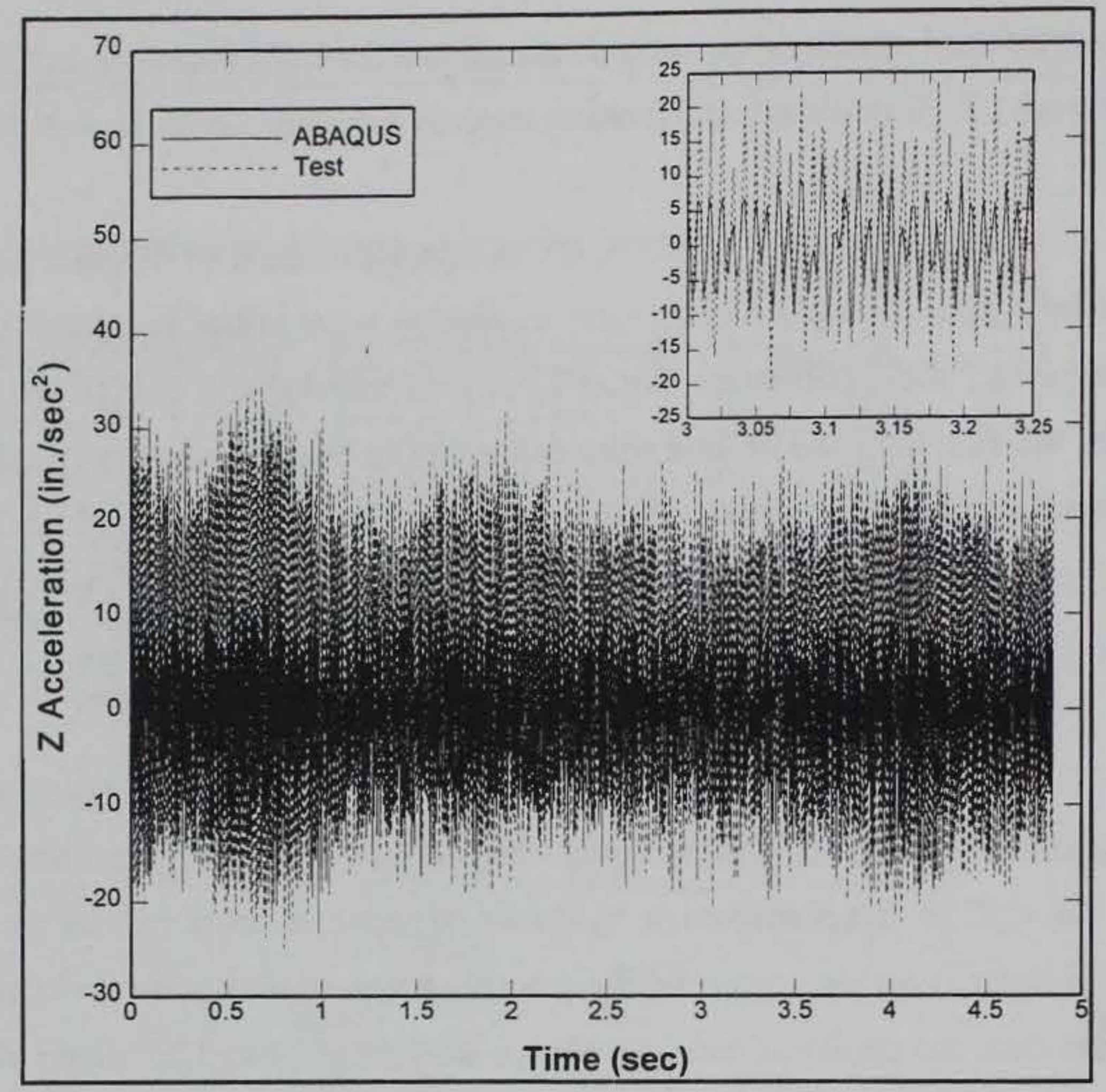

Figure 21. $\mathrm{Z}$ accelerations, node 9581 and gauge 1.

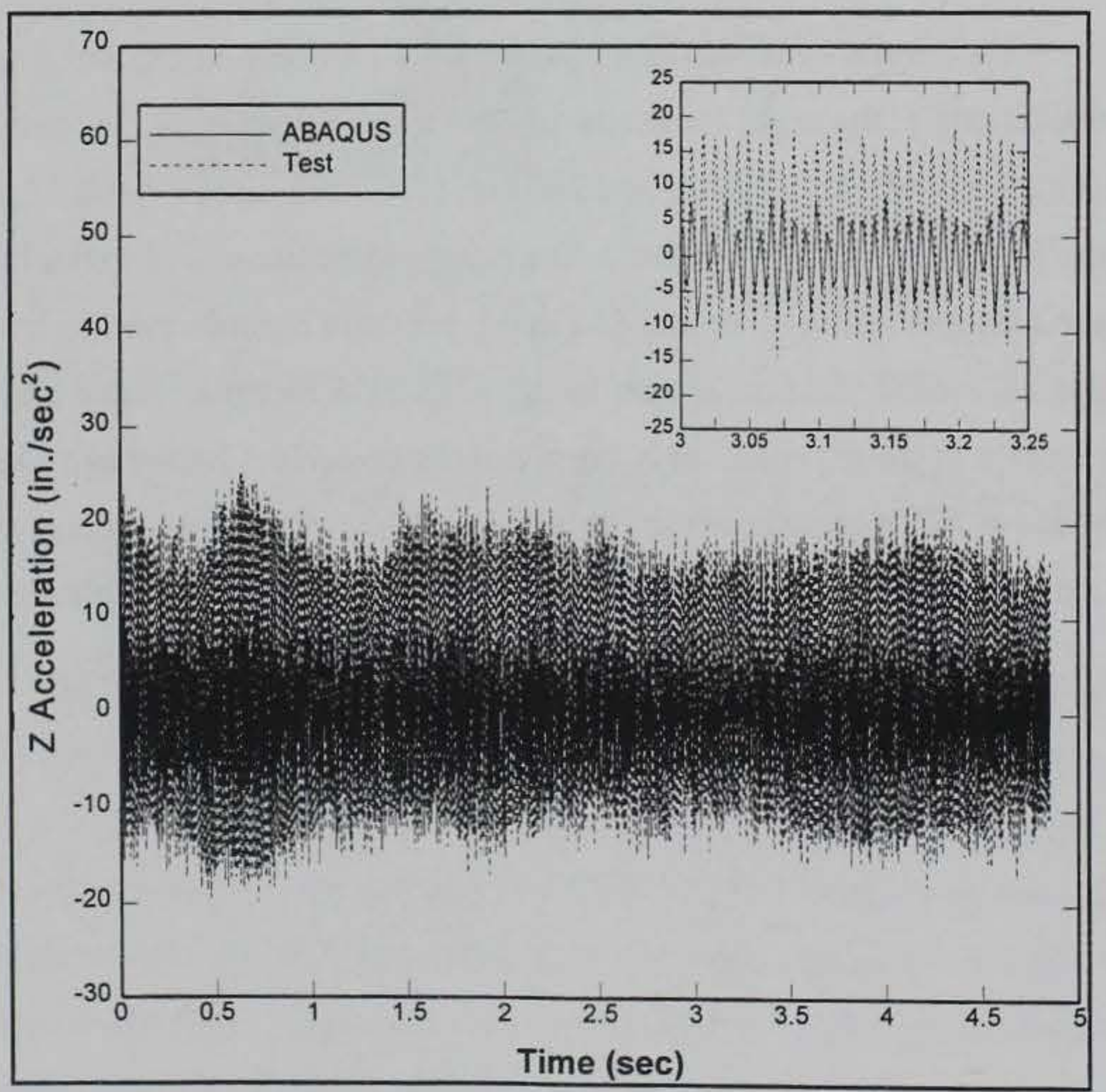

Figure 22. $Z$ accelerations, node 9728 and gauge 2 . 


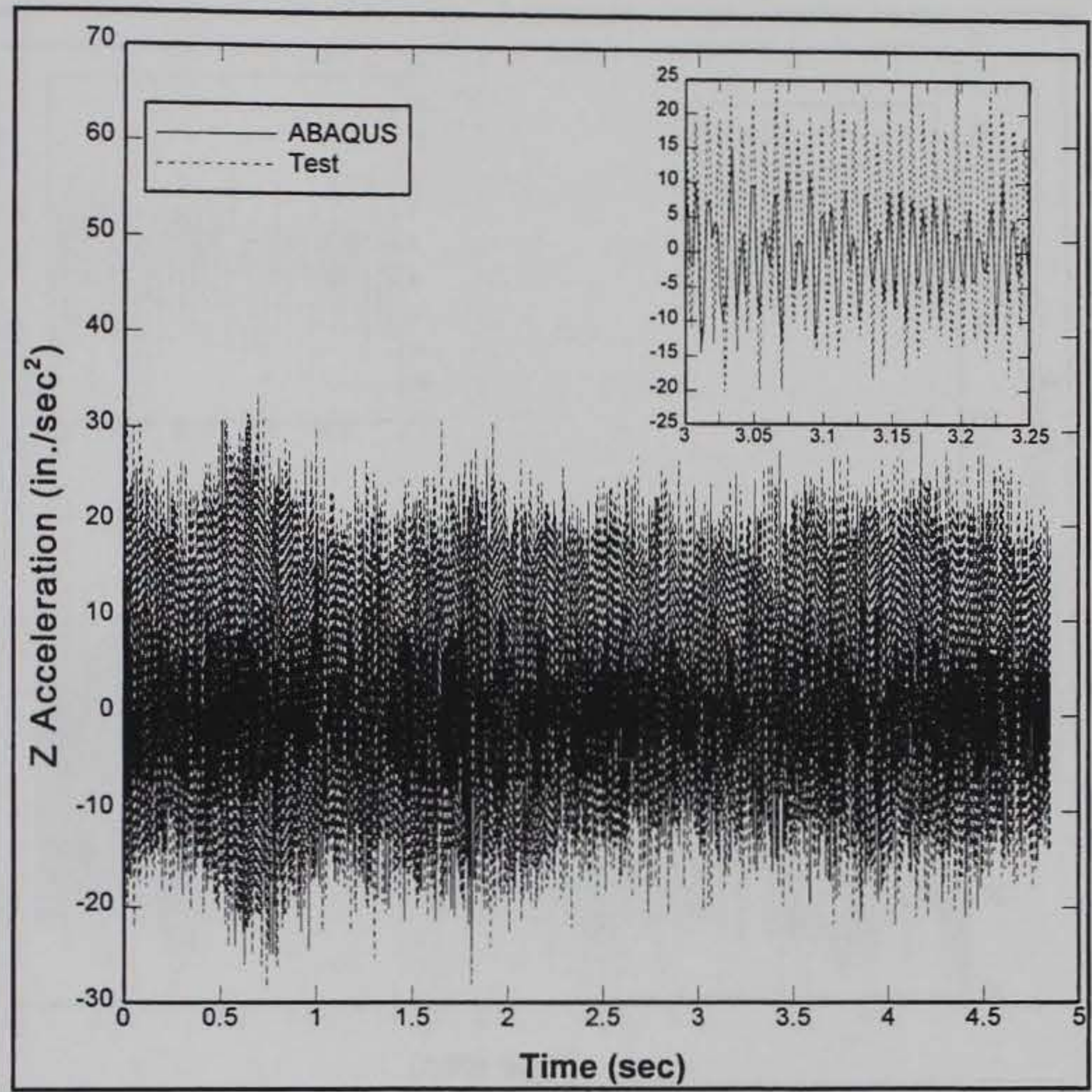

Figure 23. $\mathrm{Z}$ accelerations, node 8877 and gauge 3

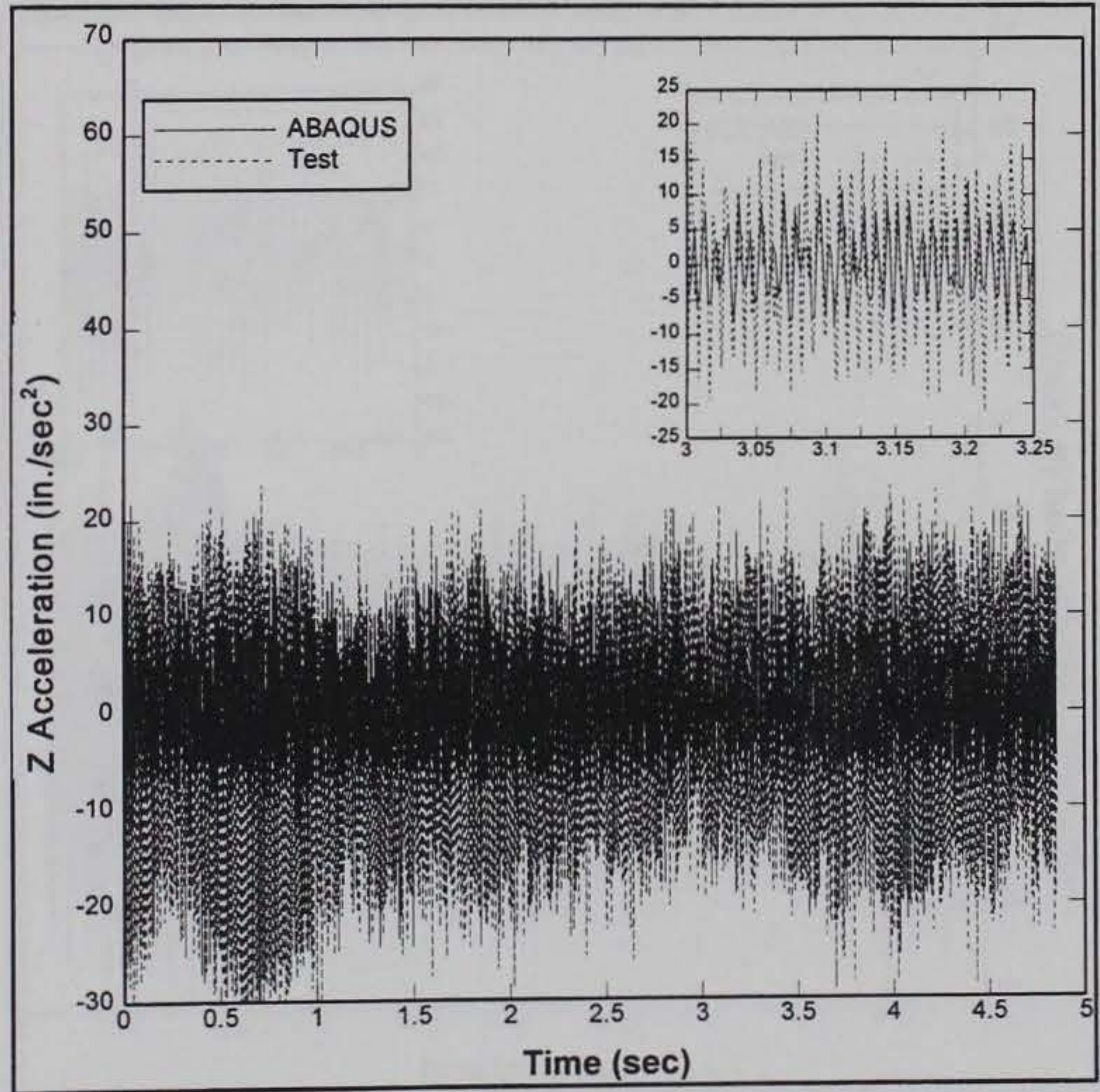

Figure 24. $\mathrm{Z}$ accelerations, node 7188 and gauge 4 


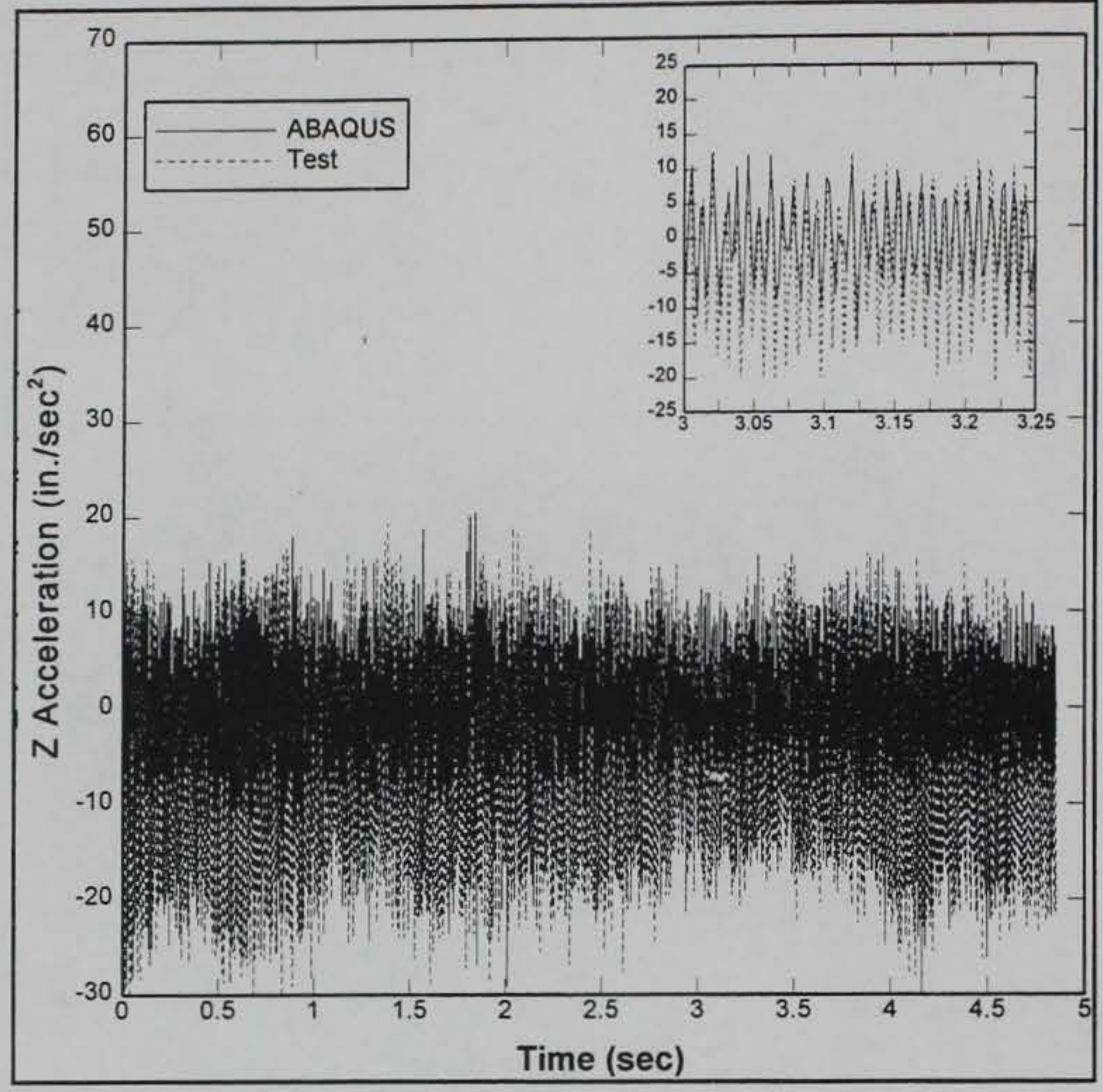

Figure $25 . \mathrm{Z}$ accelerations, node 7145 and gauge 6

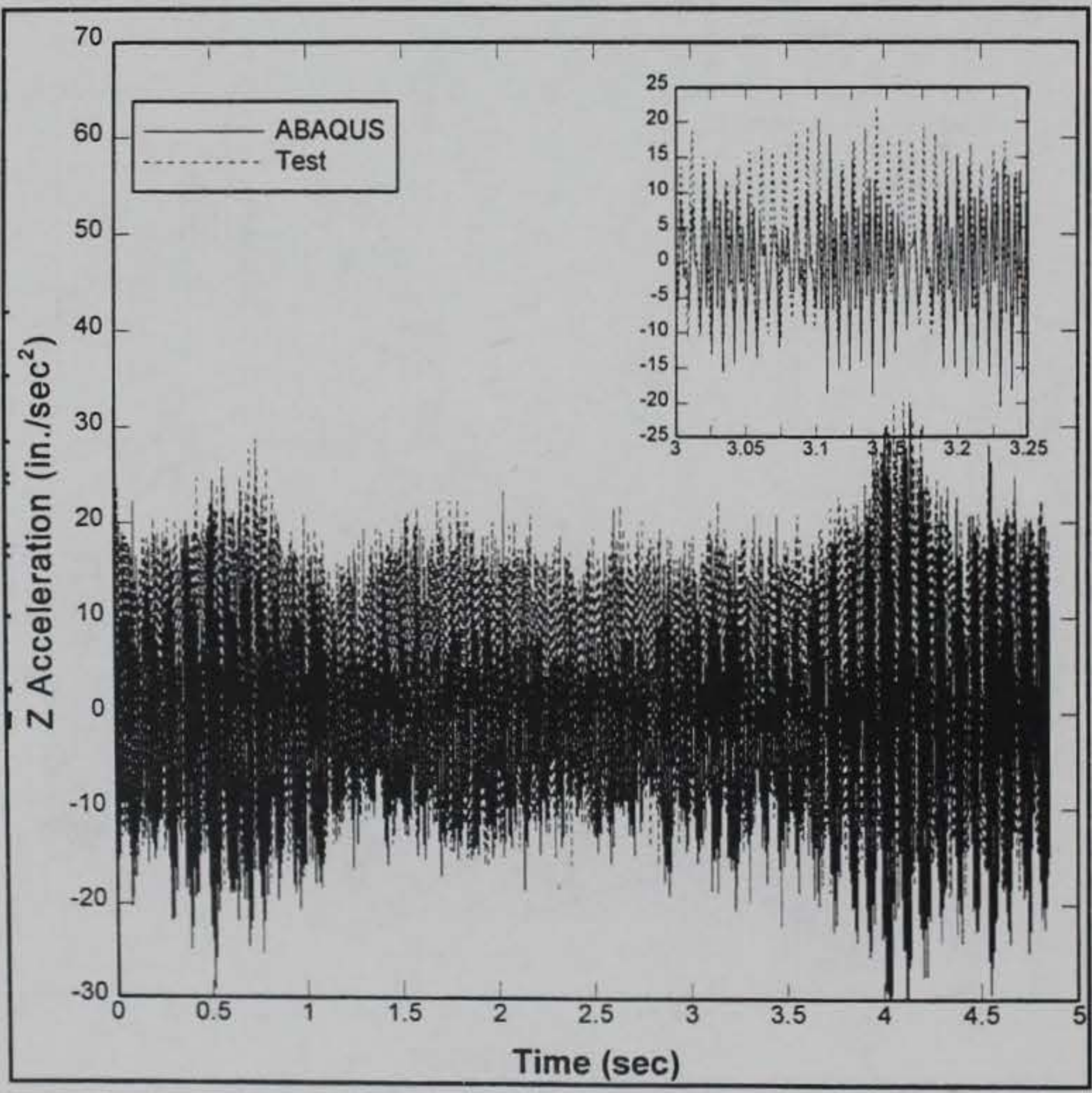

Figure 26. $\mathrm{Z}$ accelerations, node 2813 and gauge 7 


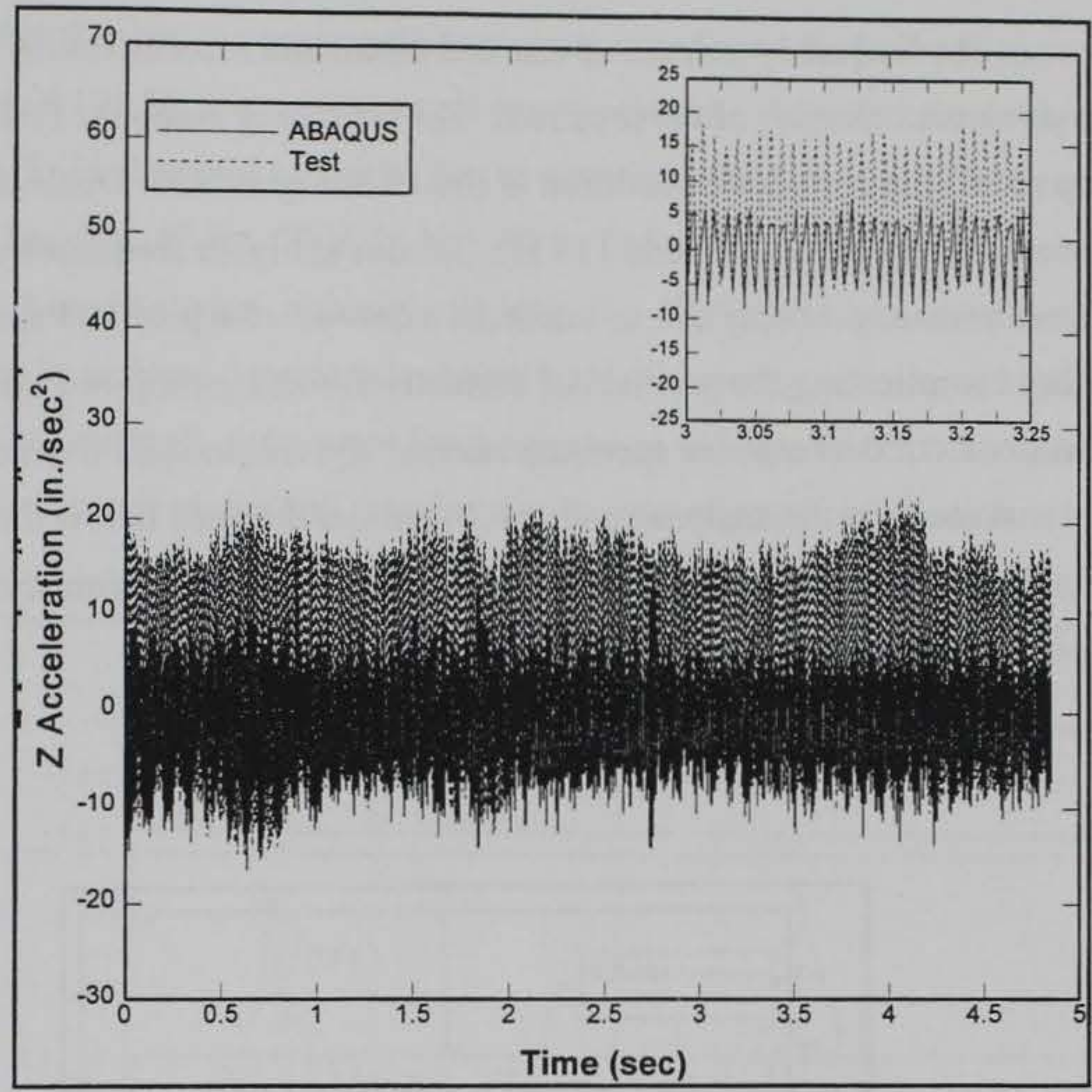

Figure 27. $\mathrm{Z}$ accelerations, node 2858 and gauge 8

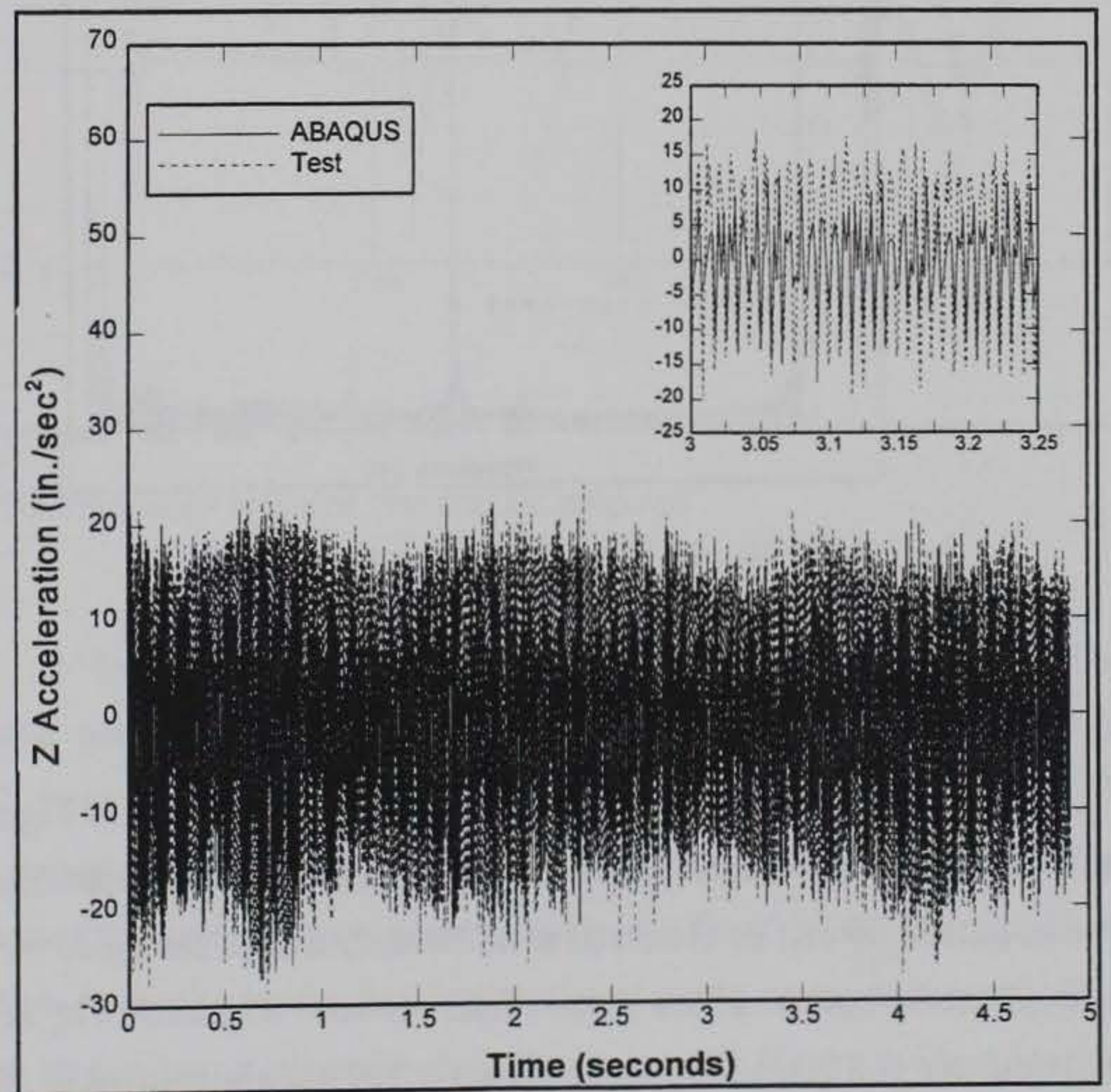

Figure 28. $\mathrm{Z}$ accelerations, node 2769 and gauge 9 
The frequency content of test and calculated records is also affected by the dynamic behavior of the prop rod. The frequency response function for the prop rod in the 21- $\mathrm{ft}$ head condition is shown in Figure 30. Distinct prop-rod modes occur at $38,58,70$, and $115 \mathrm{~Hz}$. Modes at higher frequencies are not distinct and are probably due to interaction between the prop rod and the gate, further complicating the problem of correctly modeling prop-rod boundary conditions. In the response spectrum results, the frequencies for the second torsional mode in the analyses with no $\mathrm{Z}$ restraint dropped below those of the second bending mode. This shows the heavy dependence of gate dynamic response on prop-rod response in the higher modes.

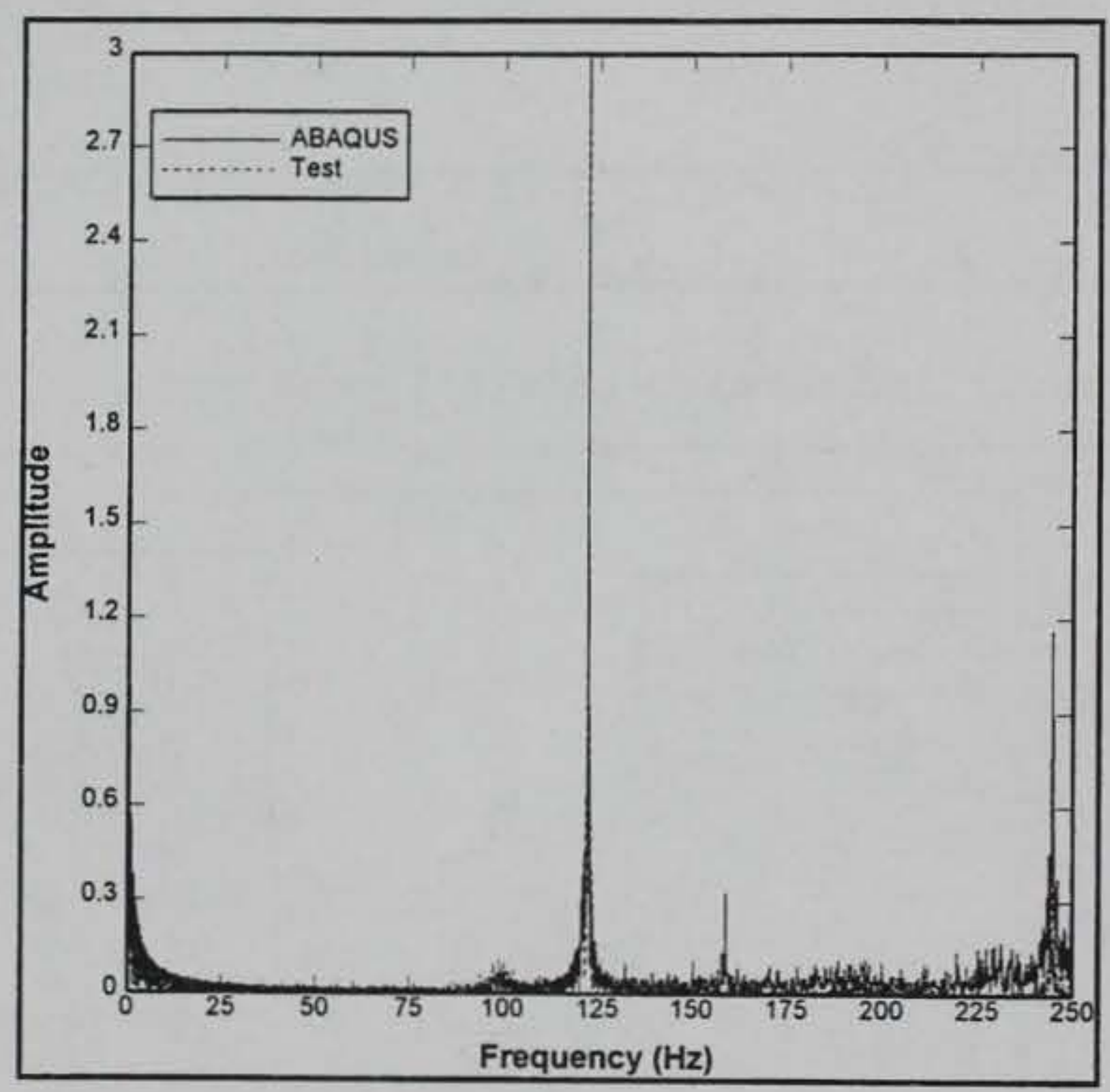

Figure 29. FFT of ABAQUS and test records, gauge 8 and node 2858

The FFTs of the test $\mathrm{z}$ acceleration records are shown in Figure 31. Peaks near $47 \mathrm{~Hz}$ can be seen in all records except those at the gate centerline. Peaks between 52 and 56 can be observed in all records except for those for gauges 7 through 9 at the bottom of the gate. Peaks between 63 and $73 \mathrm{~Hz}$, at approximately $148 \mathrm{~Hz}$, and at approximately $163 \mathrm{~Hz}$ are evident in all gauges 
except those at the gate centerline, gauges 2, 5, and 8. Peaks at approximately 99 $\mathrm{Hz}$ and $195 \mathrm{~Hz}$ are evident in all gauge records. Any structural response near $120 \mathrm{~Hz}$ is obscured by peaks due to electrical fluctuations. The first 4 frequencies, $47 \mathrm{~Hz}, 52$ to $56 \mathrm{~Hz}, 63$ to $73 \mathrm{~Hz}$, and $99 \mathrm{~Hz}$ may correspond to the first 4 mode shapes, although the lack of a $47-\mathrm{Hz}$ peak at centerline gauges would seem to indicate a torsional motion at this frequency. Peaks at higher frequencies are less defined, and except for the peaks at $163 \mathrm{~Hz}$, do not correspond to any distinct mode shape and may be due to gate-prop rod interaction.

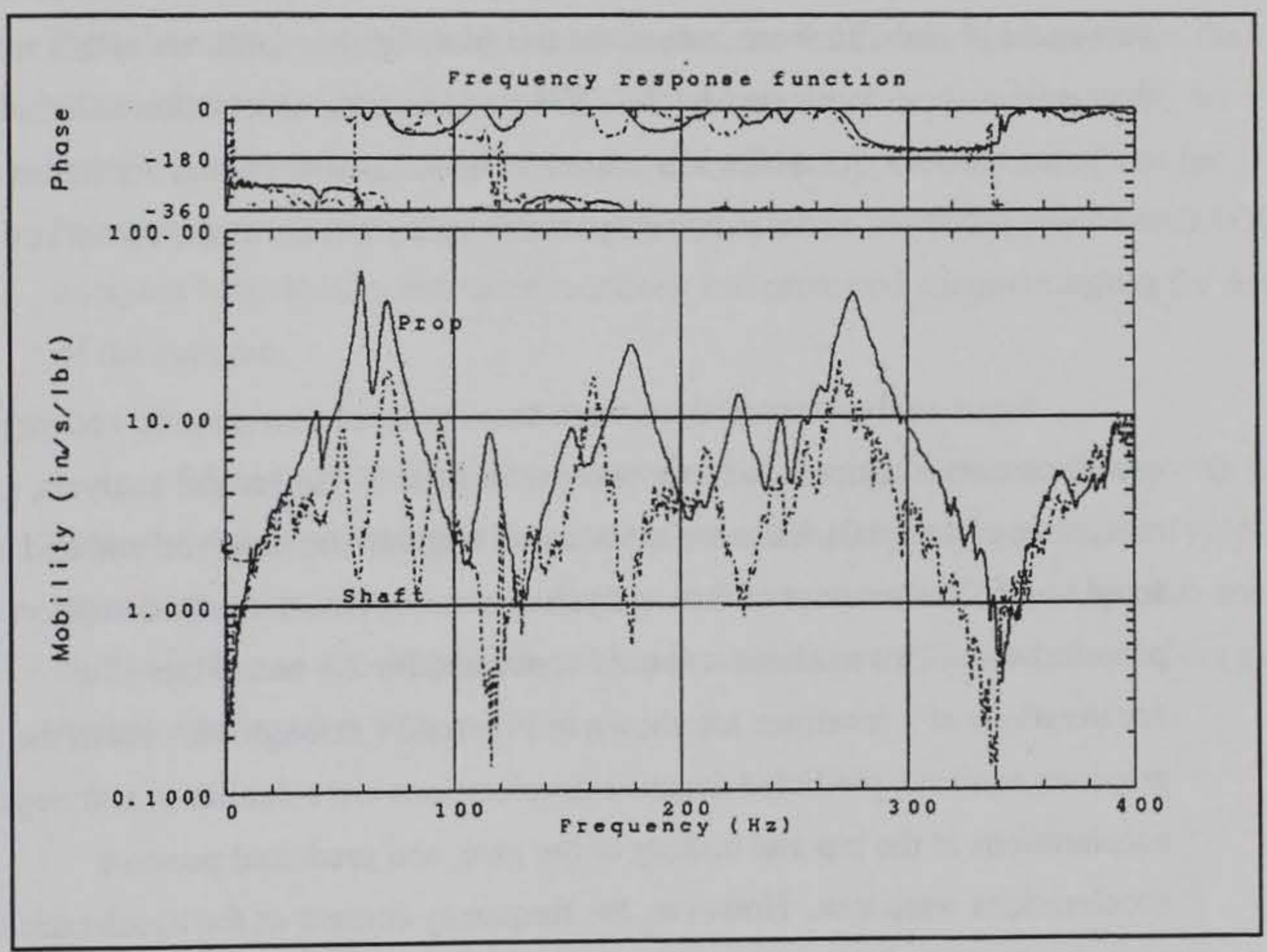

Figure 30. Frequency response function for prop rod

The frequency content of ABAQUS acceleration records for nodes located near 8 of the 9 gauges is shown in Figure 32. Accelerations at node 7451 , near the center of the gate, were not saved. Weak peaks near 47 and $55 \mathrm{~Hz}$ and strong peaks near $73 \mathrm{~Hz}$ are visible in records for nodes near the top and center of the gate and may correspond to the first 3 mode shapes. However, predicted amplitudes for the first torsional mode, at approximately $73 \mathrm{~Hz}$, are much larger than test amplitudes. Peaks near $99 \mathrm{~Hz}$ are evident for the 3 records 
at the base of the gate only. Peak amplitudes also are found near $90 \mathrm{~Hz}, 105 \mathrm{~Hz}$, $134 \mathrm{~Hz}, 150 \mathrm{~Hz}$, and $159 \mathrm{~Hz}$. These frequencies do not correspond to any mode defined by the response spectrum analyses. The appearance these indistinct higher modes and the low amplitude of the rigid-body response, which was heavily affected by prop-rod boundary conditions in the response spectrum results, can be attributed to prop-rod response and interaction between the gate and the prop rod.

Plots of test amplitude versus calculated amplitude for frequencies ranging from 0 to $150 \mathrm{~Hz}$ are shown in Figure 33. Amplitudes of frequencies between 115 and 130 were zeroed for this plot, since amplitudes in this range of frequencies were dominated by the effects of electrical fluctuation and their inclusion resulted in much wider scatter. Correlations are better for nodes near the top and bottom of the gate, and poor for nodes located at the center row of gauges.

Since analysis predictions were heavily dependent on prop-rod support conditions, an additional analysis was performed. In the second analysis, a minimum gap of 0.01 inch was maintained between the prop-rod end and the fixed node. The purpose of this analysis was to provide a less stiff support at the prop-rod end. This analysis was only continued for $2.5 \mathrm{sec}$. Plots of $\mathrm{z}$ accelerations at 3 locations are shown in Figures 34 through 36 . As in the previous analysis, predicted negative accelerations were similar to test negative accelerations at the top and bottom of the gate, and predicted positive accelerations were low. However, the frequency content of the acceleration records, shown in Figure 37, was somewhat different from that of the previous analysis. Additional peaks between 20 and $30 \mathrm{~Hz}$ and at frequencies higher than $80 \mathrm{~Hz}$ confirm that gate-prop rod interaction affects predictions in these frequency ranges.

Test reactions were only available at the gate hinges due to failure of the load cells at the prop-rod end. Global $y$ and $z$ reactions at the hinges from the two ABAQUS analyses are compared with test reactions in Figure 38, ABAQUS reactions at the prop-rod end are shown in Figure 39, and total global y and z reactions from the two analyses are shown in Figure 40 . For purposes of 
comparison, gate experimental $\mathrm{y}$ and $\mathrm{z}$ forces, shown in Figure 10, have been converted to the ABAQUS global axes. Analysis boundary conditions are shown in Figure 41.

In both analyses the gate was thrown forward by the water loading, causing the majority of the load to be carried by the support rod. In the first analysis, designated $\mathrm{AB} 1$ in Figures 38 through 41, some vertical load was distributed to the gauge hinges, resulting in small positive vertical reactions at the hinges. In the second analysis, $\mathrm{AB} 2$, uplift occurred at the gauge hinges.

However, total vertical and horizontal reactions for the two analyses were the same, as can be seen in Figure 40. Since reactions at the gate hinges are so sensitive to boundary conditions at the end of the support rod, it may not be practical to attempt to model test reactions exactly. However, the two ABAQUS analyses bounded the measured reactions and produced adequate values for design of the supports.

Maximum principal stresses were low throughout the analyses, with the largest stresses occurring at the gate hinges and the support rod hinge. Typical maximum principal stresses on the top and bottom surface of the top plate are shown in Figure 42. Maximum principal stresses on the outer surface of the gate hinges are shown in Figure 43. 


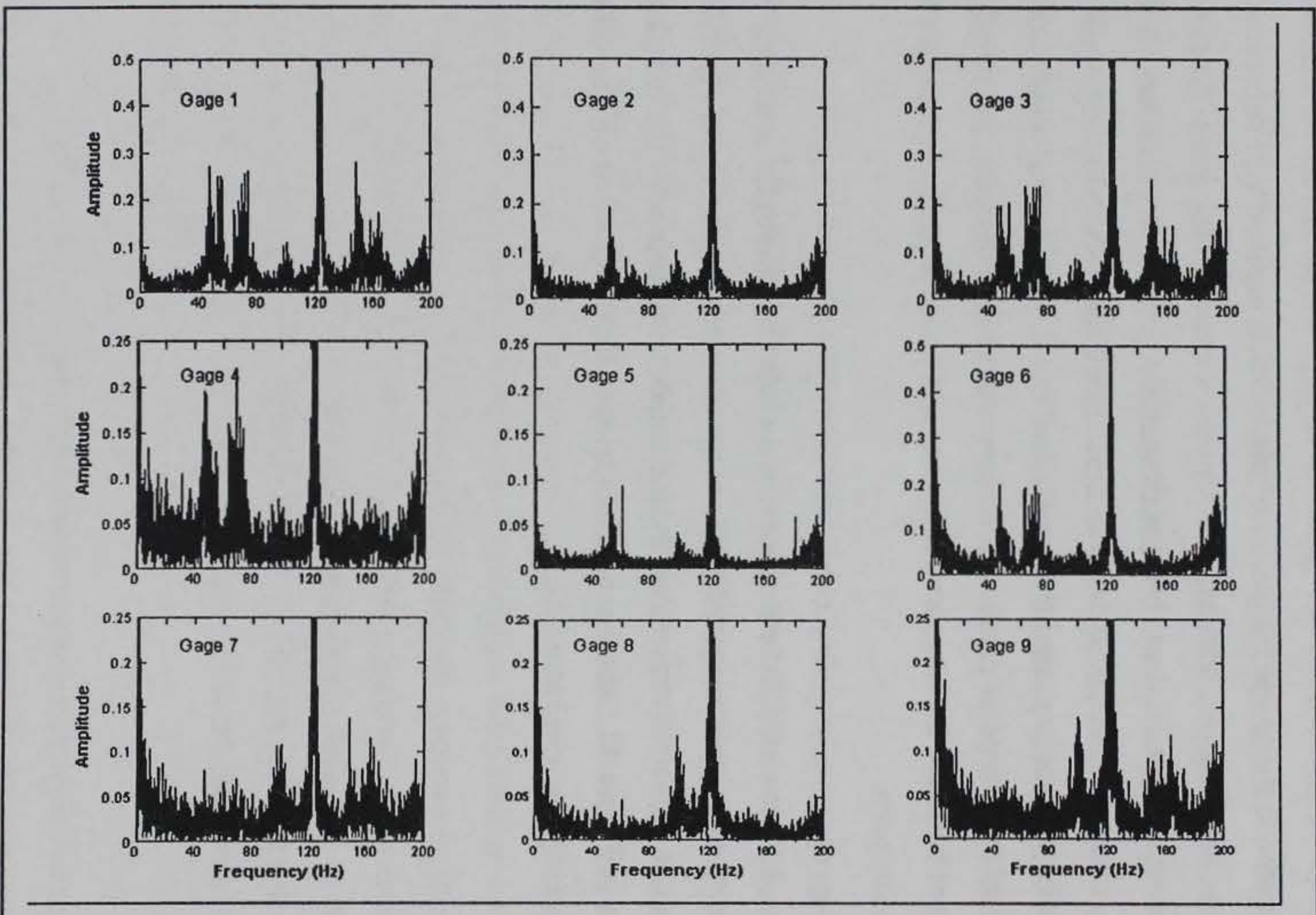

Figure 31 . FFT plots of $21-\mathrm{ft}$ head test $\mathrm{z}$ accelerations, accelerometers 1 through 9 (Amplitudes are in arbitrary units) 


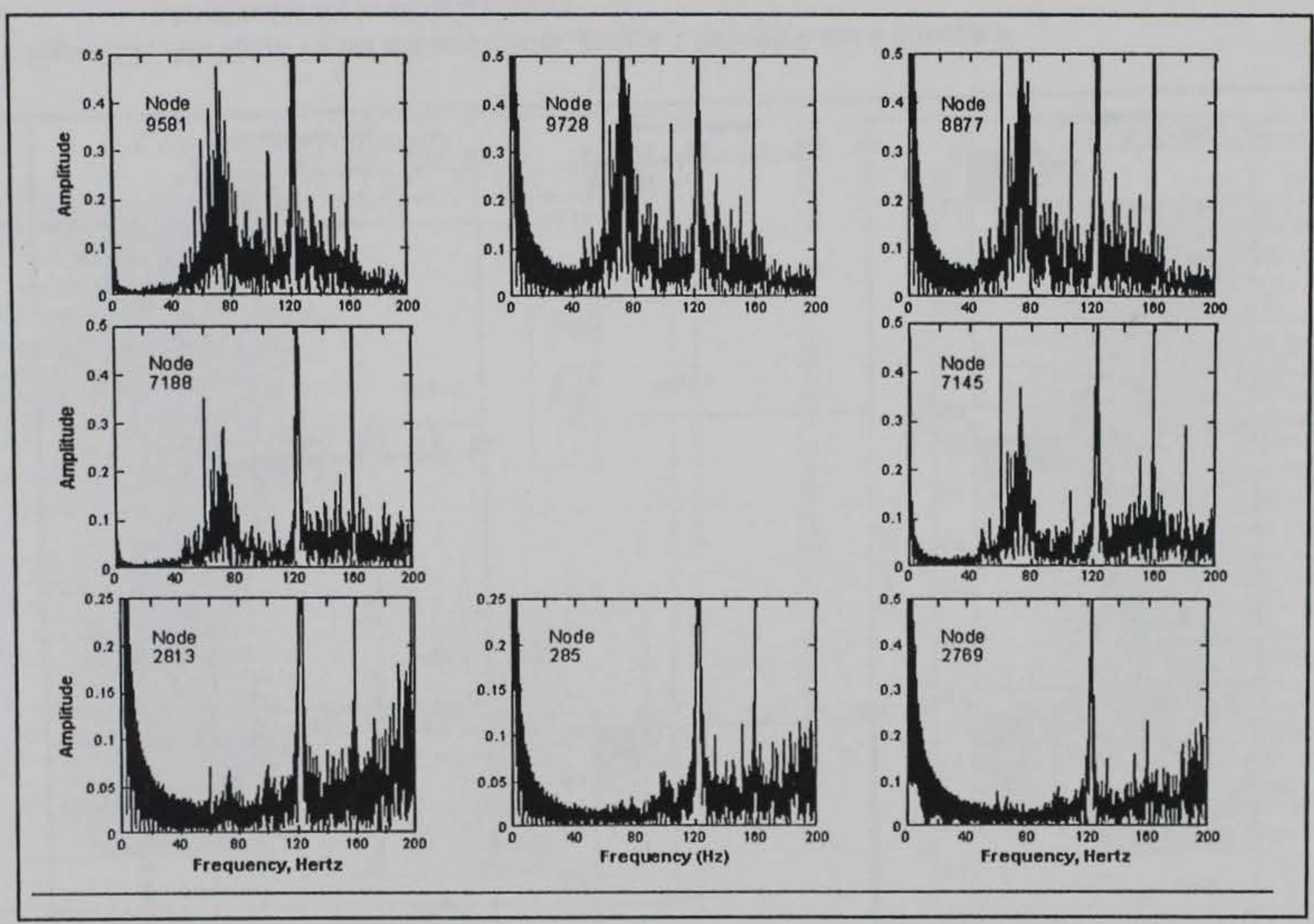

Figure 32. FFT plots of ABAQUS z acceleration records corresponding to gauges 1 through 9 (Amplitudes are in arbitrary units) 


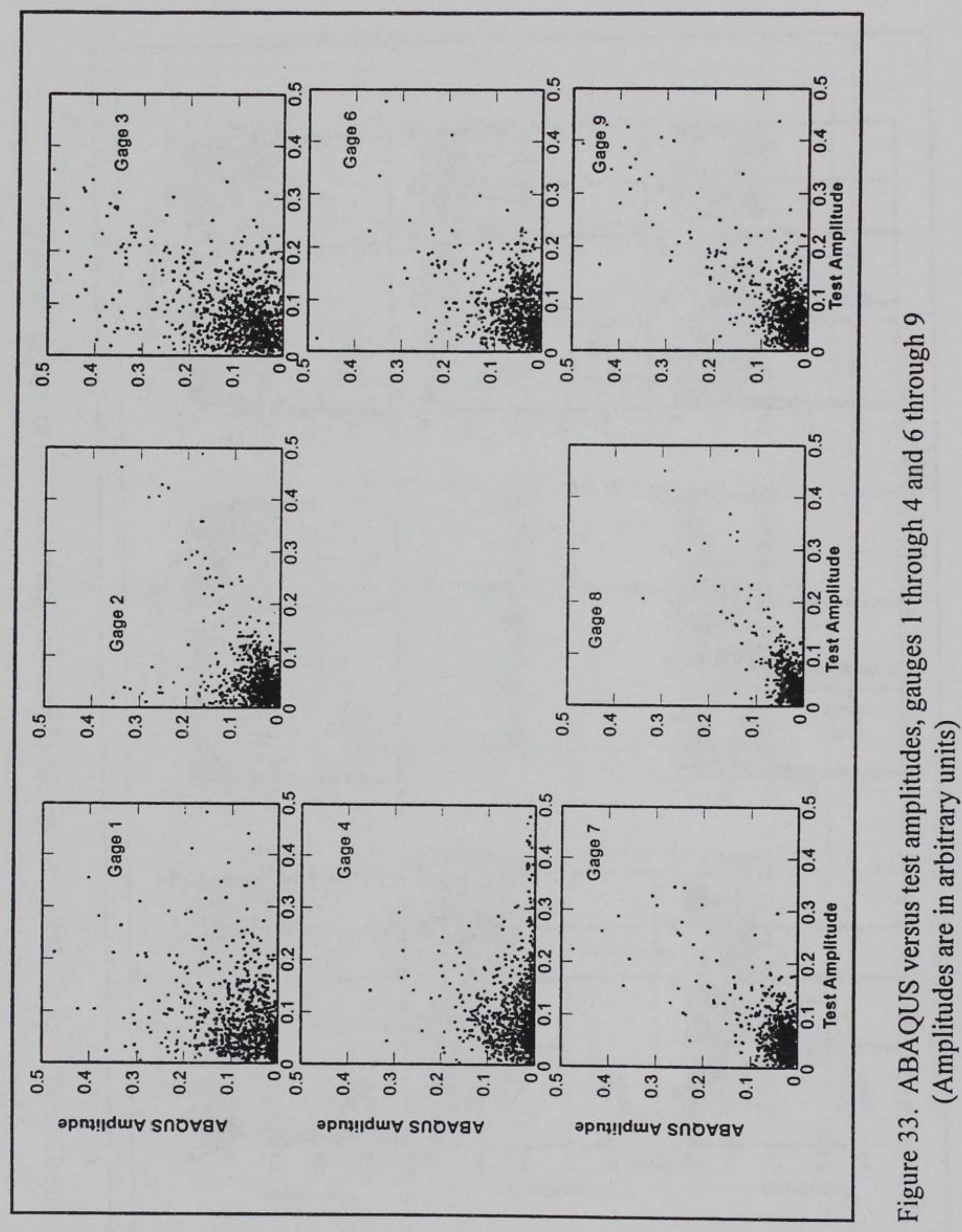




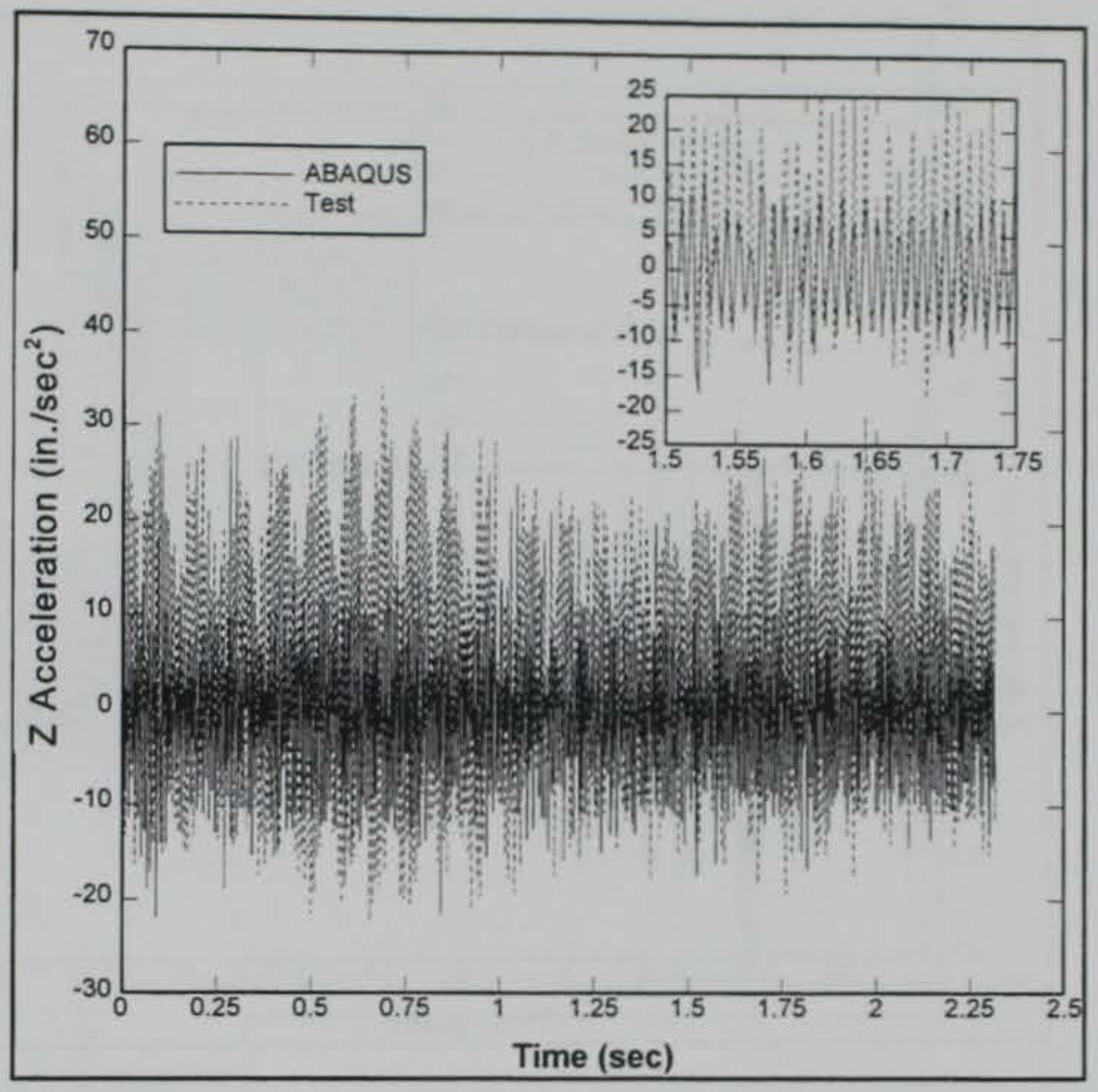

Figure 34. $\mathrm{Z}$ acceleration, node 9581 and gauge 1 , analysis 2

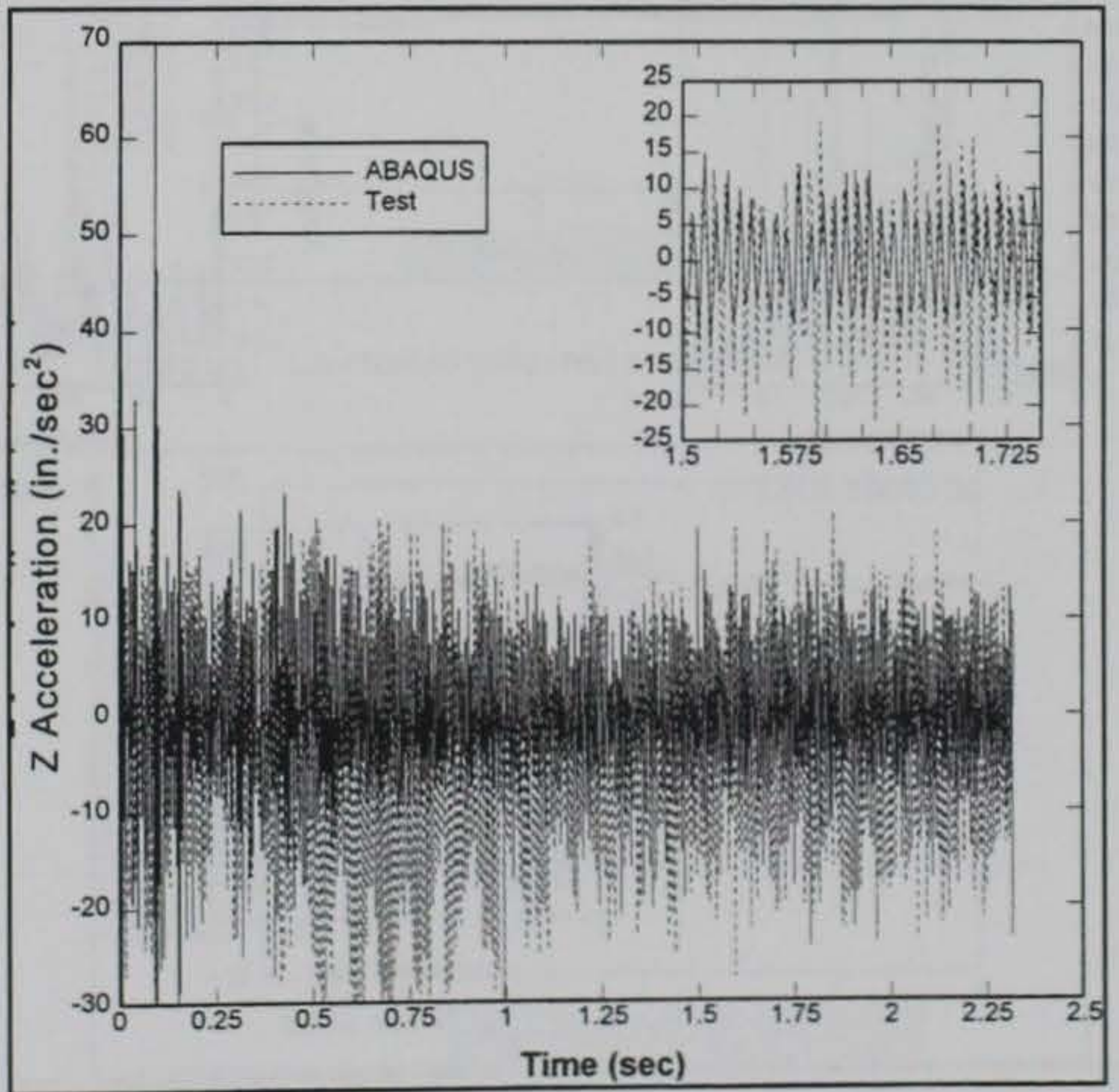

Figure $35 . \mathrm{Z}$ acceleration, node 7188 and gauge 4 , analysis 2 


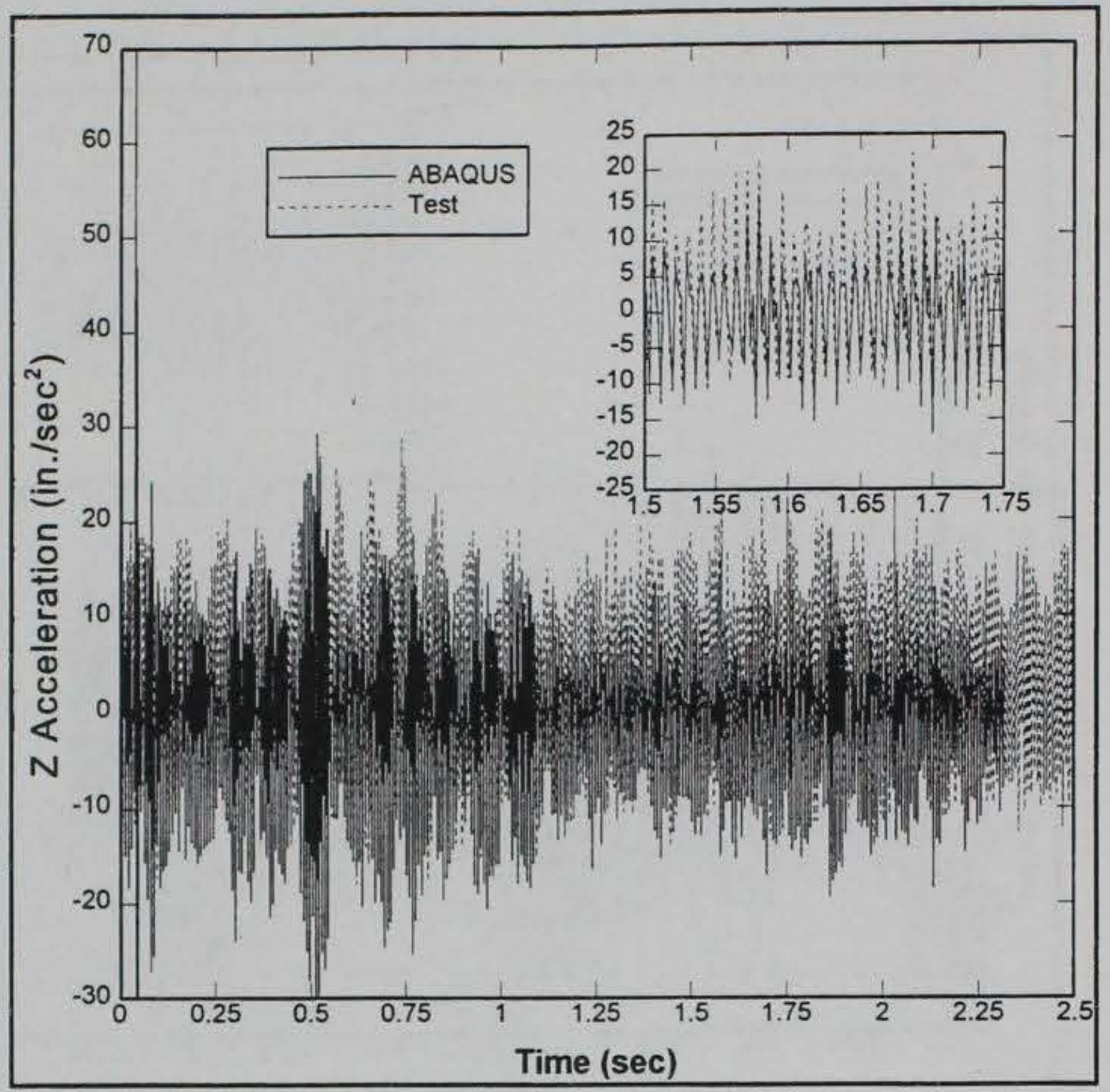

Figure $36 . \mathrm{Z}$ acceleration, node 2813 and gauge 7, analysis 2
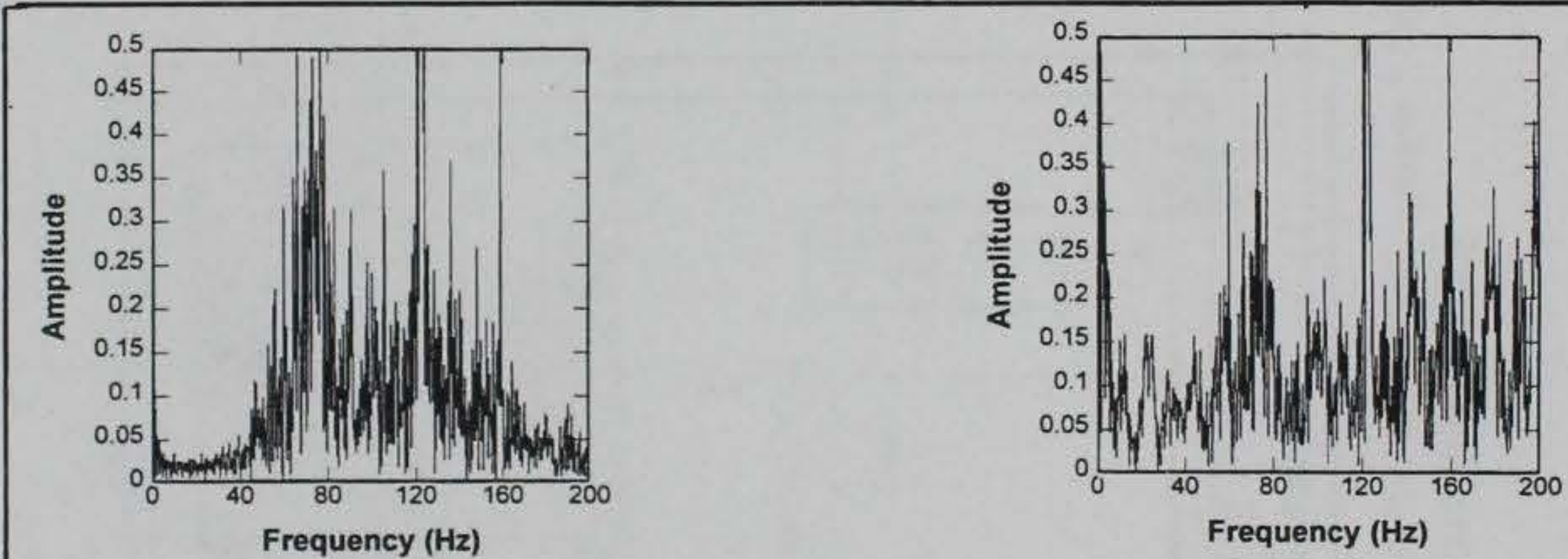

a. Node 9581

b. Node 7188

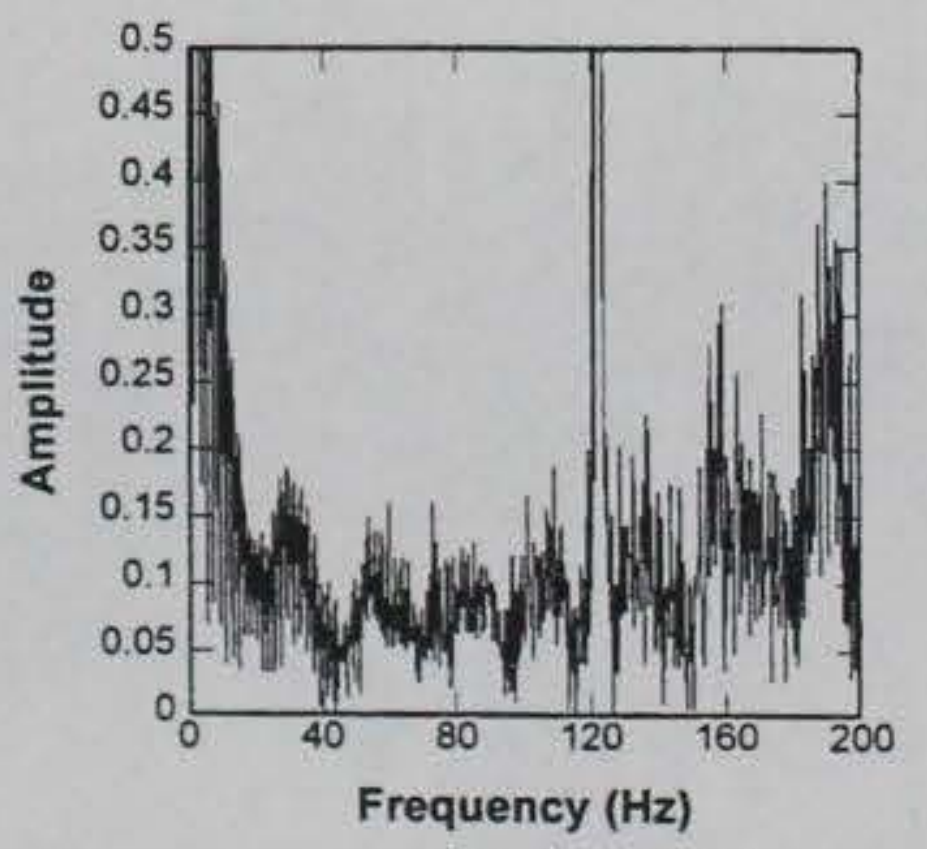

c. Node 2813

Figure 37. Frequency content of $\mathrm{Z}$ acceleration records for 3 nodes, analysis 2 


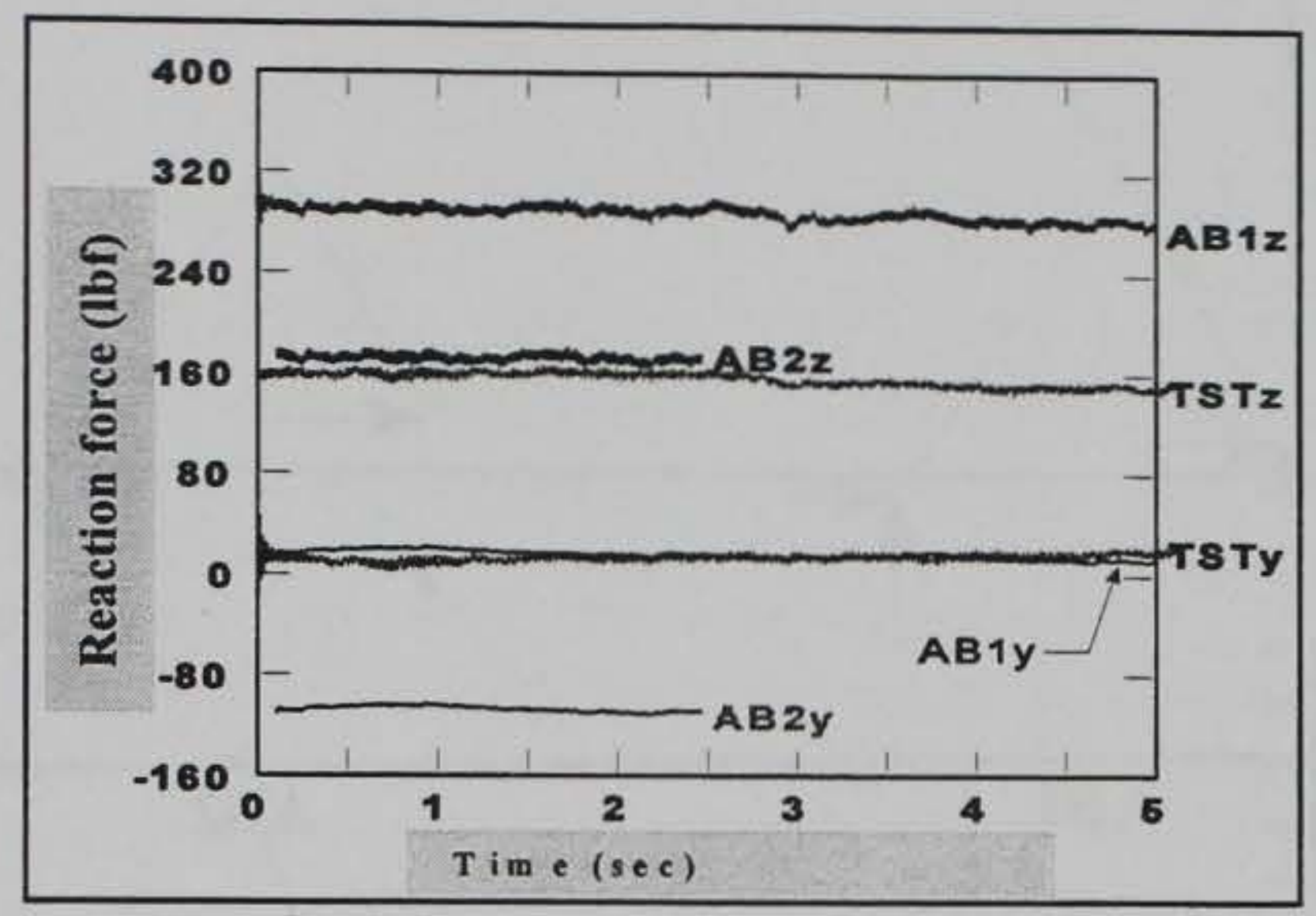

Figure 38. Measured and calculated hinge reactions

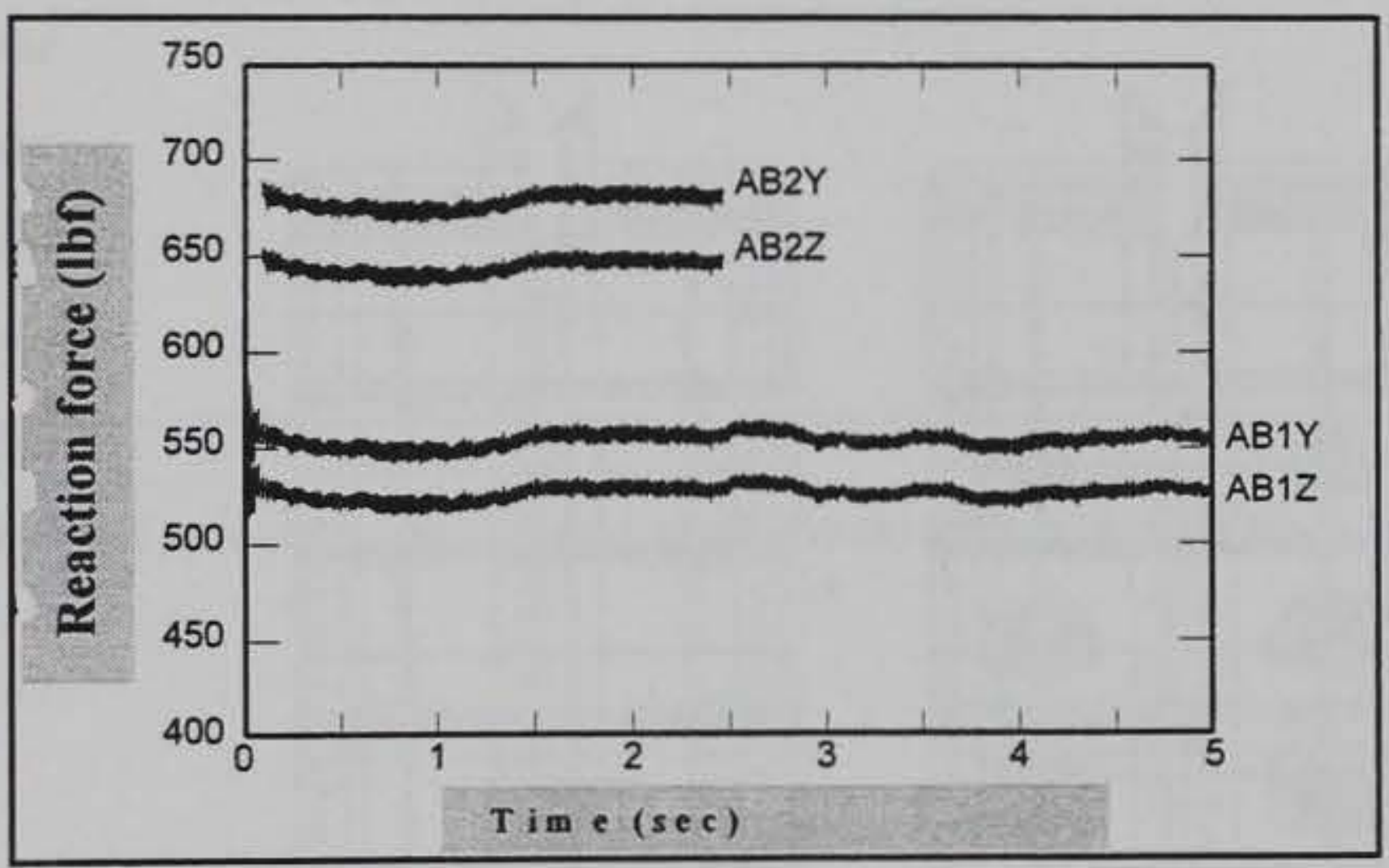

Figure 39. Calculated prop-rod reactions.

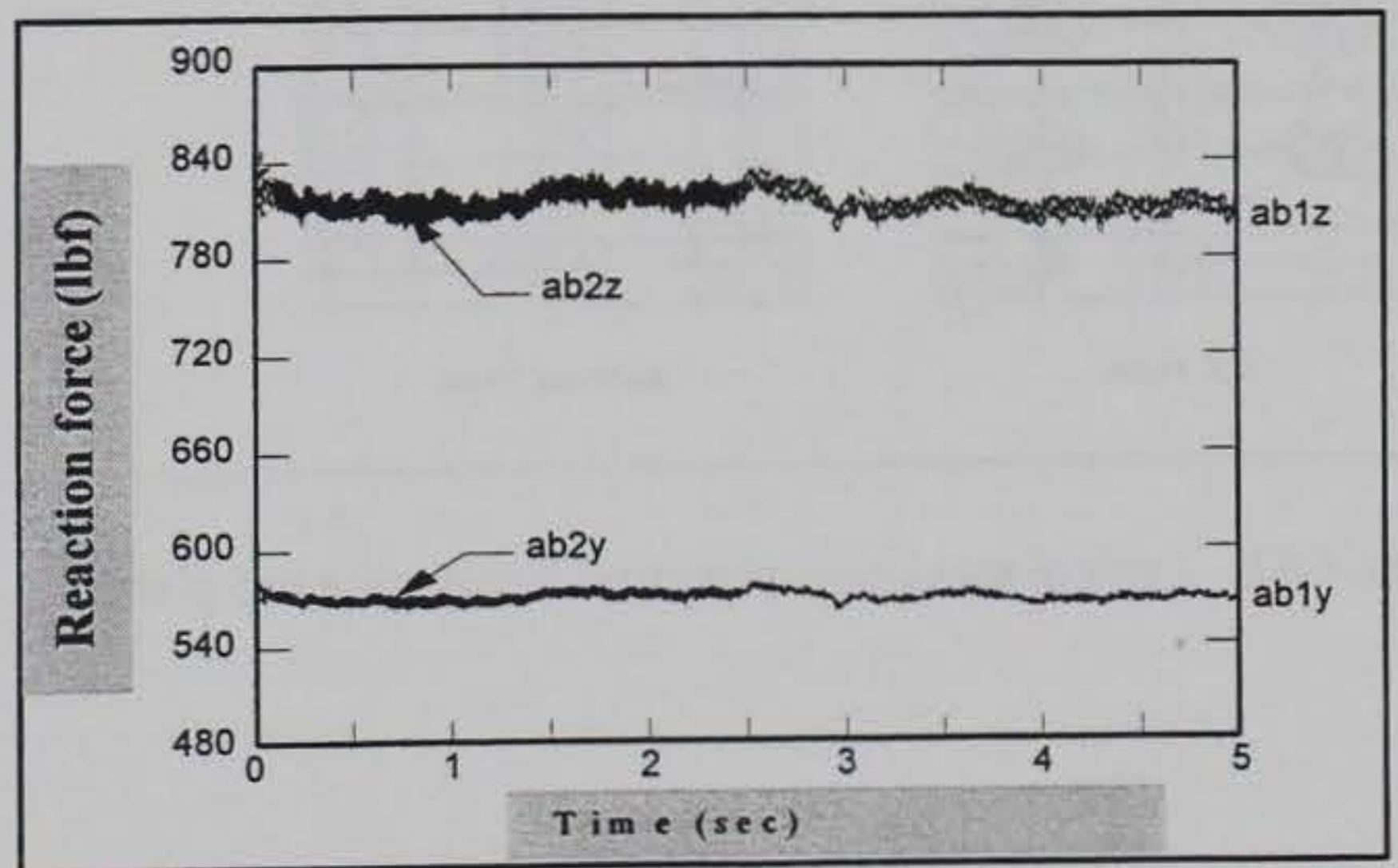

Figure 40. $A B A Q U S$ total reactions, $A B 1$ and $A B 2$ 


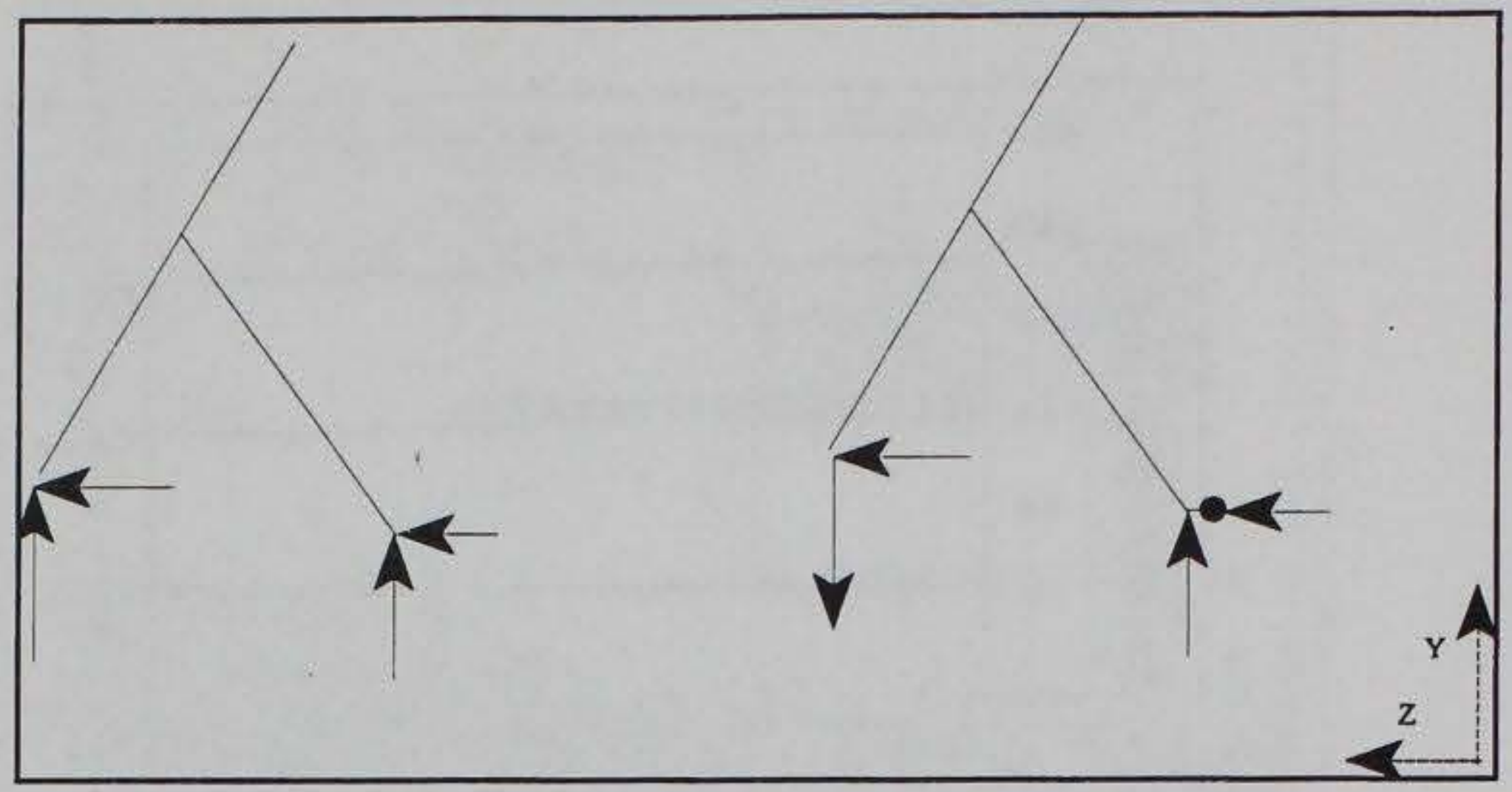

AB1

AB2

Figure 41. Location and direction of reactions, ABAQUS analyses

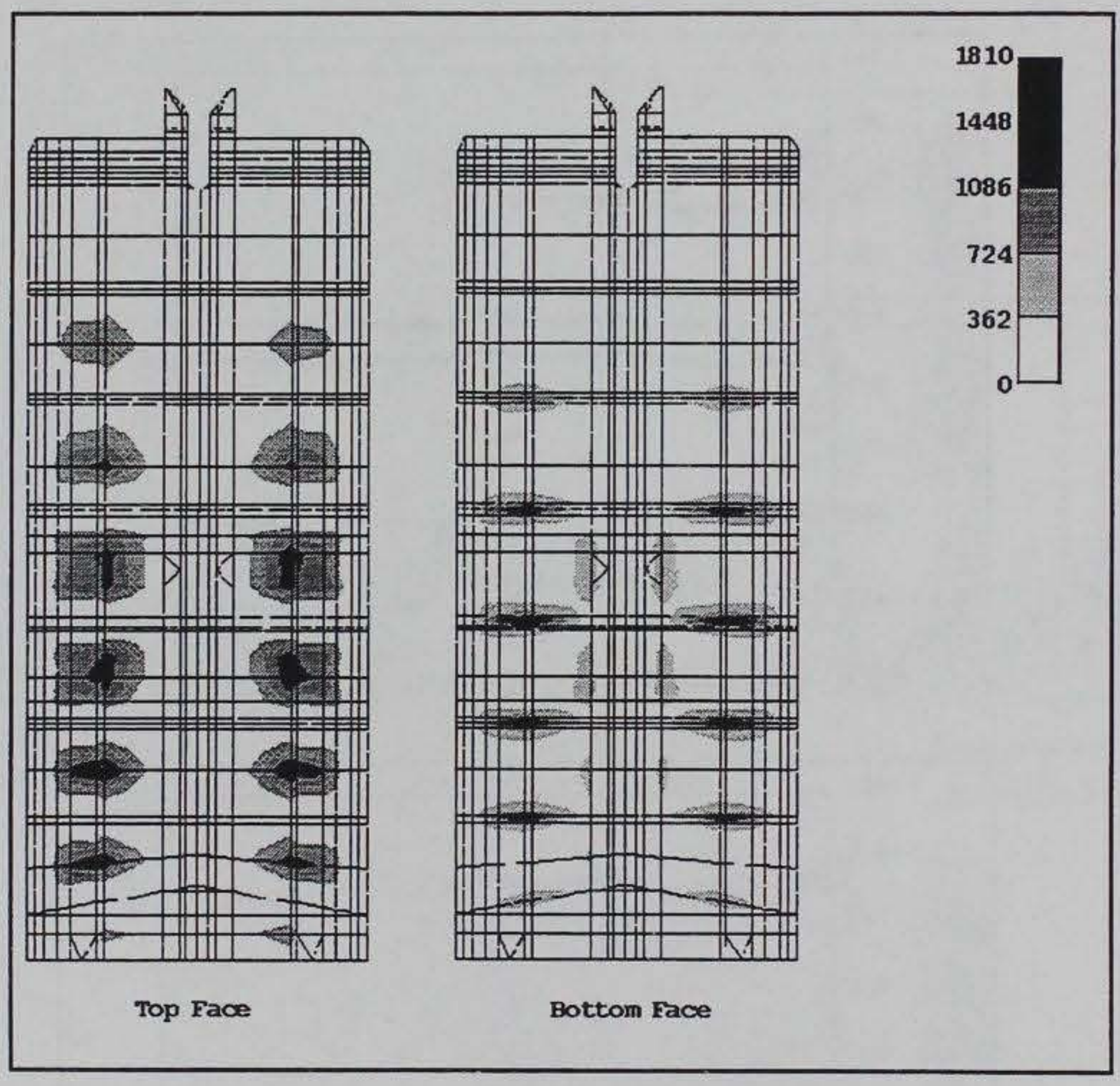

Figure 42. Typical maximum principal stress, gate top plate 


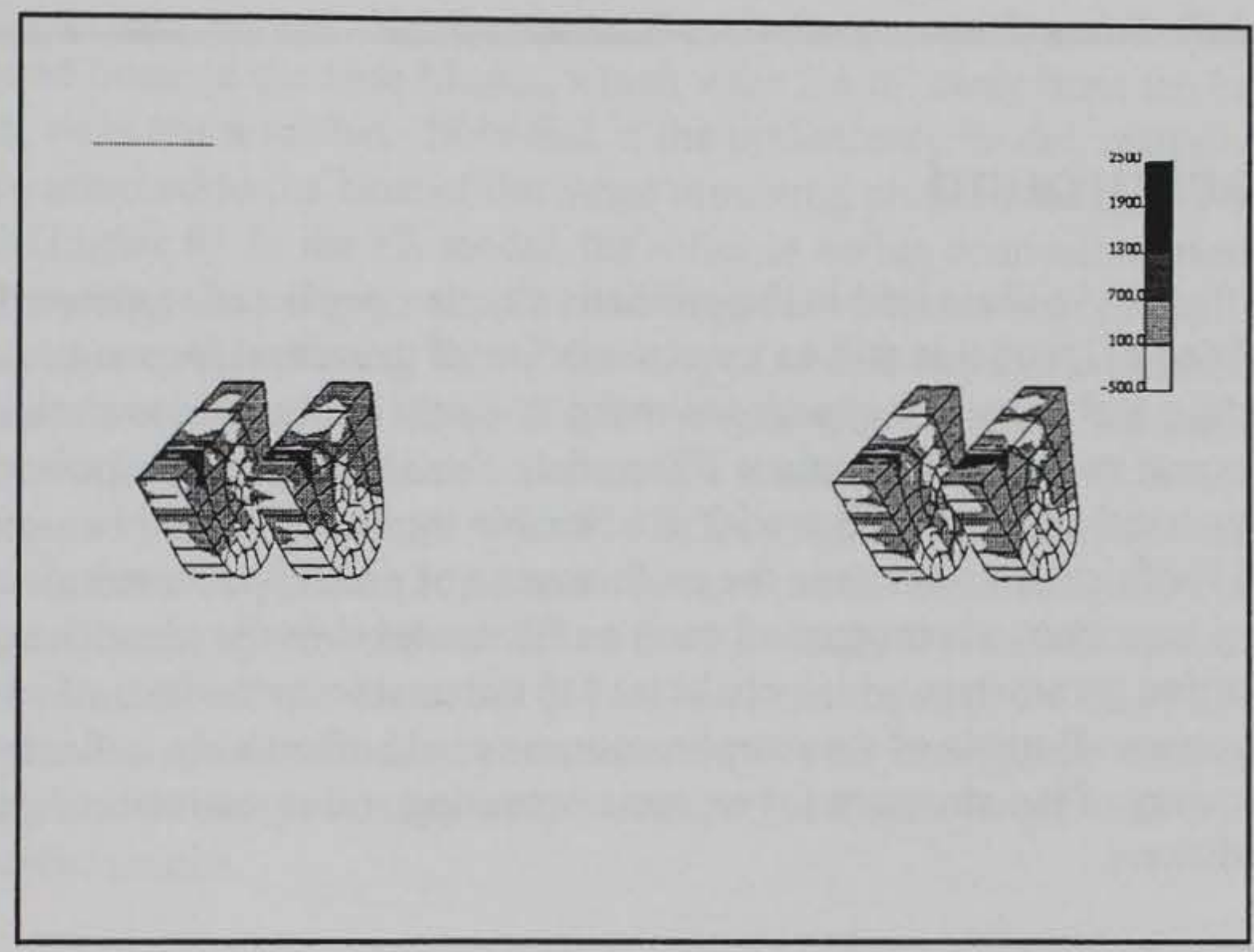

Figure 43. Typical maximum principal stress, gate-hinge surfaces 


\section{FE Model- Applications}

\section{Background}

As discussed in the previous chapter, predicted response from an updated FE model is still an approximation of the actual response. Uncertain loading and boundary conditions make it nearly impossible to simulate the true response using a deterministic FE model. For all practical purposes, however, an updated analytical FE model is a flexible tool which could be used reliably and confidently to evaluate the performance of prototype structure. One of the most important advantages of such an FE model is in the identification of sensitive parameters which could lead to determine the bounds of structural responses. Bounds of structural responses could effectively indicate the adequacy of the structure for extreme operating and sensitive boundary conditions.

In this chapter the applications of the FE model in determining sensor location using pre-experiment $\mathrm{FE}$ analysis, and the results of the fatigue study to determine the effects of cyclic loading, and the upper bounds of wicket response due to most probable limits of boundary and loading conditions are discussed.

\section{Sensitivity Study}

Static experimental results were used to study the sensitivity of different physical parameters and boundary conditions of the wicket assembly. This paramatric study was conducted using the preliminary FE model to identify the most sensible parameters of the wicket geometry. As discussed previously, no supporting devices such as base hinges and prop connections were modeled or included in the preliminary FE model. In this model, nodes located at the supports were restrained to simulate the boundary conditions of the actual structure. Hinge bases were restrained for translational motions by using pin connections in the FE model. The cylinder connection was modeled in two different ways to measure the sensitivity of predictions to the modeling of the supporting devices. Two different types of boundary conditions were considered in the modeling technique. These included a roller ( $\mathrm{Z}$-translational restraint) and a spring connection. A roller connection represented the actual holding mechanism of the ball-cup support in which the mounting ball connected to the gate frame had rested on the cup connected to the shaft of the hoisting cylinder. The spring model simulated the spring action of the hydraulic device which had 
been deformed due to compressibility of the air-entrapped inside the fluid chamber.

In the preliminary FE model, the span length between the base hinge and ball-cup support was slightly shorter than in the physical model. This difference existed because the base hinges, which were 2.6 in. away from the base of the gate, were not modeled. Note that in the preliminary model, restrained nodes were attached to the base of the hinge mounting plate on the extreme end of the gate (Figure 6). In the FE model, the roller or spring connection used for representing the cylinder support had been set on nodes near the ball-cup connection. Considering the availability of nodes, two distances of 21.4 in. and 22.3 in. were found for simulating the proper span length of the cup-ball support from the base hinge. In the experimental model, the cylinder's connection was 24 in. away from the hinge axis. Predicted results from the preliminary FE model, thus, required an adjustment to account for the discrepancy in the span length. An analytical adjustment of the FE results were made by using a ratio of the beam deflections for actual (24 in.) and simulated (21.4 in. or 22.3 in.) span length. Using beam theory, correction factors for each gauge were computed such that the compensation for not using correct span length was included in the adjusted results.

Static experimental results for three loading cases are presented in Table 13 below. These three loading cases could be described as:

Load Case 1 - in which a 500-lbf load was applied in between gauge \#1 and \#2 (Figure 9 for gauge locations).

Load Case 2 - same 500-lbf load was applied on the left side of the gate, directly over gauge \#1

Load Case 3 - same 500-lbf load was applied on the right side of the gate, directly over gauge \#2

\begin{tabular}{|c|c|c|c|c|c|c|}
\hline \multicolumn{7}{|c|}{$\begin{array}{l}\text { Table } 13 \\
\text { Measured Deflection in inches }\end{array}$} \\
\hline Load Case & Input Load, lbf & Gauge \#1 & Gauge \#2 & Gauge \#3 & Gauge \#4 & Gauge \#5 \\
\hline 1 & 500 & 0.048 & 0.048 & 0.008 & 0.003 & 0.003 \\
\hline II & 500 & 0.0805 & 0.0185 & 0.0065 & 0.007 & -0.001 \\
\hline III & 500 & 0.0215 & 0.0805 & 0.0125 & -0.001 & 0.00775 \\
\hline
\end{tabular}

The 500-lbf load was a cylindrical disk mounted on a 4.56-in.by 12 -in. steel plate which provided a distributed load over the contact surface with the gate. In the FE model, this load could be regarded either as concentrated loads applied along the center-line of contact or as uniformly distributed (UDL) over 
the surface of contact. Both of these situations will be examined in this report. In the first case, the concentrated load was applied along nodal lines corresponding to the width of the supporting plate. In the second case, the distributed load was applied over the elements holding the supporting plate.

Spring stiffnesses for the lifting cylinder were computed from the static deflection and are presented in Table 14.

\begin{tabular}{|c|c|c|c|}
\hline \multicolumn{4}{|l|}{ Table 14} \\
\hline Load Case & Reaction, Ibf & Displacement, in. & Spring Stiffness, Ibflin. \\
\hline Conc. Load & 1310 & 0.008 & 163750 \\
\hline Dist. Load & 1285 & 0.0065 & 197692.31 \\
\hline
\end{tabular}

\section{Physical parameters}

As shown in Table 1, uncertainties of material properties and physical dimensions are the reality in a physical model. To determine the effects of these variations, a series of $\mathrm{FE}$ analyses was undertaken. Using the preliminary wicket gate model and the two load distributions, bounding analyses were conducted for four variables: span length, modulus of elasticity, section thickness, and prop-support conditions.

In the first pair of analyses two span lengths were considered. These are 22.3 in. and 21.4 in. apart, respectively, from the simulated base hinge to the prop support. The next two analysis modeled two values of modulus of elasticity. These two values of modulus of elasticity, $(32,213 \mathrm{ksi}$, and 34,287 $\mathrm{ksi}$, respectively), were used based on the experimental results presented in Table 1. The first set was based on the minimum value of the modulus of elasticity for the major structural components of the wicket. And the second set was based on the average magnitudes of the modulus of elasticity of the double I-beams. The I-beams were the main structural component of the wicket that ran vertically along the length of the gate.

Different values of thickness for the major structural components were also considered for evaluation. The minimum and average thickness for the beams and transverse stiffeners were used in two separate FE analyses of the wicket. Table 15 shows the variation of thickness for the major structural components. These changes were considered to determine the effects of the uncertainty of the thickness on the structural performance.

The final pair of analysis simulated the boundary condition at the ball support in two ways: as a spring, and as a roller. 


\begin{tabular}{||c|c|c||}
\hline \multicolumn{3}{|l|}{ Table 15} \\
Thickness Variations in the Major Gate Components \\
\hline Component & Average Thickness, in. & Minimum Thickness, in. \\
\hline \hline Beam Flange & 0.3192 & 0.3100 \\
\hline Beam Web & 0.1793 & 0.1500 \\
\hline Long Stiffeners & 0.0750 & 0.0700 \\
\hline
\end{tabular}

The relative importance of variations in each of thesepairs of analyses can be seen in plots of deflections from analysis 1 versus deflection from analysis 2, shown in Figures 44 through 47 . Figure 44 shows the effects of span length on the static response of the wicket due to two different load-modeling techniques. Figure 45 presents the relationships of gauge deformations due to changes in the modulus of elasticity. In this figure, results corresponding to the two different moduli are compared indicating the contribution of elasticity on the overall stiffness of the wicket. These figures indicate that the stiffness changes due to variation in span length and material properties are marginal and proportional when applied load was treated as line-load. For the distributed case, asymmetric loading (load case 2 ), showed non-proportionality in one of the gauge deformation due to changes in span length and modulus of elasticity.
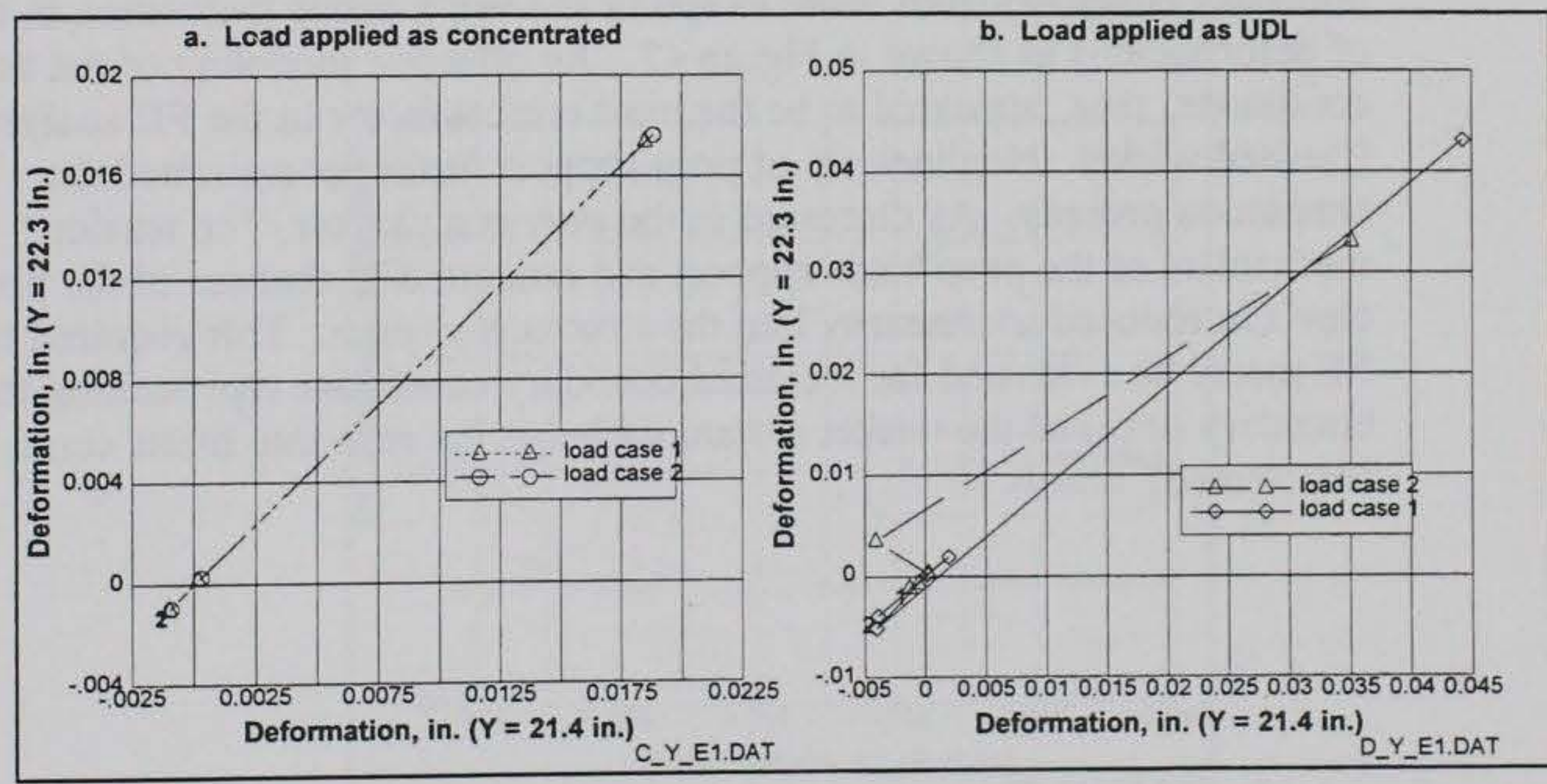

Figure 44. Variation of deflection at gauge locations due to changes in span length ( $E=32,213 \mathrm{ksi}$ and roller model) 


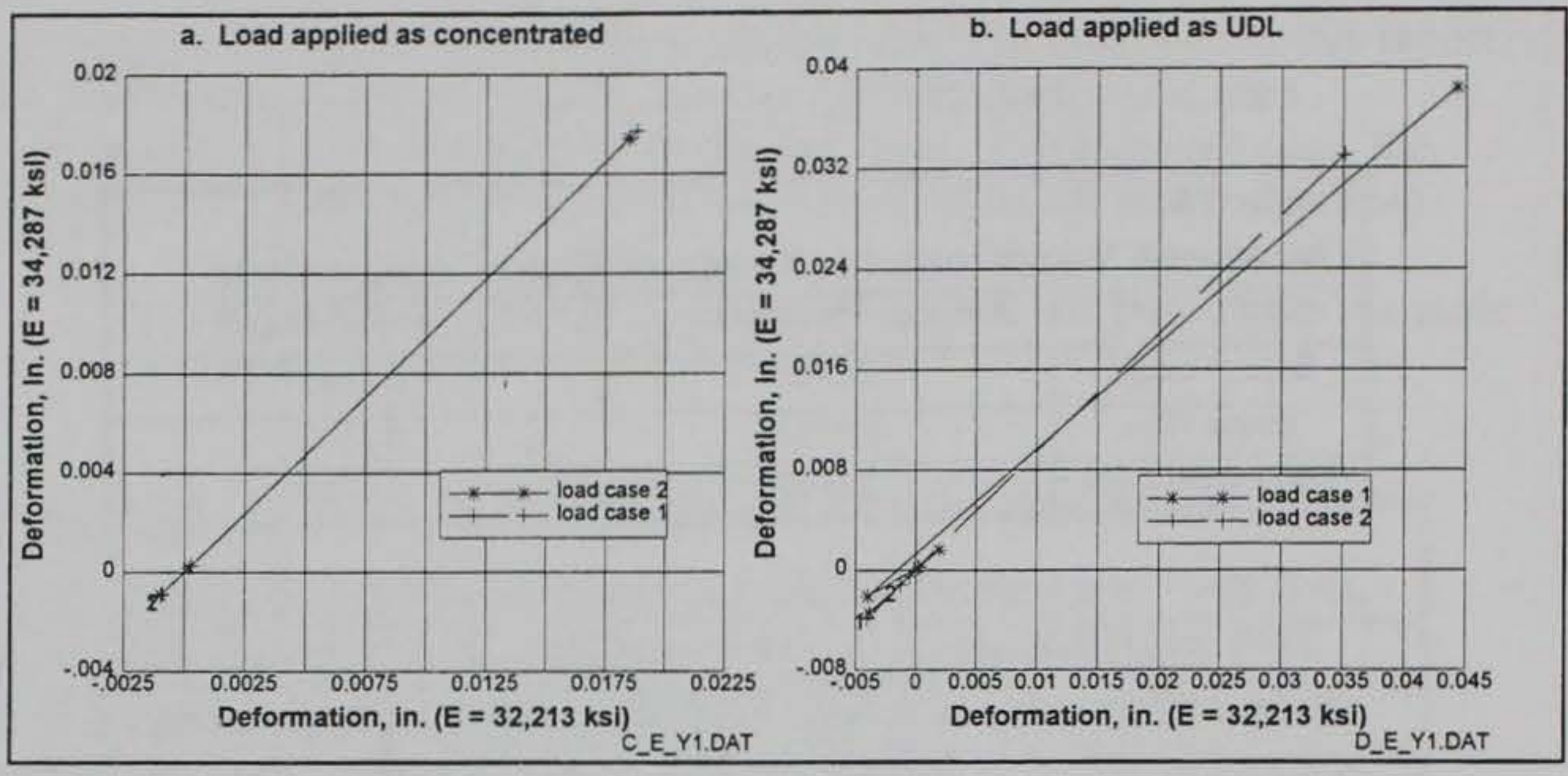

Figure 45. Variation of deflection at gauge locations due to changes in modulus of elasticity ( $\mathrm{Y}=\mathbf{2 1 . 4}$ in. and roller model)

The effects of wicket component thickness on the overall stiffness of the wicket are analyzed in Figure 46. In this figure, deformation results for two different material thicknesses are compared. As in the previous cases, this figure indicates that the ratio of deformations for different material thickness is constant. Boundary condition, however, appeared to be the most sensitive parameters among the variables studied in this investigation. A change in boundary condition from roller to spring showed a major fluctuation in the ratio of deformations as shown in Figure 47. An effective modeling of the boundary conditions, thus, appeared to be the most critical factor in the FE analysis of the Olmsted wicket. Nonlinearity of prop support further complicated the simulation process. As discussed in the previous chapter, "no tension" mechanism of the prop blade support and random disturbances of the prop top clevis introduced nonlinearity into the structural system. This required that the FE model be evaluated for idealized boundary conditions representing the actual boundary limits of the wicket system such that the response limits could be determined. 


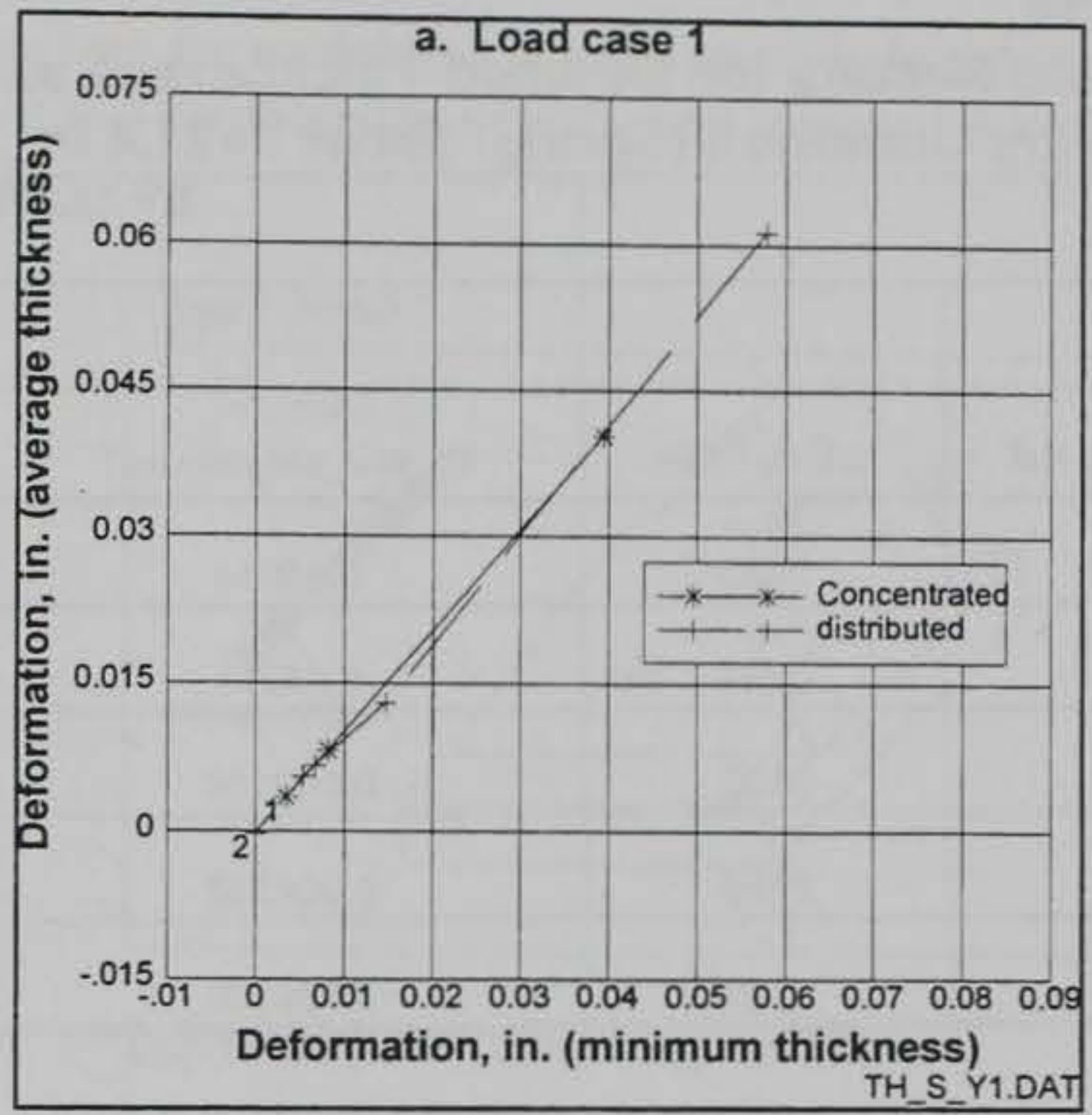

Figure 46. Variation of deflection at gauge locations due to changes in component

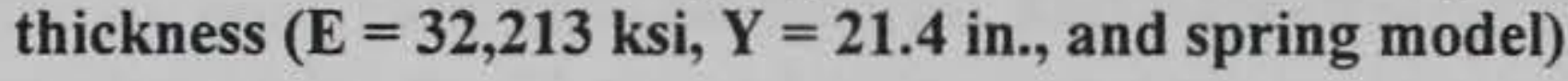

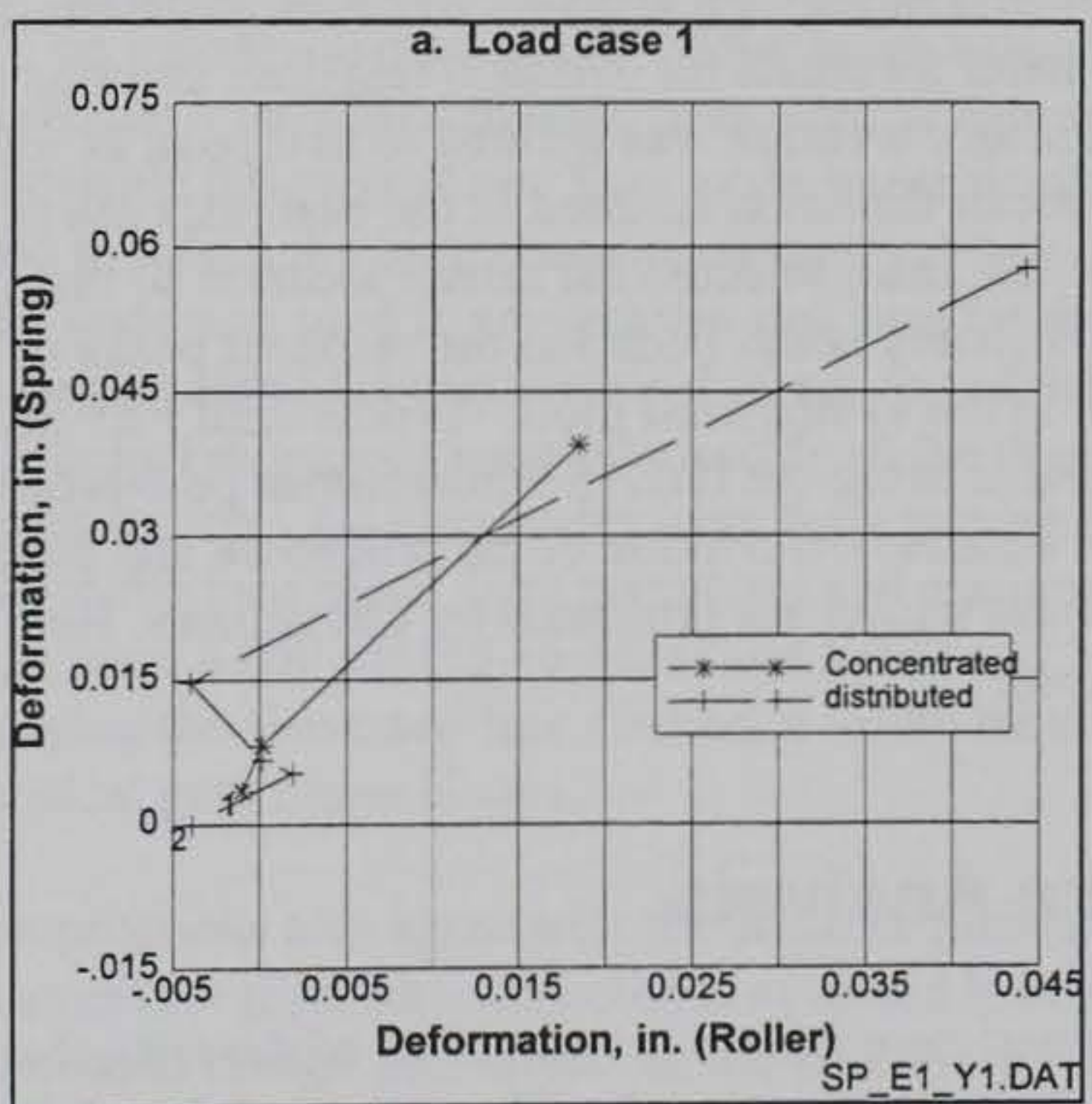

Figure 47. Variation of deflection at gauge locations due to changes in support conditions $(E=32,213 \mathrm{ksi}$ and $\mathrm{Y}=21.4 \mathrm{in}$.)

These results also indicate that the best representation of the static tests in the FE model is given by the case in which the lower modulus of elasticity, and spring support were used. Adjusted static results using preliminary FE model for load case 1 are presented in Table 16. 


\section{Table 16 \\ Adjusted Results for Modified Thicknesses and \\ Boundary Condition (Spring) set at $Y=21.4$ in.}

\begin{tabular}{|c|c|c|c||}
\hline & & \multicolumn{2}{c||}{$E=32,213$ E3 psi } \\
\hline Gauge No. & Node FEM & Conc. Load & Dist. Load \\
\hline 1 & 7630 & 0.04214 & th_spr_slowdload1 \\
\hline 2 & 8294 & 0.04213 & 0.062873 \\
\hline 3 & 3408 & 0.008188 & 0.013359 \\
\hline 4 & 2120 & 0.004330 & 0.06688 \\
\hline 5 & 2156 & 0.004320 & 0.006862 \\
\hline
\end{tabular}

\section{Pre-experiment Investigation}

A preliminary $\mathrm{FE}$ analysis was used to determine the best built-in accelerometer locations for dynamic response investigation of the wicket gate. The best sensor location was defined as that point at which excitation in a specific vector direction resulted in the best response of all modes of interest. This analysis, thus, selected the sensor location so that the accelerometers were not placed on any nodal lines and the resonant peaks of the FRF responses were dominant in the synthesized plots. Synthesized FRF plots were generated from the FE results using the IDEAS-Masterseries post-processing module (SDRC 1993). A detailed description of the procedure and the sensor location for the experimental wicket are presented by Chowdhury, Hall, and Davis (in preparation).

\section{Fatigue Analysis}

A post-experiment fatigue investigation of the critical components was performed separately using the FE analysis of the wicket assembly (Chowdhury, Hall, and Davis in preparation). Base hinges and the shear pins shown in Figure 48 are the most critical components of the wicket system that could be subjected to fatigue failure due to reversed loading. A fatigue analysis of the most sensitive components was conducted using the modified Goodman line method which required the computation of the mean and alternating normal stresses on the structure based on the maximum and minimum stress applied to the component. FE analysis of the components provided the maximum and minimum stresses for the critical operating condition. The modified Goodman 
line method determines the usefulness against possible fatigue failure of a component subject to a combination of static and reversed dynamic loading (Lindeburg 1994).

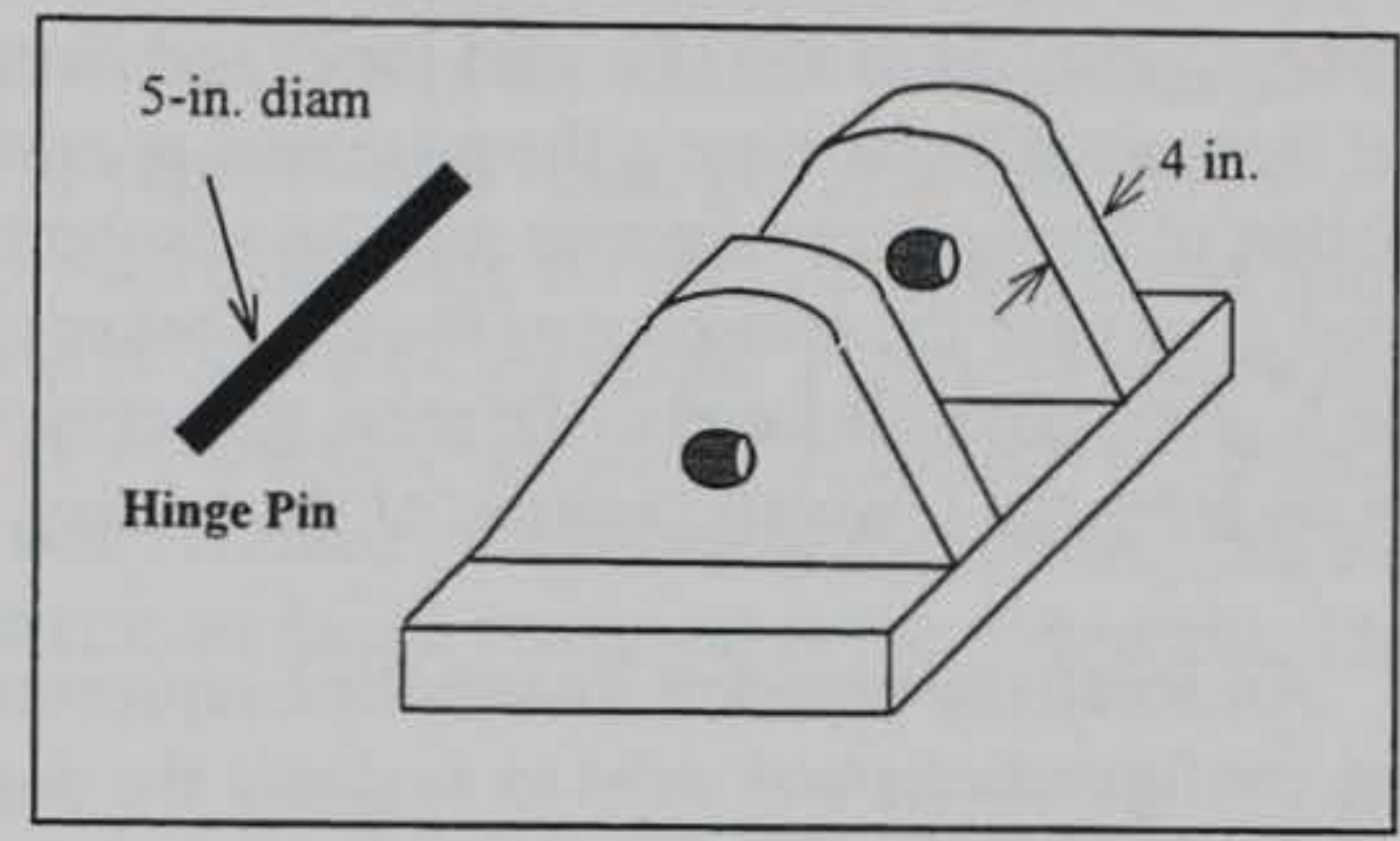

Figure 48. Gate frame hinge assembly

For the FE analysis, the critical normal loads were obtained from the experiment conducted for the $21-\mathrm{ft}$ head difference, three-gate gap configuration, when the physical experimental gate was fixed at $24 \mathrm{deg}$ position. The predicted loads were applied on a finite-element model of the hinge base and the maximum and minimum Von-Mises stresses were used to determine the factor of safety against possible fatigue failure. Four-node linear tetrahedron solid elements were used to model the hinge bases as shown in Figure 43. ABAQUS general purpose $\mathrm{FE}$ code was used to analyze the structure for the dynamic loads (reaction forces) applied along the two principal directions of the base. Hinge forces along the principal directions were obtained from the experimental results for the critical configuration. All base nodes were fully restrained to model the fixity of the hinges to the base plate. The maximum and minimum Von-Mises stress on the hinges were $8,000 \mathrm{psi}(55.16 \mathrm{MPa})$ and $5,000 \mathrm{psi}(34.475 \mathrm{MPa})$ respectively. Applying the Goodman line method, a safety factor of 7.39 was obtained for the critical gate frame hinges.

Above computations also agree with the AISC requirements for the fatigue allowable stress for members subjected to reversed loading. Based on the AISC (1989) strength-design consideration, the maximum allowable stress range for the wicket members subject to fatigue loading must not exceed $22 \mathrm{ksi}$ $(151.69 \mathrm{MPa})$. This allowable stress is higher than the applied mean stresses found for both cases presented above. The allowable fatigue stress range is estimated for the loading condition 1 (number of loading cycles in the ranges 20,000 to 100,000 ), and the type and location of member connections as in the hinge base. 


\section{Critical Response Simulation}

FE analysis of the wicket due to the most critical loading configuration was performed to determine the adequacy of the proposed design. Design parameters obtained from a three-gate gap (3GG-L) flow configuration were used in the FE model to determine the most critical response for the anticipated operating conditions of the Olmsted locks and dam. A $3 \mathrm{GG}$ provided the most critical flow conditions among the proposed operating sequences. Highest fluctuation of the wicket response and the absolute maximum of the responses occurred at or near the breaking of the air-pocket underneath the gate surface. For the highest possible head difference, this critical condition existed at about $24 \mathrm{deg}$ up from the lowered position of the wicket.

An idealized pressure distribution representative of the most critical loading configurations was used to evaluate the design performance of the wicket by determining the upper bounds of flow-induced dynamic wicket response. Experimentally measured first bouncing mode for the wet gate provided the shaft stiffness of the cylinder support of the wicket. Using a single degree of freedom model for the bouncing mode, the stiffness for the lifting system was obtained using the equation shown below.

$$
\kappa=M \omega_{1}^{2}=\frac{2100}{386.4}(21.06 \times 2 \pi)^{2}=95,161 \quad l b f / \text { in } .
$$

In this equation, the mass, $M$, was assumed as the experimentally measured equivalent thrust exerted on the cylinder by the flowing water. The added mass obtained from the experimental results, as discussed in the previous chapter, was distributed on the wicket FE model for properly simulating the wet dynamic behavior of the operational wicket.

\section{Idealized loading}

Upper boundaries of the random responses, based on the Type - I Extreme Value Design (EVD) approach (Wirsching 1993), provided the input pressure loads for the FE model. These estimated design values at 99.99 percent confidence level were the extreme estimation of the input loads for the proposed flow-boundaries and the likely service conditions anticipated during the life cycle. Experimental results for the most critical flow configuration were used to compute the EVD "design" values. Note that the most critical response used in this evaluation occurs momentarily during the raising and lowering of the gate at $24 \mathrm{deg}$ position. The wicket has to pass through this transition phase to engage in a prop support for regulating the navigational pool. A prop-supported gate is the actual service condition for an actively operated gate. Service loads for the prop-supported gate do not impose any threat to the current design as demonstrated in the analysis presented in the previous chapter. 
A linear spatial distribution of pressure envelopes was considered to represent the actual distribution of the flow-induced upstream pressure. Experimental results indicated that such a linear distribution would adequately represent actual loading situation for the operating wicket (Chowdhury, Hall, and Davis in preparation). The design amplitudes of the pressure envelopes, $\mathrm{P}(\mathrm{t})$, were constructed by oscillating the random pressure response about the maximum average, $\mathrm{P}_{\mathrm{o}}$, experimental readings, such that $P(t)=P_{o} P_{n}(t)$. Average maximum pressure readings are the maximum of the gauge readings obtained from the critical flow configuration. Figure 49 shows the assumed pressure distribution at critical configuration. A conservative estimation of the downstream suction was obtained by uniformly distributing the design negative pressure (absolute maximum gauge readings) at the downstream face of the wicket.

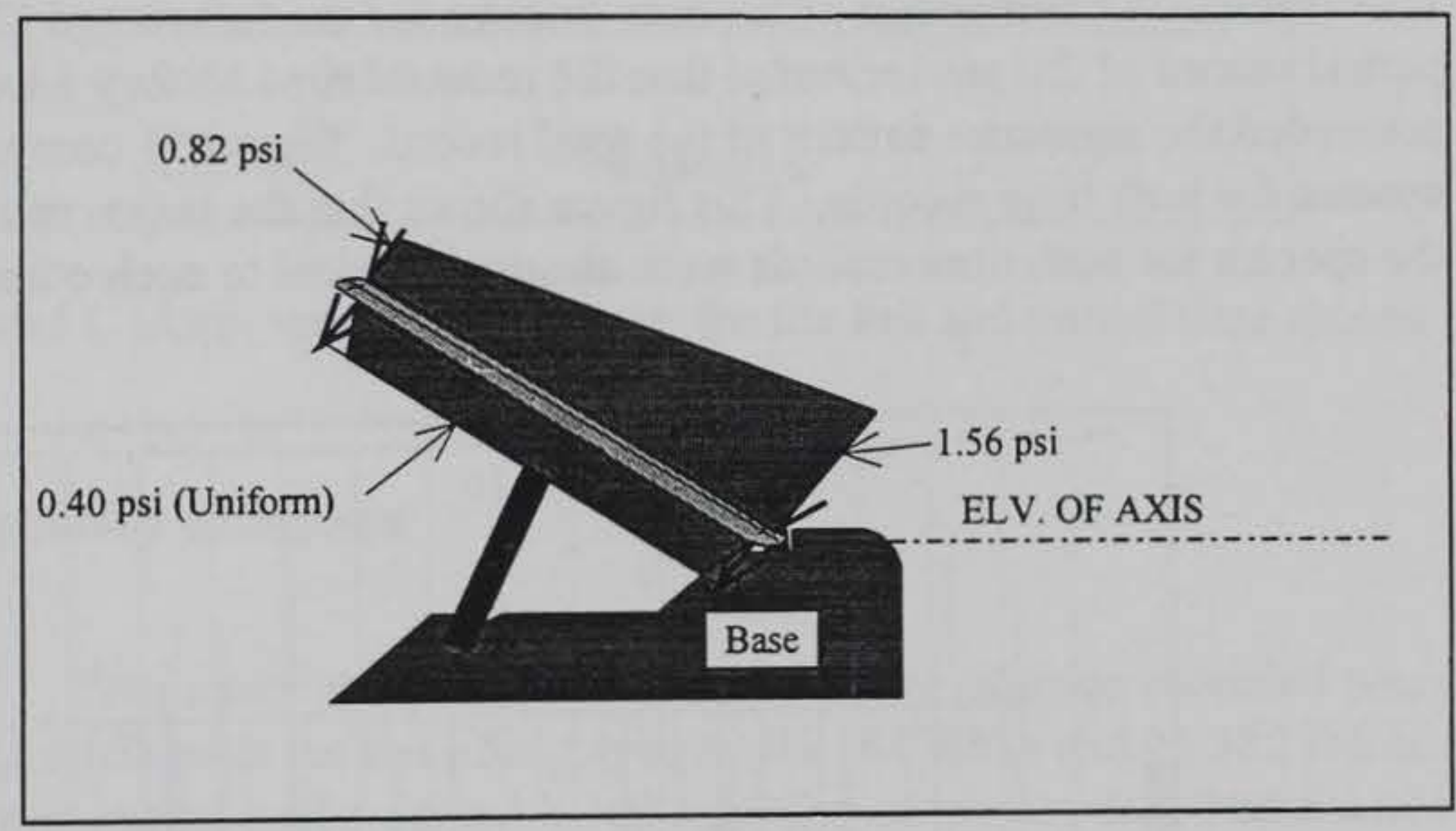

Figure 49. Average maximum pressure distribution at critical configuration (24 deg)

The time dependency of the pressure field was based on a typical normalized accelerometer-time history obtained from the experimental results. An accelerometer response history included the most sensitive structural modes and better incorporated the flow-structural interaction due to the flow-induced vibration. For design evaluation, thus, a reconstructed time-dependent pressure history, $\mathrm{P}_{\mathrm{n}}(\mathrm{t})$, based on the measured normalized accelerometer-time history, would represent one of the most dynamically critical loading configuration. A typical normalized pressure-time history indicative of the dynamic fluctuation of the anticipated pressure response was obtained from the random accelerometer 
history, $\tilde{a}(t)$, using the equation, $\left(p_{n(t)}=\frac{\widetilde{a}(t)}{\left|\mu_{\widetilde{a}(t)}\right|}\right)$. In which, $\mu$ is the mean of

the accelerometer record. Thus, the peak of the normally distributed pressure signal would have magnitude exceeding the design magnitude obtained from the EVD estimation. The synthesized signal would have the frequency content similar to that of the original acceleration record. As a result of such idealization, a built-in load factor was implicitly considered in the critical response evaluation of the wicket.

Figure 50 presents a normalized accelerometer time-record for the physical wicket model. This record was obtained from an accelerometer mounted at the top right corner of the wicket during the most critical flow configuration. For computation efficiency, however, it was required to analyze the gate for a fraction of the total record. A 2.0 -sec time record was analyzed in the FE model to simulate the dynamic behavior of the operational wicket. As shown in Figure 50, this segment of the record had a maximum amplitude of 1.33 (ratio). A comparison of the auto-spectra for the full record $(30 \mathrm{sec})$ and partial record of $2.0 \mathrm{sec}$ indicated that the reduced time history adequately preserved the signature pattern of the total record. Figure 51 compares the autospectra for both time records. This figure shows that the major resonant peaks in the spectra for both time records were almost identical to each other.

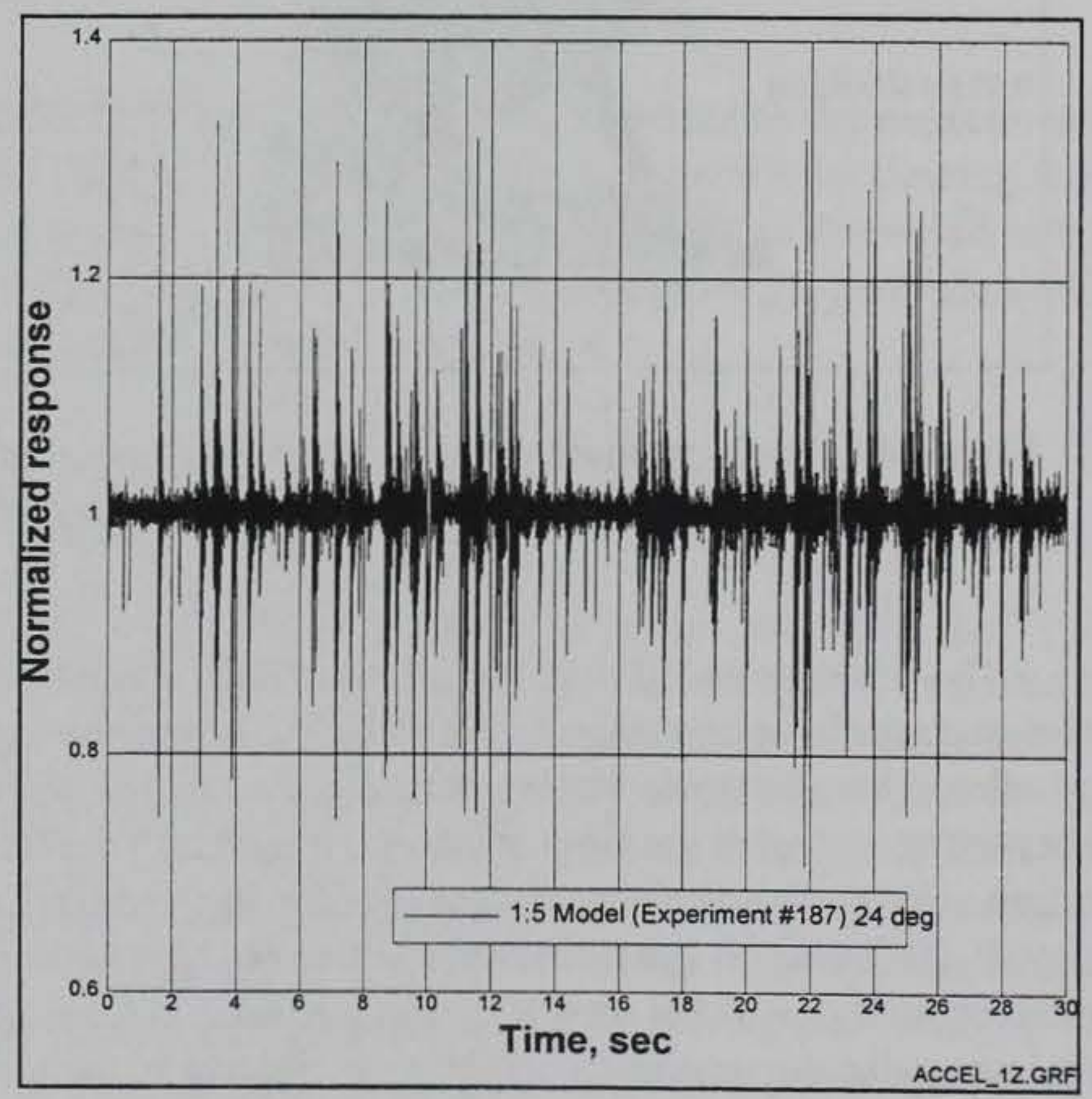

Figure 50. Normalized random acceleration (ratio) record for the critical configuration 


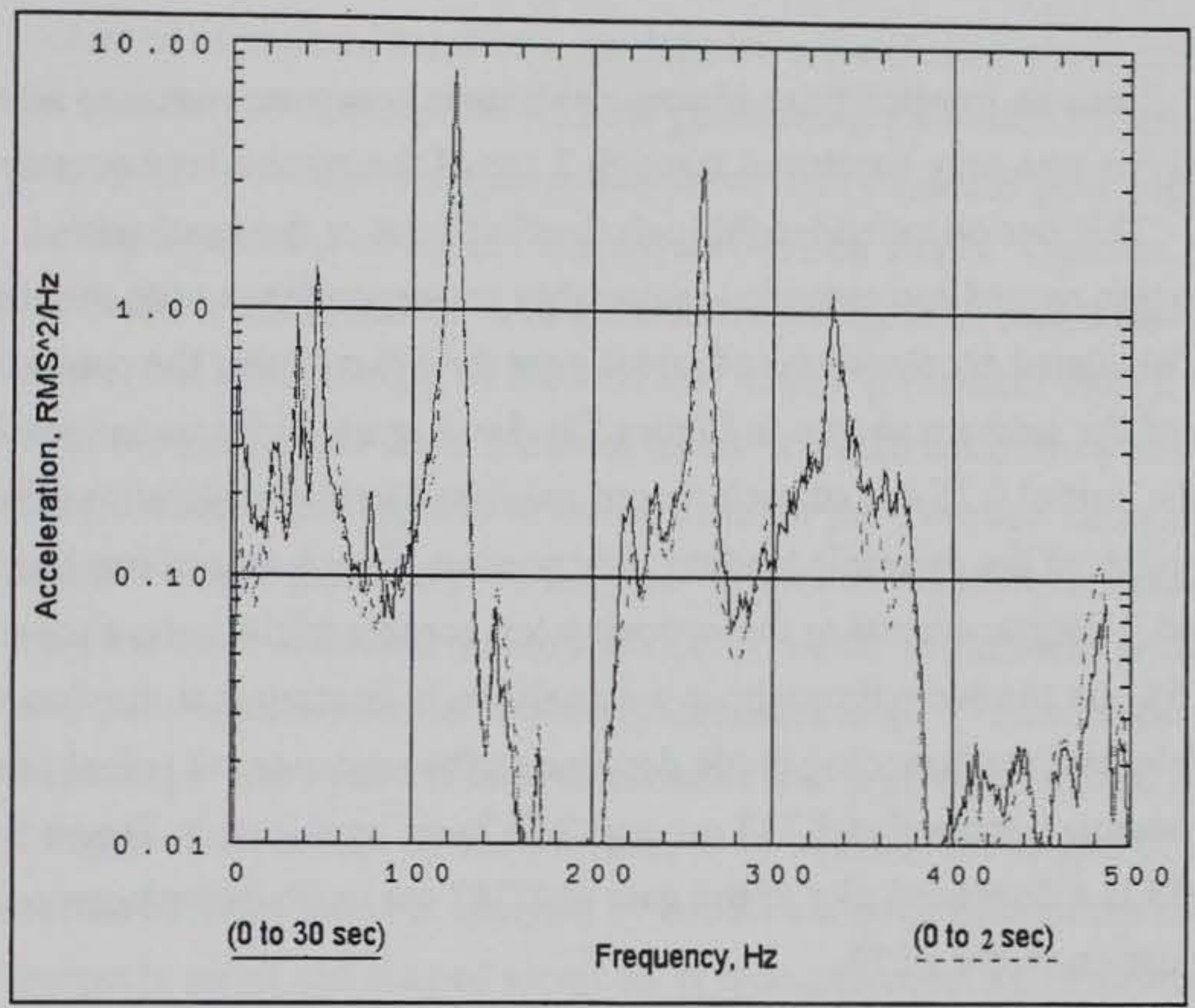

Figure 51. Auto spectra comparison for the full and partial time record

\section{Frequency analyses}

Frequency analyses of the gate at $24 \mathrm{deg}$ position modeled two different spring stiffnesses for the lifting system: $95,161 \mathrm{lbf} /$ in and 11,382 lbf/in. In both analyses, water was modeled by the addition of masses distributed across the top surface of the gate. Analytical mode shapes were similar for both conditions, and are shown in Figure 52. Calculated frequencies are presented in Table 17.

As would be expected from the results of previous analyses, the first bending mode, mode 2 , and the first and second torsional modes, modes 3 and 4 , were not affected by the stiffness of the lifting system. In previous analyses, the frequency of mode 2 was not affected by support conditions or added mass and the frequency of mode 3 depended primarily on added mass, while the bouncing and second bending modes were heavily dependent on support conditions. In the analyses in the 24-deg position, calculated frequencies for the bouncing mode, mode 1 , and the second bending mode, mode 5 , were lower for the lower spring stiffness. 


\section{Time-history analysis}

Since an implicit time-history analysis is computer resource intensive, the analysis was only continued through $2 \mathrm{sec}$ of the synthesized pressure history record. This period extended through the first peak in the synthesized acceleration record and provided reasonable correspondence with the test modal data. Calculated accelerations of nodes near the hinges, near the center and at the top of the gate are shown in Figure 53. See Figure 19 for node locations. Since the initial $0.25 \mathrm{sec}$ of each record exhibited large accelerations due to the initial shock of the dynamic loading, this portion of each record has been removed. Displacements at the opposing top corners of the gate, shown in Figure 54 are the same throughout the analysis, indicating that torsion was negligible, and the bouncing mode dominated the response. Typical peak displacements occurred at $2.748 \mathrm{sec}$ and $2.787 \mathrm{sec}$, as shown in Figure 54. Figure 55 is a displaced plot of the gate at $2.787 \mathrm{sec}$, with a displacement magnification factor of 20 .

Maximum principal stresses at the top and bottom faces of the gate were less than 12,000 psi, and are shown in Figure 56. Larger stresses occurred at the end plates where the gate hinges were attached and at vertical stiffeners near the center support. Maximum principal stresses and Von-Mises stresses at the end plates are shown in Figures 57 and 61. Maximum principal stresses in vertical stiffeners are shown in Figure 58. Maximum principal stresses in the gate and support rod (ball-cup connection) hinges were also relatively high, with stresses in the gate hinges approaching $40 \mathrm{ksi}$ at isolated locations corresponding the regions of high stress in the end plates. Maximum principal stresses at these locations are shown in Figures 59 and 60 . Von-Mises stresses at the gate hinges are shown in Figure 62. In general, however, except at vary few isolated localized spots, the upper boundaries of stresses obtained from the FE analysis do not exceed the allowable stress limit for Grade 50 steel. Since the applied maximum principal stress of $40 \mathrm{ksi}$ and also the calculated Von-Mises stress of $40 \mathrm{ksi}$ does not exceed the material yield stress of $50 \mathrm{ksi}$, respectively, the stress state will not cause any material failure according to the Tresca's maximum shear stress theory and the Von-Mises maximum distortion energy failure theory (Buchanan 1988).

Even though alarming magnitudes of maximum principal stresses 
occurred at isolated locations, no definitive conclusion about their validity can be ascertained at this point without performing a detailed FE analysis of these hot spots. Potential problems of element distortion and poor aspect ratio can induce numerical errors in FE analysis (Ridlon 1987). Like the element shape, the relative element size in relation to the adjacent elements can affect the numerical conditioning of the stiffness matrix (Shephard 1987). Numerical illconditioning arises if the stiffness terms in a matrix differ by several orders of magnitudes. This appears to be the case for the elements showing maximum stresses in the gate and prop hinges. As seen in these figures (see Figure 59 and 62), the most localized maximum stresses occur at elements with distorted shape and poor size in relation to the adjacent elements. (The element aspect ratio is a measure of the squareness of an element and is often measured by dividing the longest element side by the shortest, or in terms of the angles of the element corner). A detailed $\mathrm{FE}$ analysis by subdividing the base of the hinges with properly sized and shaped elements is recommended for determining the realism of the existence of high localized stress. 


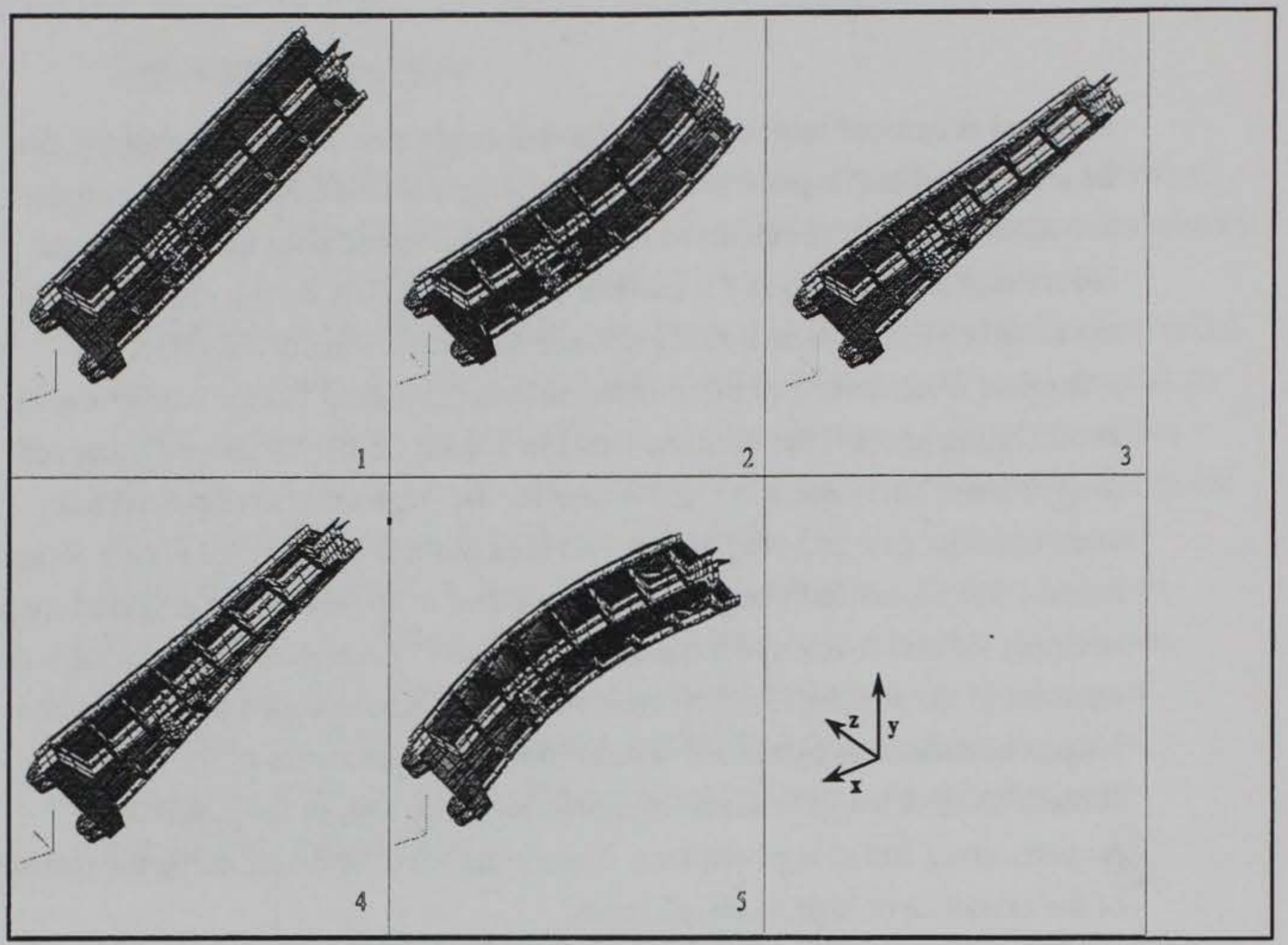

Figure 52. Modes 1 through 5, gate at $24 \mathrm{deg}$

\begin{tabular}{|c|c|c|}
\hline \multicolumn{3}{|c|}{$\begin{array}{l}\text { Table } 17 \\
\text { Frequencies for Modes } 1 \text { through } 5\end{array}$} \\
\hline \multirow[b]{2}{*}{ Mode } & \multicolumn{2}{|l|}{ Frequency $(\mathrm{Hz})$} \\
\hline & Spring Stiffness $95,161 \mathrm{lbf} /$ in & Spring Stiffness $11,382 \mathrm{lbf} / \mathrm{in}$ \\
\hline 1 (rigid body) & 37.67 & 25.48 \\
\hline 2 (bending) & 57.74 & 57.74 \\
\hline 3 (torsion) & 73.75 & 73.51 \\
\hline 4 (torsion) & 84.00 & 83.75 \\
\hline 5 (bending) & 167.05 & 157.91 \\
\hline
\end{tabular}




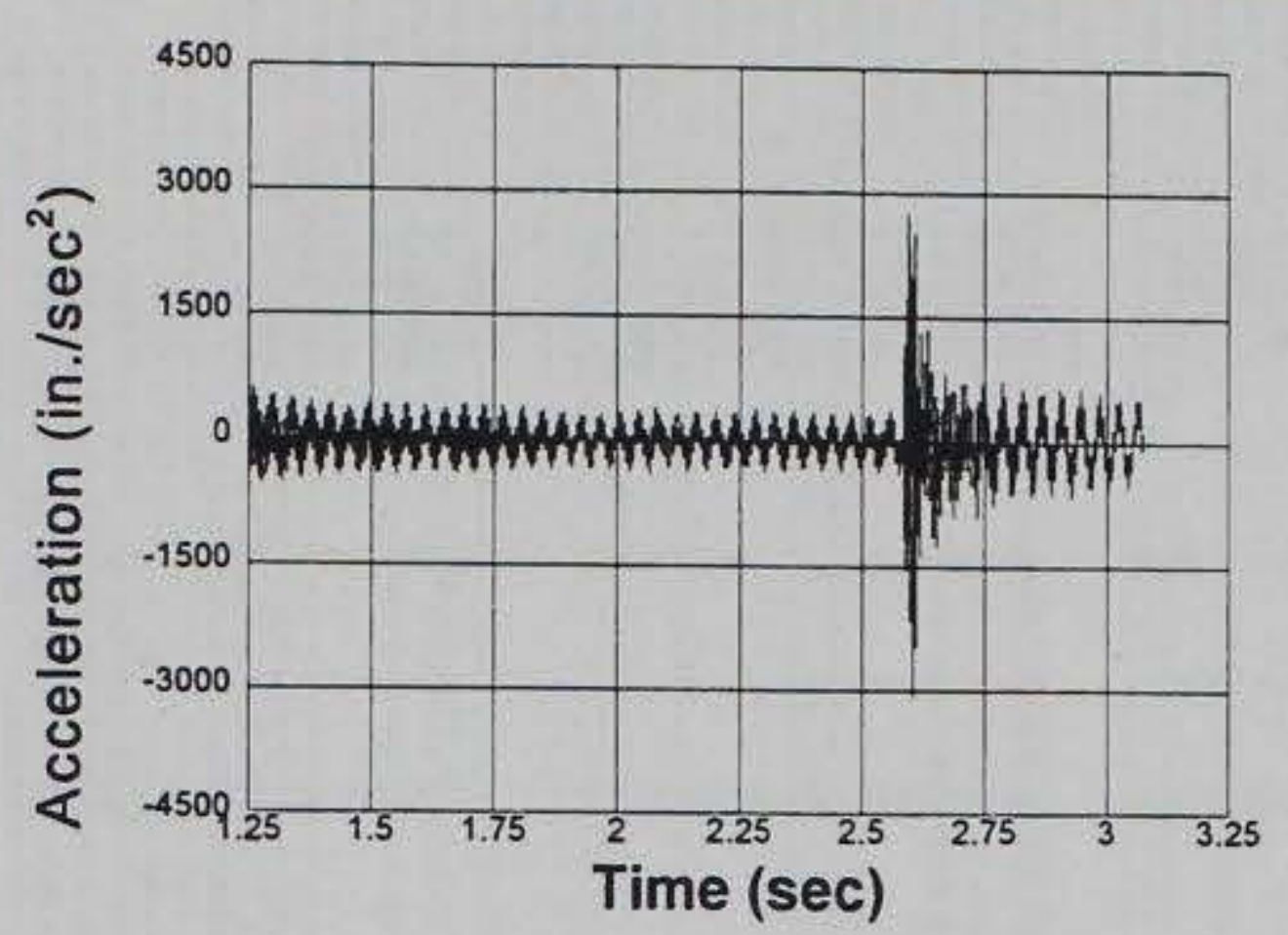

a) Acceleration at node 2828

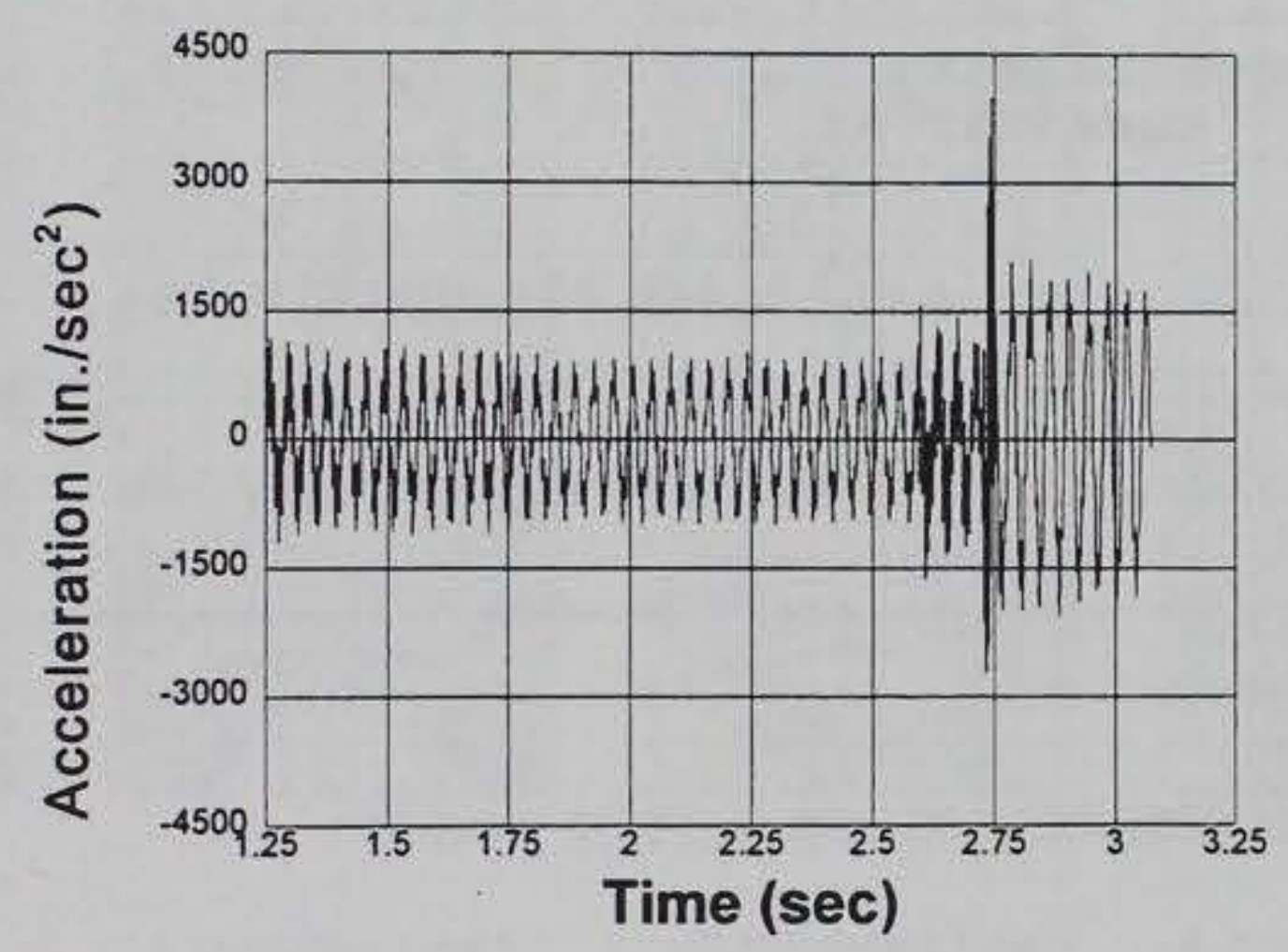

b) Acceleration at node 7200

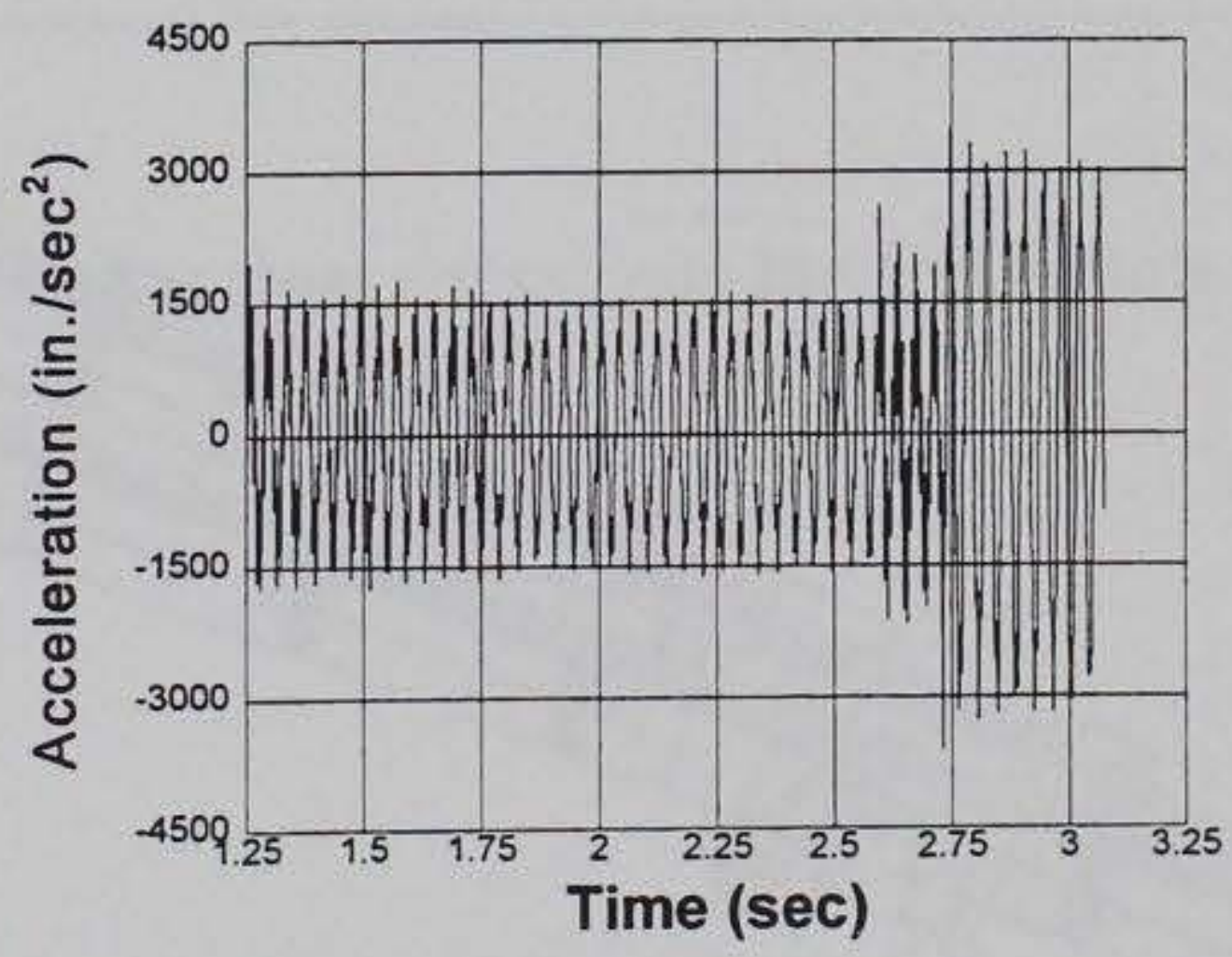

c) Acceleration at node 9728

Figure 53. Accelerations at nodes near hinges, at center of gate, and near the top of the gate 


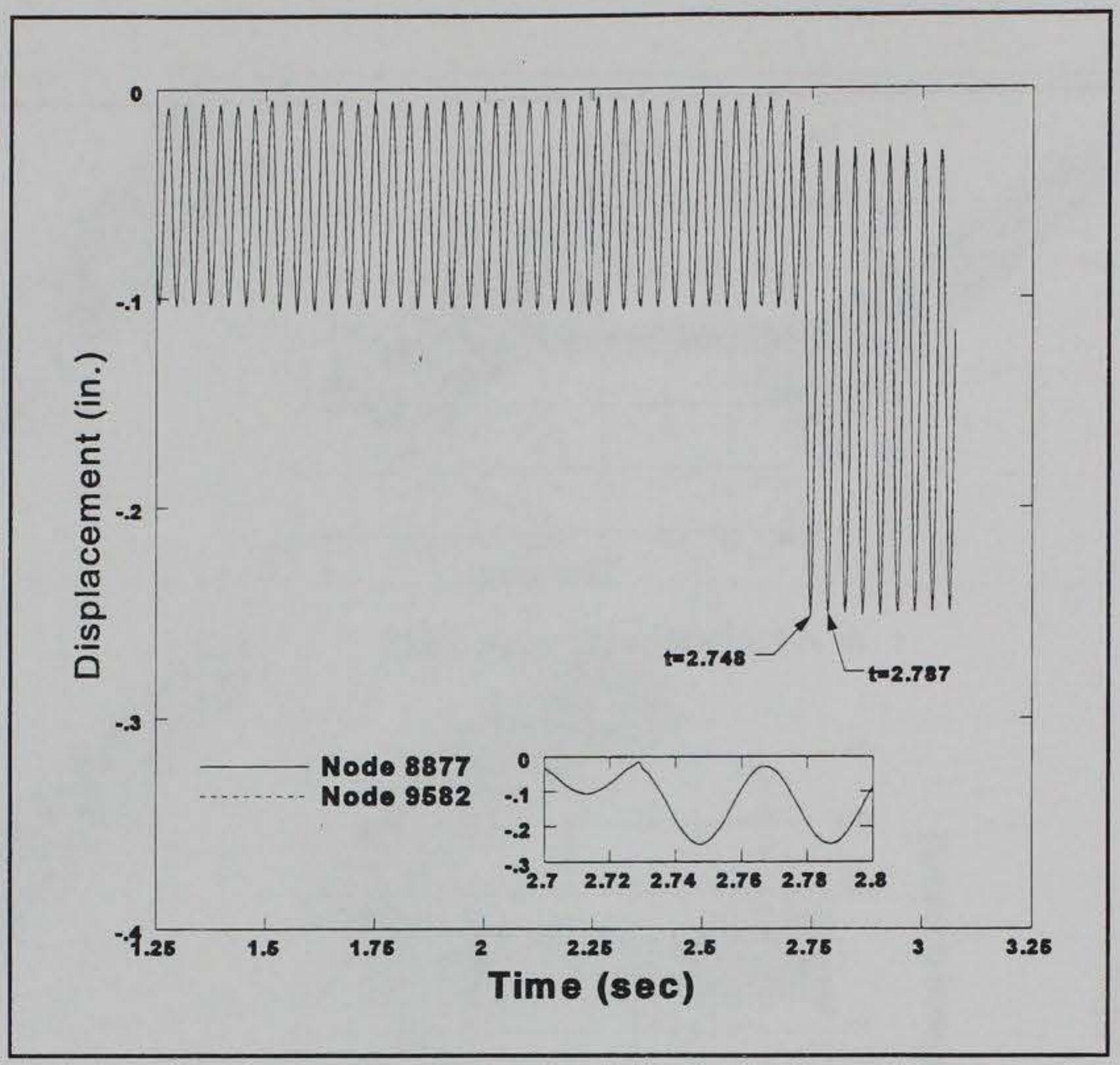

Figure 54. Displacements at top corner nodes

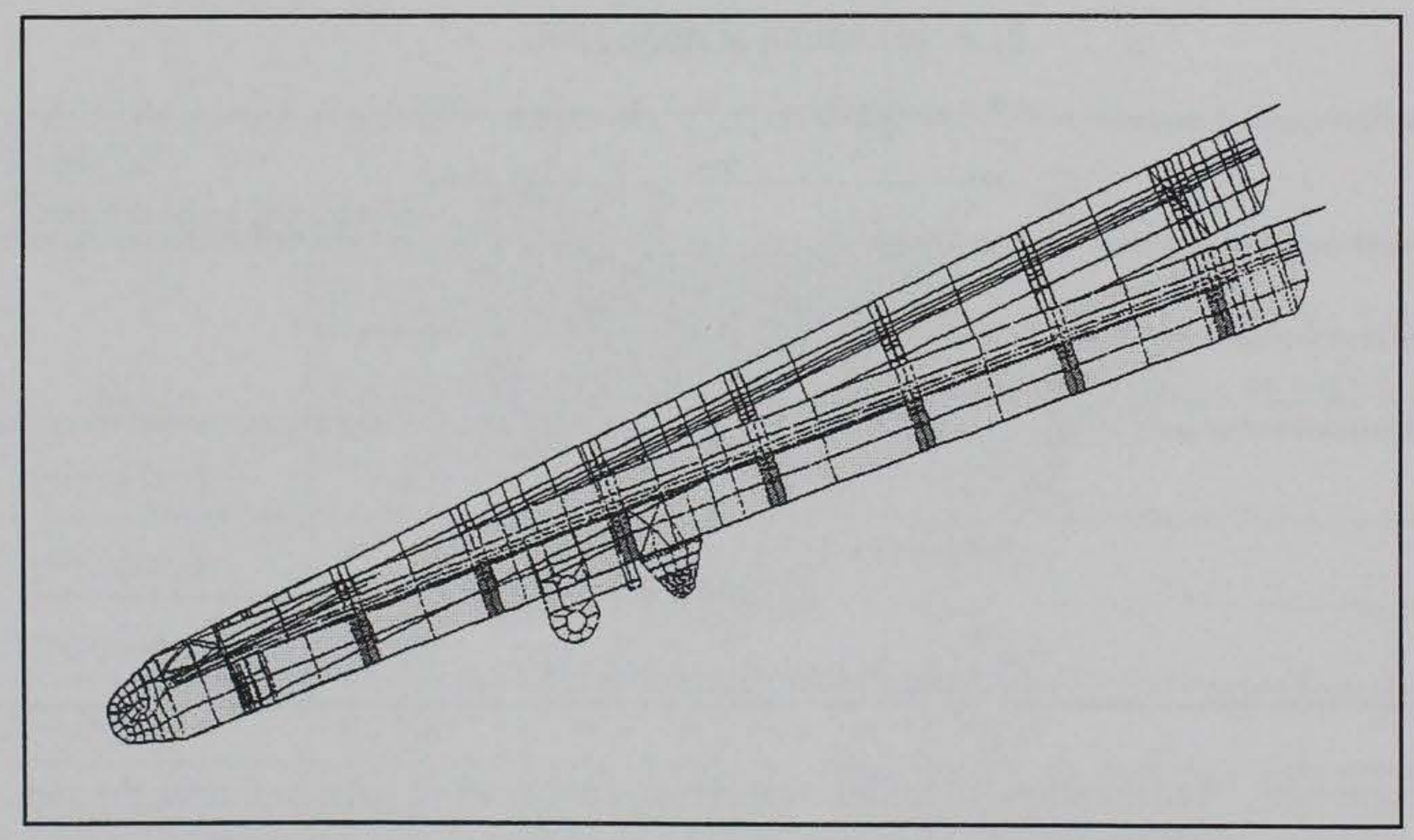

Figure 55. Displaced shape at $2.787 \mathrm{sec}$, magnification factor 20 


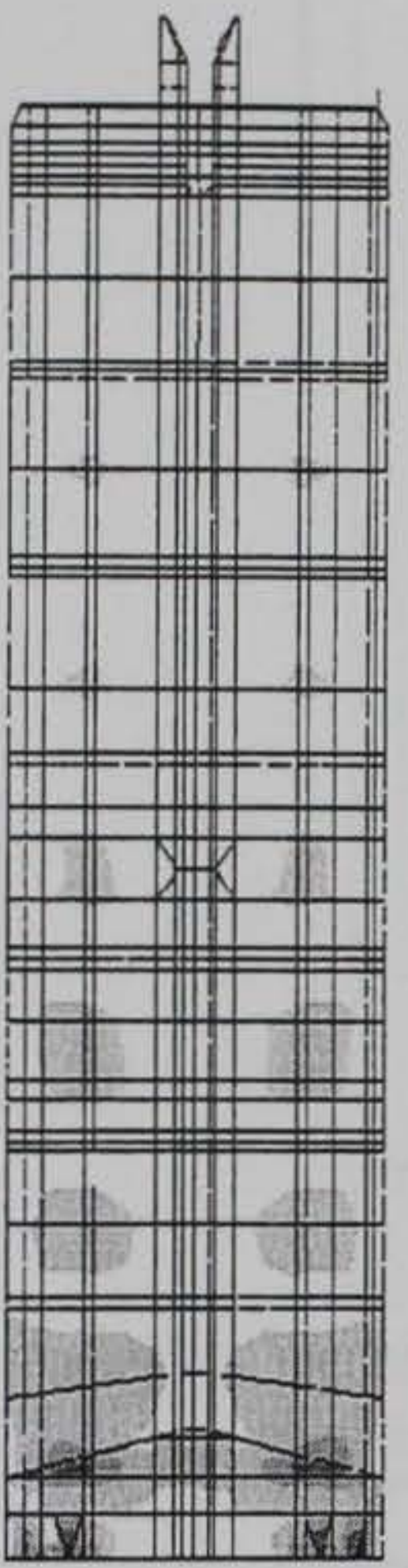

a. Top Surf, Layer 1

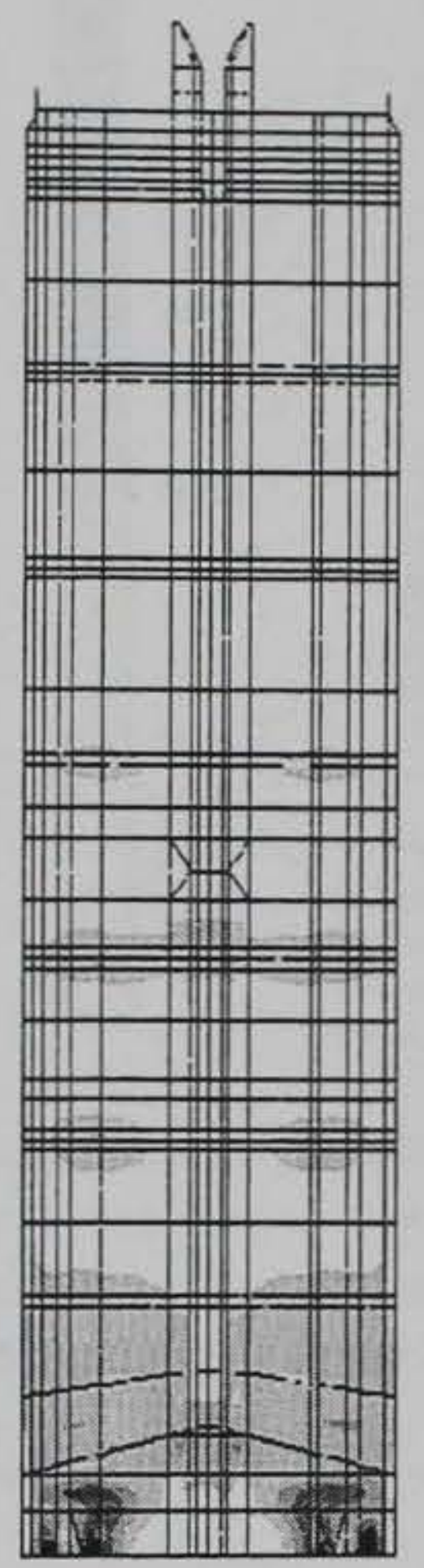

b. Top Surface, Layer 5
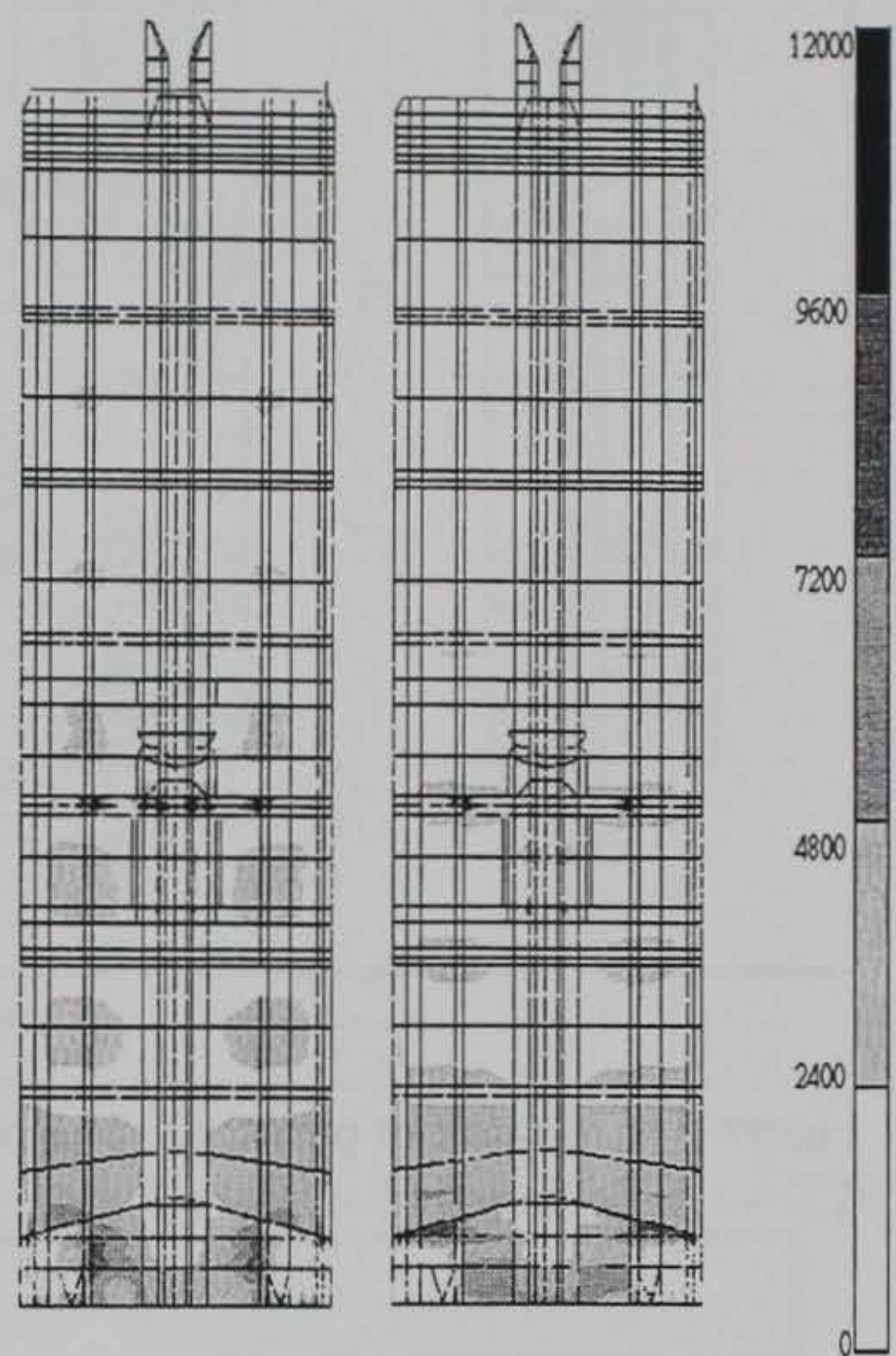

c. Bottom Surfaces, Layer 1

Figure 56. Maximum principal stress, gate top and bottom surfaces, $t=2.787 \mathrm{sec}$ 


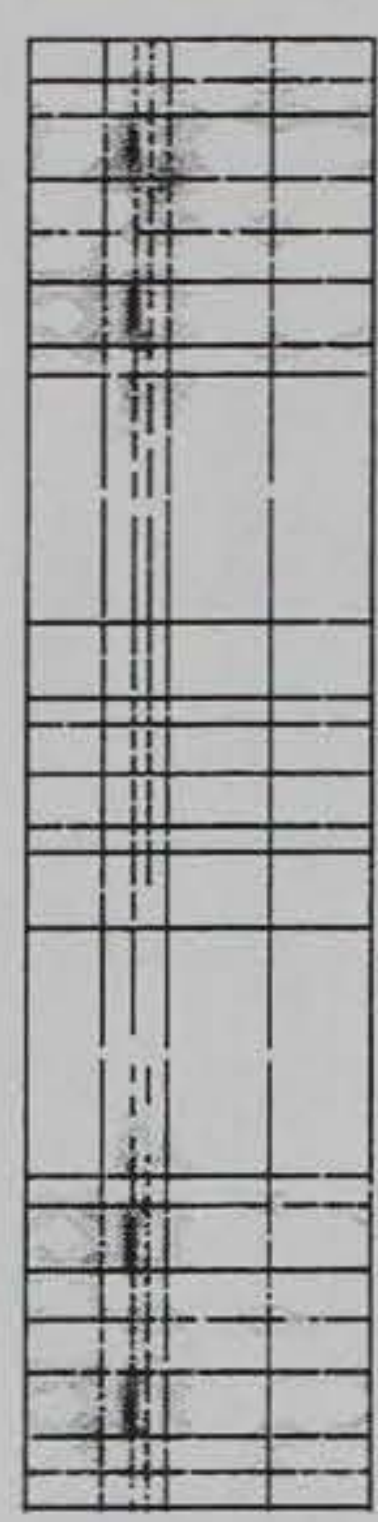

a. Layer 1

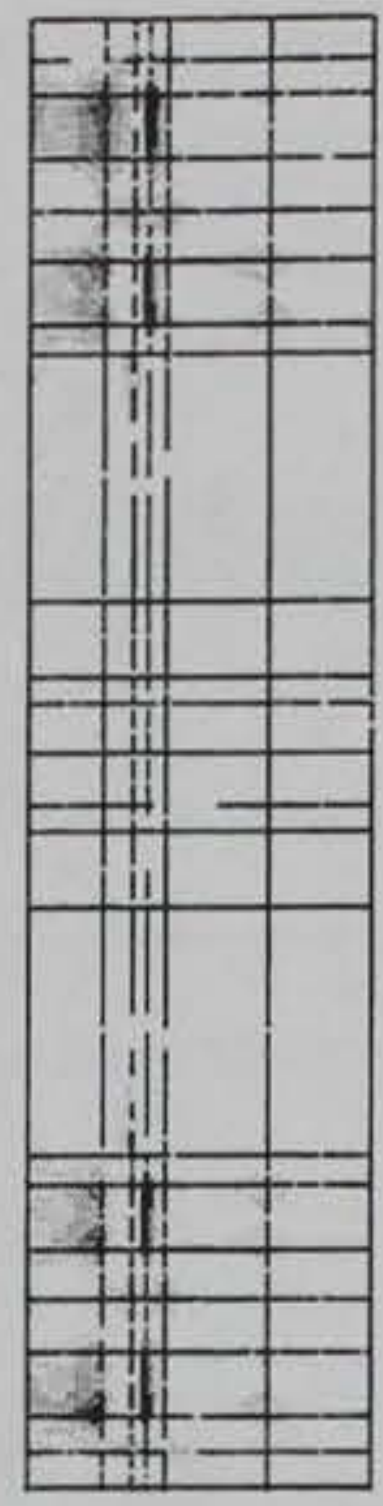

b. Layer 5

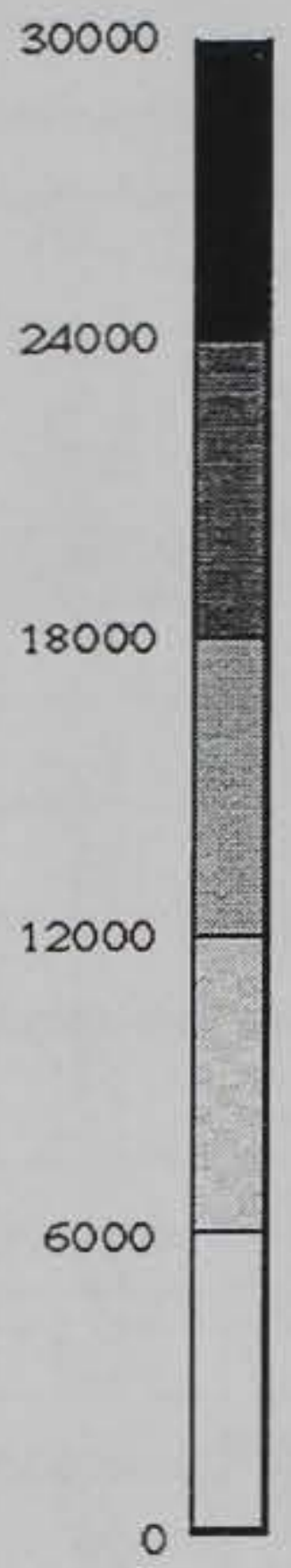

Figure 57. Maximum principal stresses on end plate, time $=2.787 \mathrm{sec}$

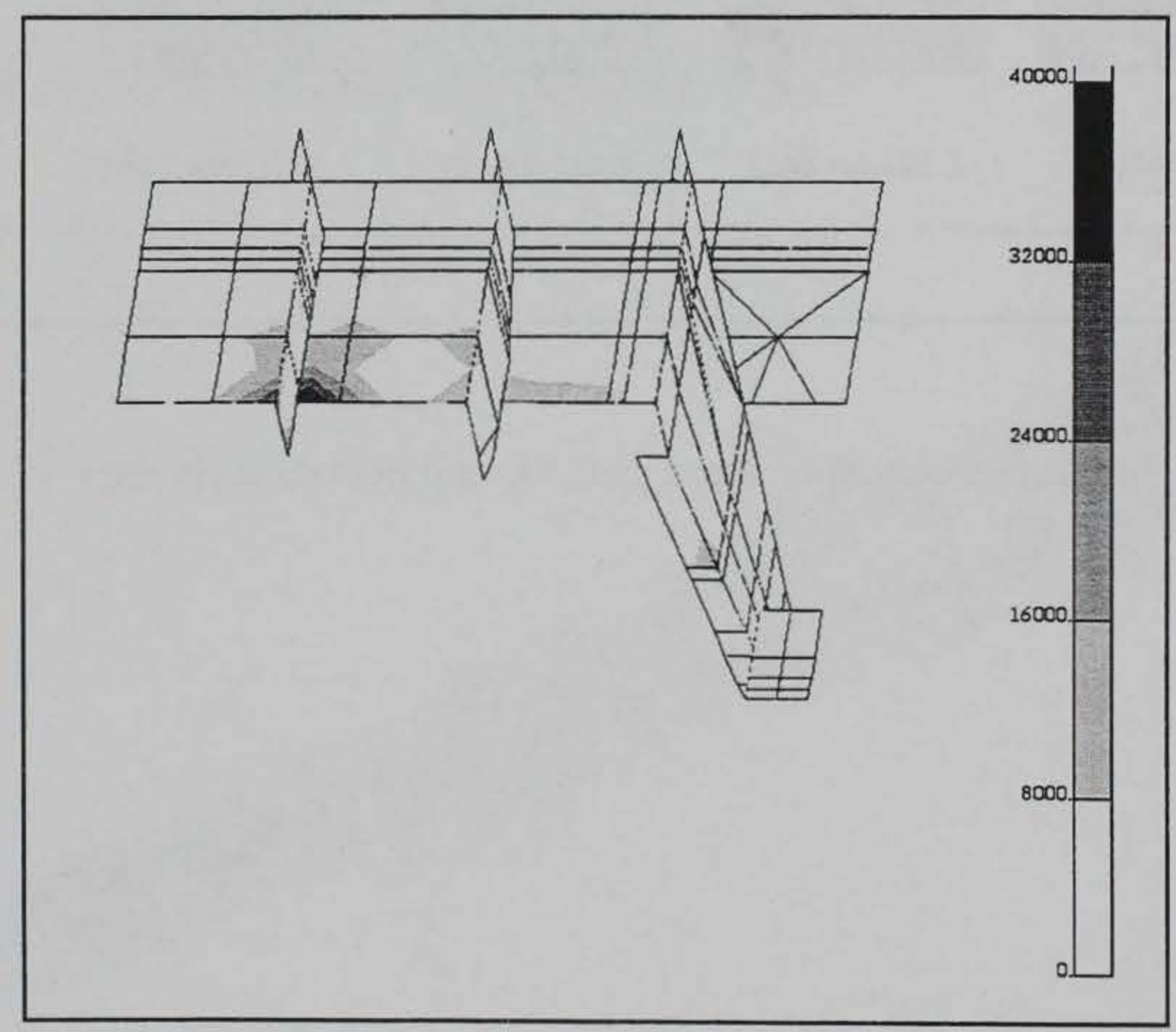

Figure 58. Maximum principal stresses at center support stiffeners, $\mathrm{t}=2.787 \mathrm{sec}$ 


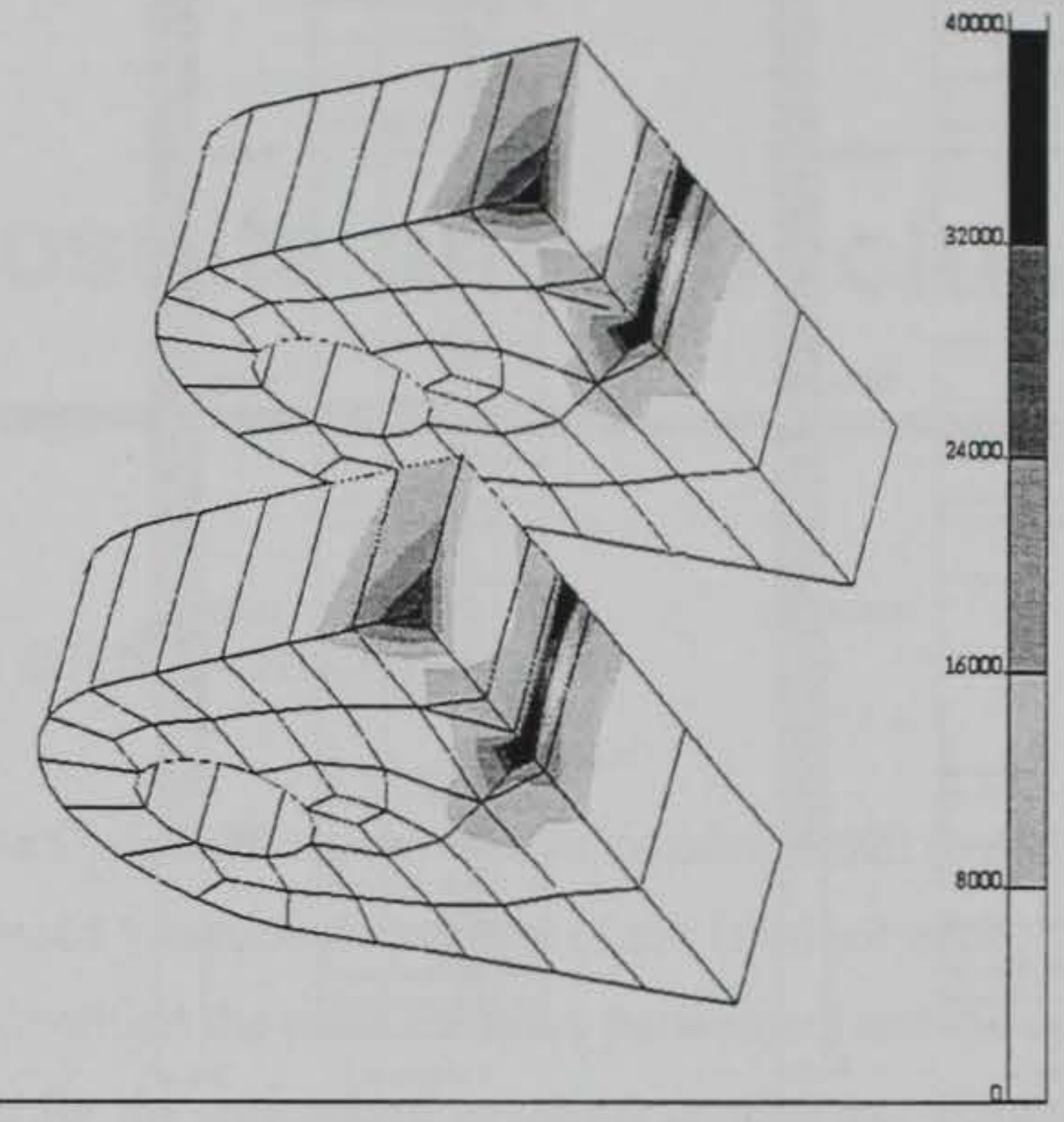

Figure 59. Maximum principal stresses in gate hinges, $\mathrm{t}=2.787 \mathrm{sec}$.

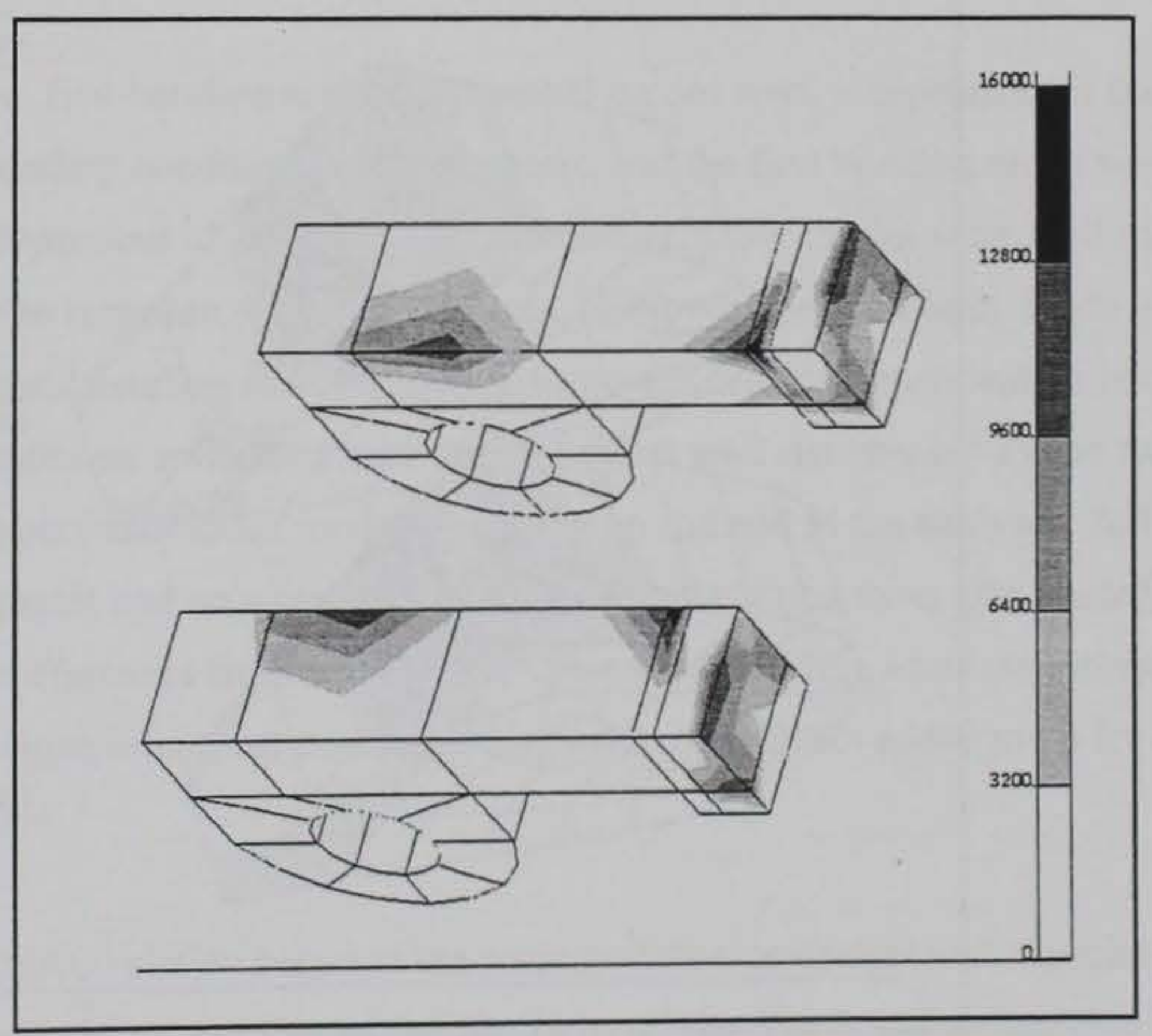

Figure 60. Maximum principal stresses at support-rod hinge, $\mathrm{t}=2.787 \mathrm{sec}$. 


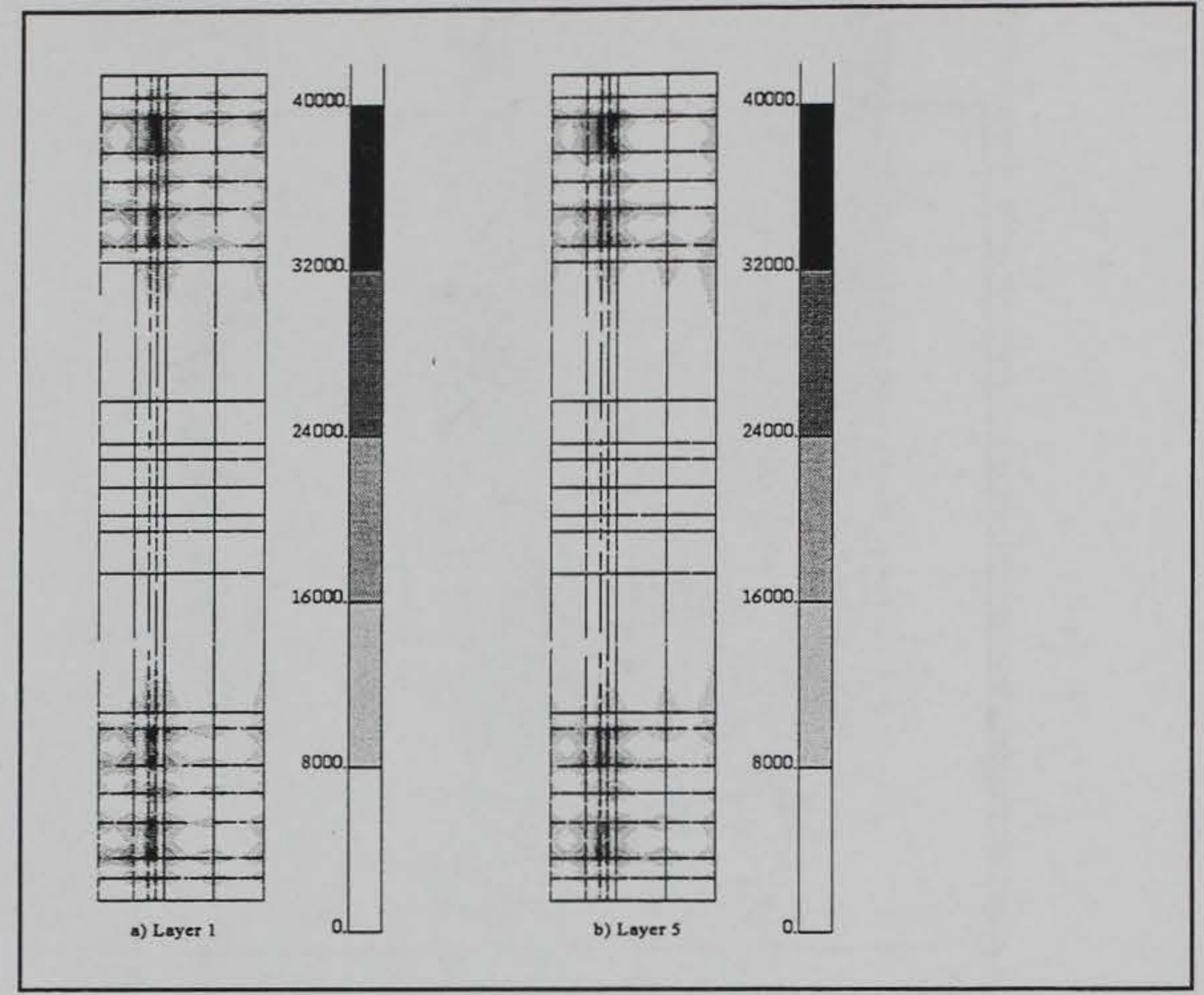

Figure 61. Von-Mises Stresses at end plate

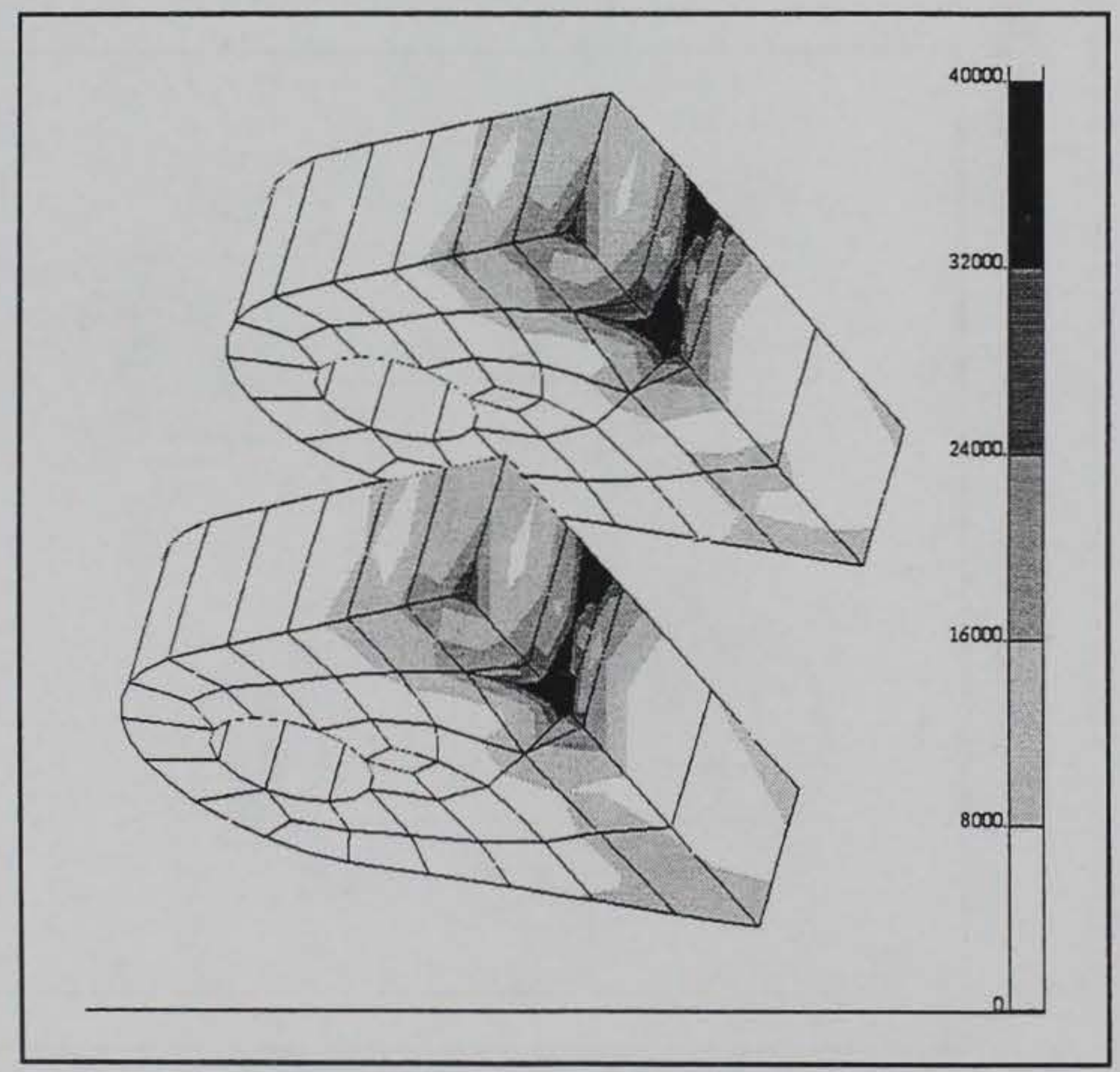

Figure 62. Von-Mises stresses at gate hinges 


\section{Results and Conclusions}

\section{Results and Conclusions}

An analytical FE model was successfully used to predict the static and the flow-induced vibrational response of the Olmsted wicket model. This study effectively identified the most sensitive parameters and the upper boundaries of the responses for the anticipated operating conditions. Boundary conditions were the most sensitive parameters among the variables studied in this investigation. Added-mass greatly influenced the dynamic characteristic of the wet wicket. This study also found:

a. The first bending and first torsional modes were independent of the boundary conditions at the supports, and the first bending mode was also independent of head of water. Therefore, these modes were well modeled in the response spectrum analyses. However, the rigid body mode and the second bending and torsional modes were heavily dependent on boundary conditions and added mass and were less well represented by the two support conditions modeled at the prop rod end in the analyses: full $\mathrm{z}$ restraint and no $\mathrm{z}$ restraint. The use of a weighted mass also contributed to differences from test data for these modes. More accurate estimations of eigenvalues can be obtained by using the correct added mass for each mode.

b. A MAC relation between the corresponding analytical and experimental mode shapes confirmed the similarity of the first four fundamental modes of the dry wicket. A high degree of correlation existed between the modes compared for the dry wicket. The participation factor obtained 
from the analytical results indicated that the most influential mode ( mode \# 5) that contributed significantly to the dynamics of the dry gate had a substantially high correlation (a MAC of 0.984 ) between the experimental and analytical shapes.

A good modal correlation of the corresponding most contributory modes indicated a good analytical representation of the wet physical model. The strong modes that are most contributory to the dynamics of the wet wicket had a high degree of correlation (a MAC of 0.826 ) with that of the physical mode.

c. The static test was modeled fairly accurately using a spring stiffness of $15,1761.6 \mathrm{lbf} / \mathrm{in}$, although the predicted displacements at the top of the gate were 22.8 percent less than test displacements, indicating that the F.E. model may be slightly stiffer than the test $1: 5$ model.

d. For the time period analyzed in the 65 -deg position of $5 \mathrm{sec}$, the frequency content of the dynamic analysis acceleration records differs somewhat from that of the test accelerometer records. Amplitudes of structural frequencies were low due to the low level of excitation, but peaks are visible in all records at approximately $46 \mathrm{~Hz}, 55 \mathrm{~Hz}$, and 72 to $75 \mathrm{~Hz}$ that may correspond to the rigid body mode, the first bending mode, and the first torsional mode, respectively. ABAQUS amplitudes are generally lower than test amplitudes for the first and second mode and higher than test amplitudes for the first torsional mode.

e. Calculated reactions (and therefore stresses) are extremely dependent on boundary conditions at the prop-rod end, and test reactions could not be reproduced by a single ABAQUS analysis. However, the two time-domain dynamic analyses (z-restraint and partial z-restraint at the prop end) produced reactions that bounded test reactions. In both analyses for the prop-supported wicket maximum principal stresses were low and should not present a problem for the simulated operating condition. 
A critical dynamic response analysis of the FE model indicated that a maximum principal stress of about $40 \mathrm{ksi}$ would develop on a very few isolated localized spots on the wicket for the extreme loading condition expected for the proposed flow-boundaries and the likely service conditions of the Olmsted wicket. In general, however, except at these few isolated spots, the upper boundaries of stresses of about $12 \mathrm{ksi}$ on the top and bottom faces of the wicket do not exceed the allowable stress limit for Grade 50 steel. Based on the Tresca's maximum shear stress and Von Mises maximum distortion energy failure theories, no failure state is anticipated due to the simulated applied load.

Larger stresses occurred at the end plates where the gate and proprod support hinges were attached and at vertical stiffeners near the center support. These hot spots are believed to be due to numerical error resulting from a few elements with distorted shape, poor aspect ratio, and relatively smaller size element compared to the adjacent ones. Like the element shape, the relative element size in relation to the adjacent elements can affect the numerical conditioning of the stiffness matrix (Shephard 1987). Numerical ill-conditioning could be a problem if the stiffness terms in a matrix differ by several orders of magnitudes.

A detailed $\mathrm{FE}$ analysis by subdividing the base of the hinges with properly sized and shaped elements is recommended for determining the realism of the existence of high localized stress.

This critical analysis used the upper boundaries of the pressure responses based on the Type - I EVD approach. These design loads at 99.99 percent confidence level provided the most critical estimation of the input pressures which would occur only during the lowering and raising of the wicket at or near the separation of the air-gap beneath the wicket. This analysis also included a pseudo load-factor of 1.18 in the analyzed segment of the input-pressure time-history. The wicket has to pass through this transition phase to engage in a prop support for regulating the navigational pool. A prop-supported gate is the actual service condition 
for an actively operated gate. Service loads for the prop-supported gate would induce a maximum principal stress of $2.5 \mathrm{ksi}$.

In general, the predicted critical stress for the Olmsted wicket is far below the AISC design flexural stress of $33 \mathrm{ksi}$ for the compact I-beam. This comparison effectively validates the design of the Olmsted wicket. A fatigue analysis using the modified Goodman line method also indicated a very high safety factor of 7.39 for the critical gate frame hinges. This observation is, however, limited to the operational sequences, head differences, and geometric configurations of the wicket and the flow-field covered in the experimental study. 


\section{References}

Allemang, R.J., and Brown, D.L. (1982). "A correlation coefficient for modal vector analysis." First International Modal Analysis Conference. Society of Experimental Mechanics, Union College, Bethel, CT.

American Institute of Steel Constructions (AISC). (1989). Manual of steel construction. $9^{\text {th }}$ ed., Chicago, IL.

American Society of Testing Materials (ASTM). (1995). "Test methods for tension testing of metallic materials." Annual book of ASTM standards. 03.01, West Conshohocken, PA.

Bretl, J. (1992). "Updating dynamic models using response sensitivities," Society Structural Dynamics Research Corporation, Milford, OH. (Copies can be requested from ATTN: SDRL, 2000 Eastman Dr. Milford, OH.)

Brillhart R. D., Dreyer W. M., Hunt, D. L., and Gehringer M. (1991). "Advanced modal test and correlation methods applied to the Atlas II payload fairing." Proceedings of the th $^{\text {th }}$ International Modal Analysis Conference. Society of Experimental Mechanics, Union College, Bethel, CT, 2, 1242-1248.

Buchanan, G. R. (1988). Mechanics of materials. Holt, Rinehart, and Wilson, New York, NY.

Calayir, Y., And Dumanoglu, A.A. (1993). "Static and dynamic analysis of fluid and fluid-structure systems by the Lagrangian method," Computers \& Structures 49(4), 625-632.

Chang, T. P. (1993). "Dynamic finite element analysis of a beam on random foundation," Computers \& Structures 48(4), 583-589.

Chowdhury, M. R., Hall, R. L., and Pesantes, E. (1997). "Flow-induced vibrational test results for a 1:25 flat wicket gate," Technical Report SL-97-04, U.S. Army Engineer Waterways Experiment Station, Vicksburg, MS.

Chowdhury, M. R., Hall, R. L., and Davis W. G. (1997). "Flow-induced structural response of a 1:5-scale Olmsted Wicket Model,", Technical Report SL-97-xx (in preparation), U.S. Army Engineer Waterways Experiment Station, Vicksburg, MS. 
Chowdhury, M. R., Ross, D. G., and Hall, R. L. (1997). "Experimental comparison of prototype and 1:5 wicket gates," Technical Report SL-97-05, U.S. Army Engineer Waterways Experiment Station, Vicksburg, MS.

Daniell W.E. and Taylor C.A. (1994). "Full-scale dynamic testing and analysis of a reservoir intake tower," Earthquake Engineering and Structural Dynamics 23(11), 1219-1237.

Dascotte, E. (1991). "Applications of finite element model tuning using experimental modal data," Sound and Vibration 25(6), 22-26.

Elder R. A. (1992). "Review of the 1:25 scale hydraulic model Olmsted wicket dam," Consulting Hydraulics Engineers, Cincinnati, $\mathrm{OH}$.

Ewins, D.J. (1984). Modal testing: Theory and practice. Research Studies Press, Letchworth, England.

HKS Inc. (1994). “ABAQUS users manual,” Version 5.4, Pawtucket, RI.

Ishii, N., and Knisely, C., (1992). "Flow-induced vibrations of long-span gates due to shed vortices," JSME International Journal, series 3, 35(1), 1-8.

Lance, G. R. (1992). "Developing an operating plan for Olmsted locks and dam." $4^{\text {th }}$ Water Resources Operations Management Workshop. American Society of Civil Engineers, New York, NY.

Lin, R. M., Du, H., and Ong, J.H. (1993). "Sensitivity based method for structural dynamic model improvement," Computers \& Structures 47(3), 349-369.

Lindeburg, M. R. (1994). Mechanical engineering reference manual. $9^{\text {th }}$ ed., Professional Publications, San Carlos, CA.

March, T. A., and Elder, R. A. (1992). "Review of the 1:25-Scale Hydraulic Model Olmsted Wicket Dam," U.S. Army Engineer Division, Ohio River, Contract \# DACW55-92-0187, Cincinnati, OH.

Meyer, C., and Will, K.M. (1987). "Models for dynamic analysis." Finite element idealization. C. Meyer, ed., ASCE, New York, NY, 273-301. 
Niedbal, N. (1985). "Experimental system identification for experimental/ analytical correlation and modeling." Joint ASCE/ASME Mechanics Conference. ASME, New York, NY, 67, 195-204.

Okuma, M. (1993). "Correction of finite element models using experimental modal data for vibration analysis," The International Journal of Applied Finite Element \& Computer Aided Engineering 14(2 and 3), 153-162.

Petrick L. (1993). "Correlation of experimental and analytical models of a crosscountry ski, "Sound and Vibration 27(6), 18-23.

Ridlon S. (1987). "Modeling guidelines." Finite element idealization. C. Meyer, ed., ASCE, New York, NY, 212-272.

Seda-Sanabria, Y. (1994). "Dynamic behavior study of a wicket gate of the Olmsted Dam in Ohio River", M.S. thesis, University of Puerto Rico-Mayaguez.

Shephard M. S. (1987). "Preanalysis processing." Finite element idealization. C. Meyer, ed., ASCE, New York, NY, 142-175.

Soast, A. (1994)., "Record size lock and dam project gets a soggy launch as rains swell the lower Ohio River for months," Engineering News Record 24-26.

Structural Dynamic Research Corporation. (1993). "I-DEAS Master Series 1.2," Milford, $\mathrm{OH}$.

Thang, N.D. (1982). "Added mass behavior and its characteristics at sluice gates." Flow induced vibrations in fluid engineering. BHRA Fluid Engineering, Cranfield, England, 13-28.

Touhei, T., and Ohmachi, T. (1994). "Modal analysis of a dam-foundation system based on an FE-BE method in the time domain," Earthquake Engineering and Structural Dynamics 23(1), 1-15.

Wirsching, P., and Ortiz, K. (1993). "Reliability Methods in Mechanical and Structural Design." $14^{\text {th }}$ Annual Seminar and Workshop, College of Engineering and Mines, Aerospace and Mechanical Engineering Department, University of Arizona, Tucson, AZ. 


\section{Appendix A Selected Prototype Design Sheets}




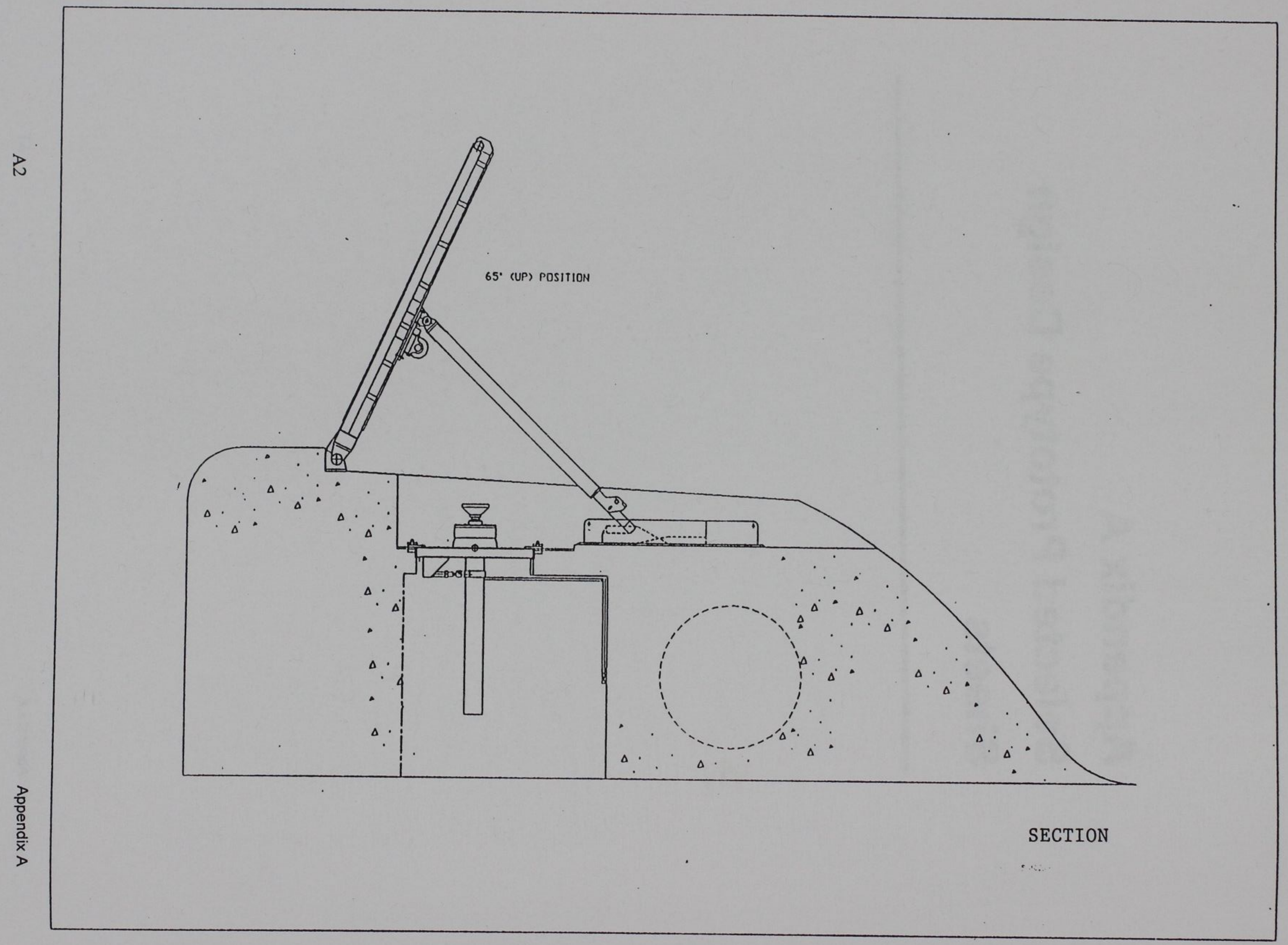




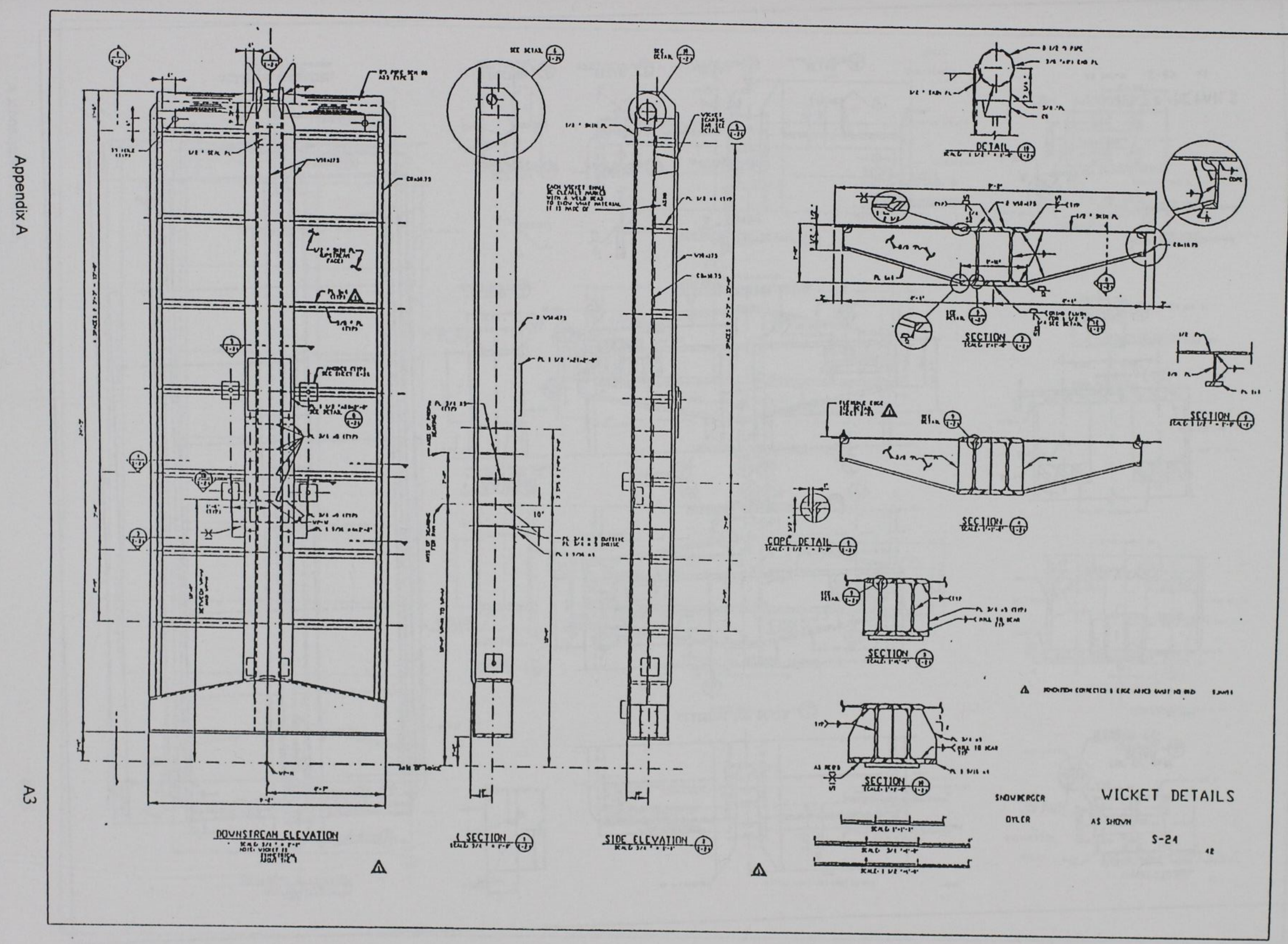




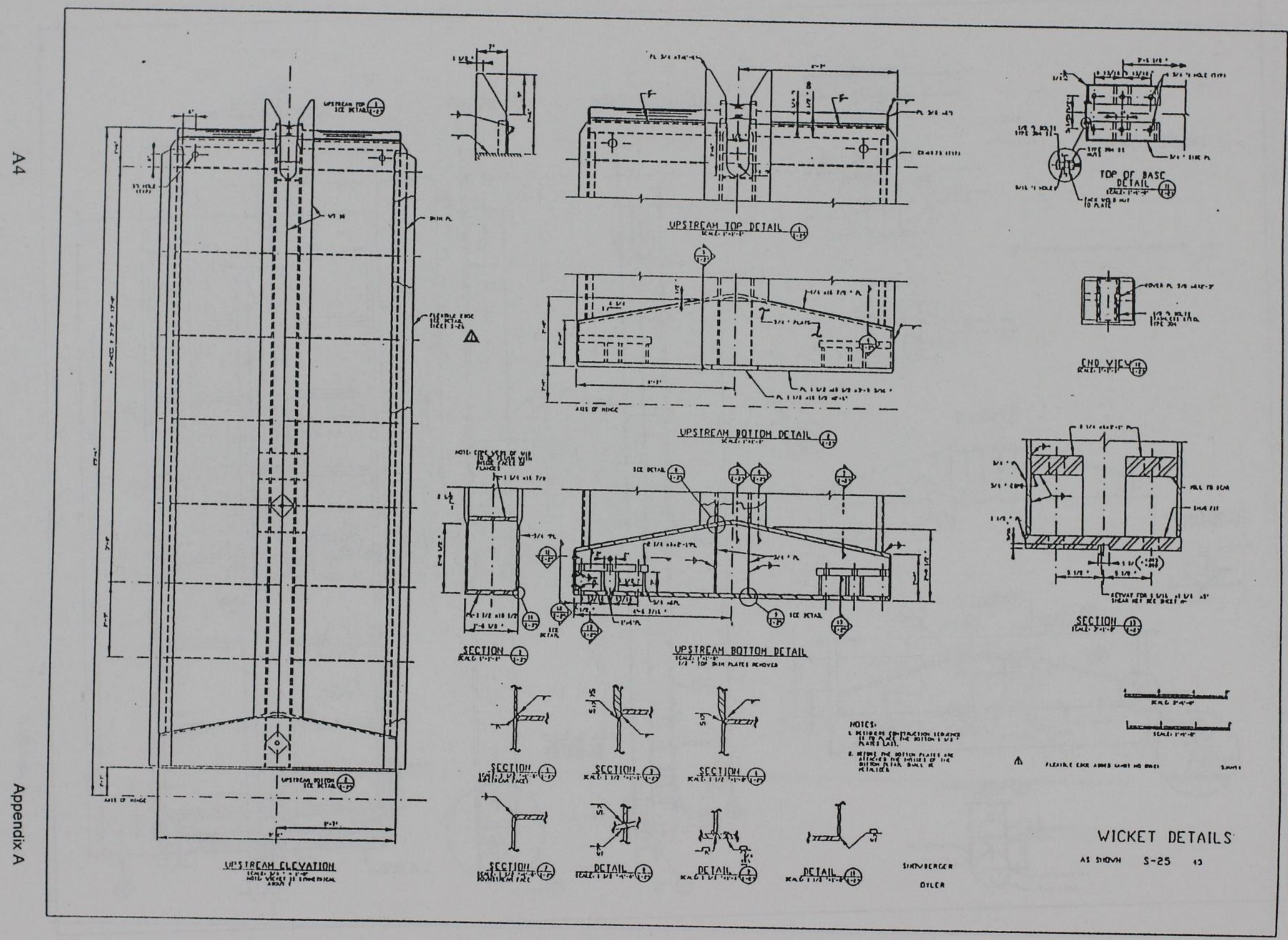




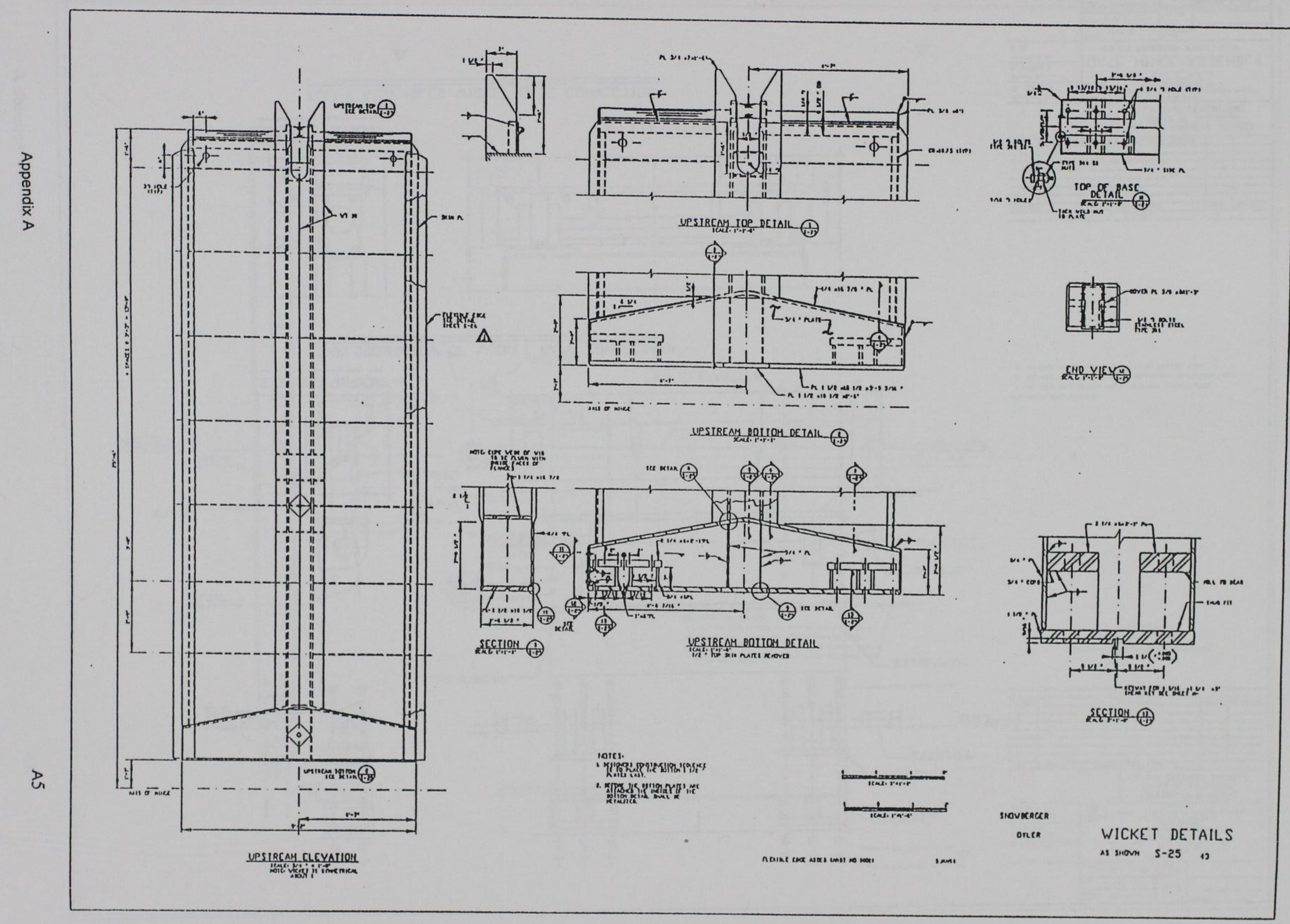




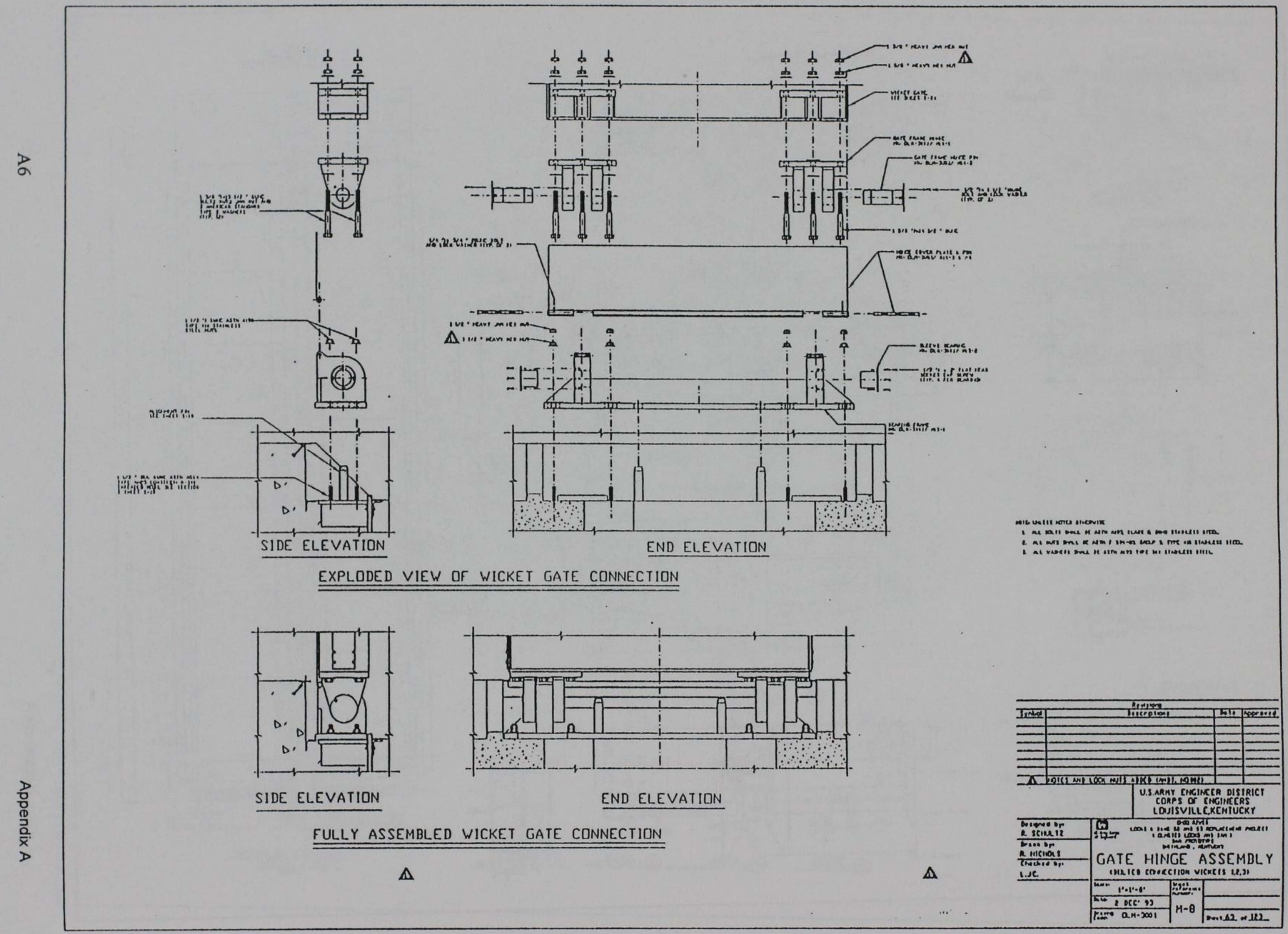




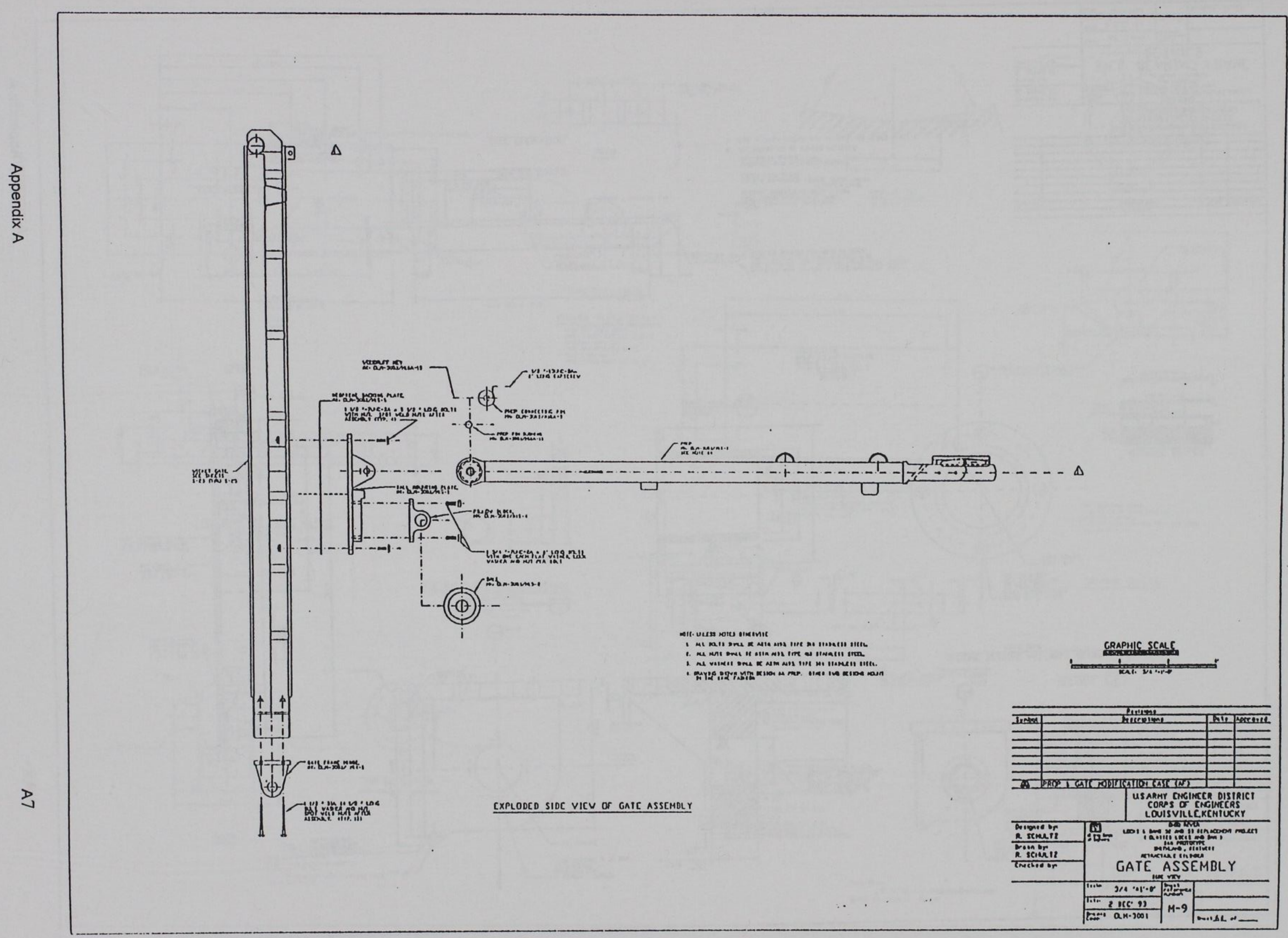




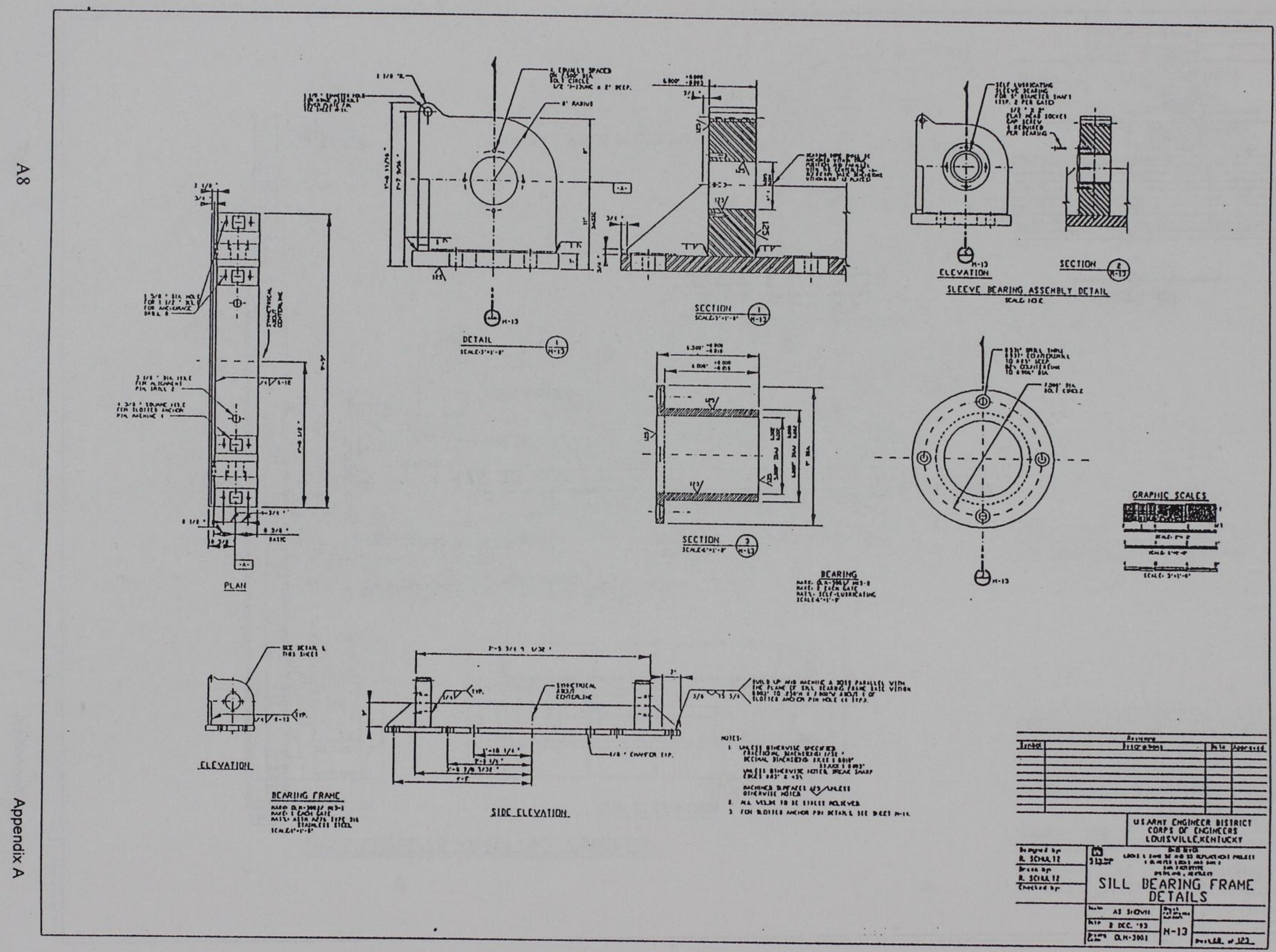




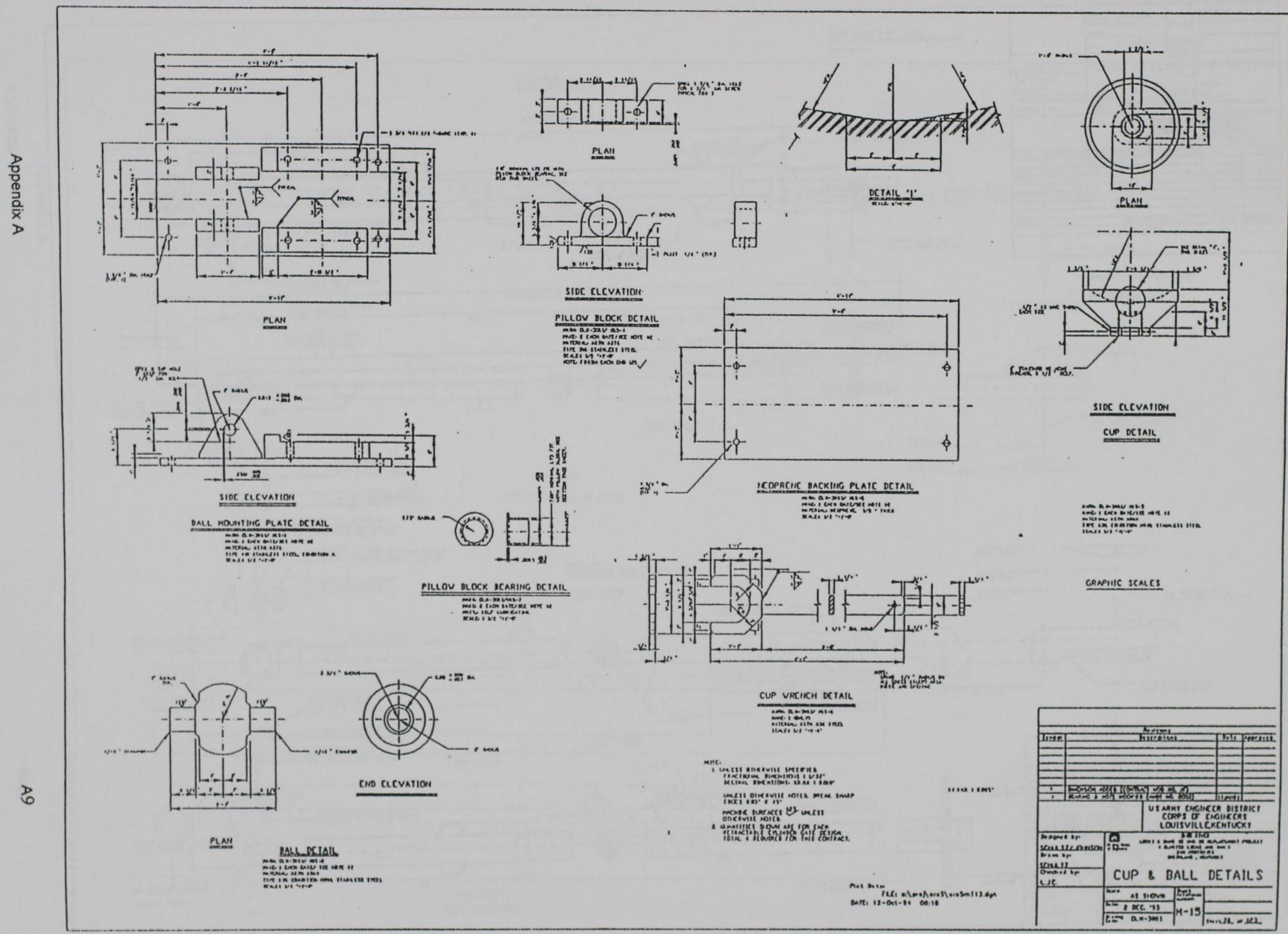




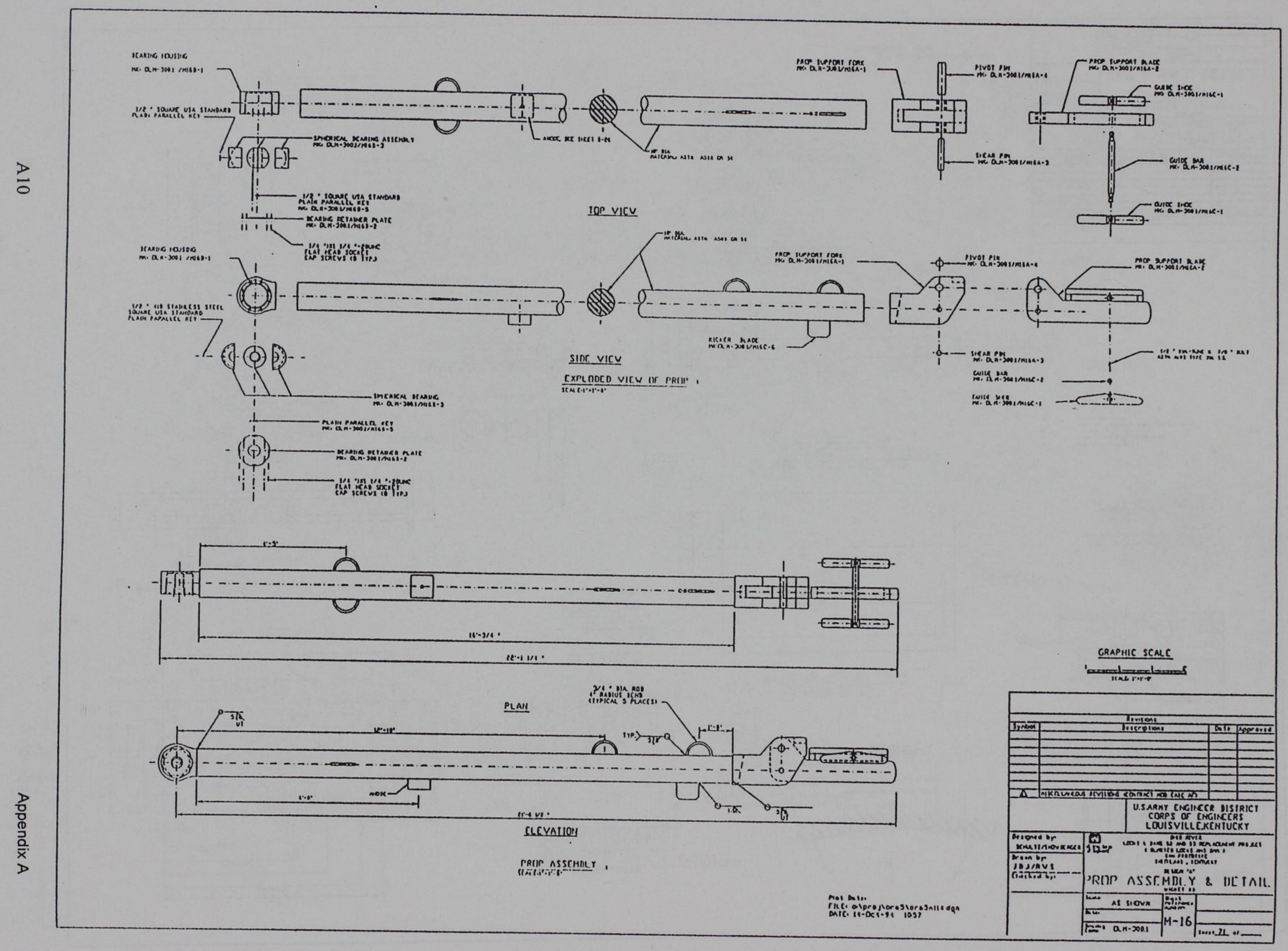




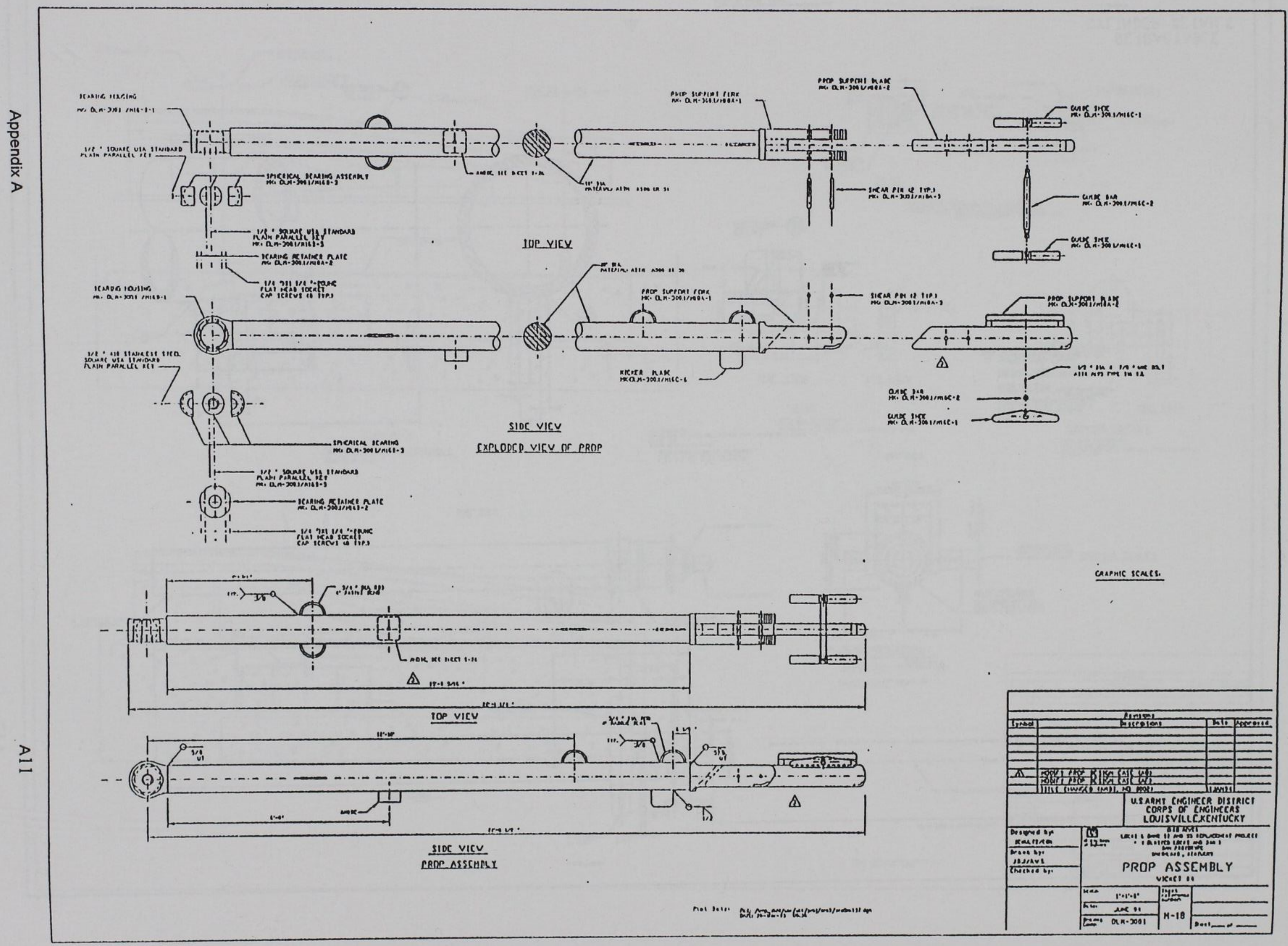




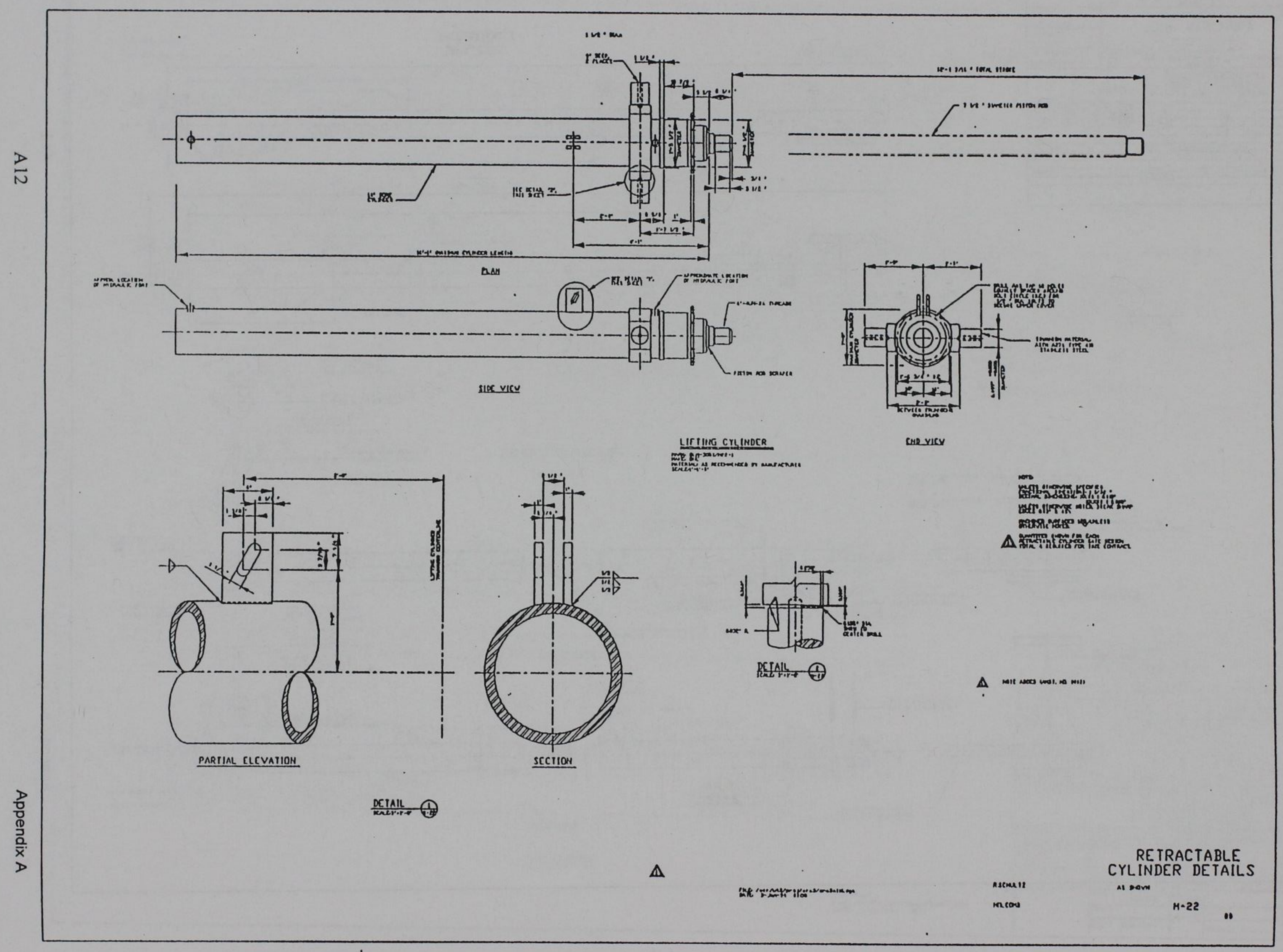




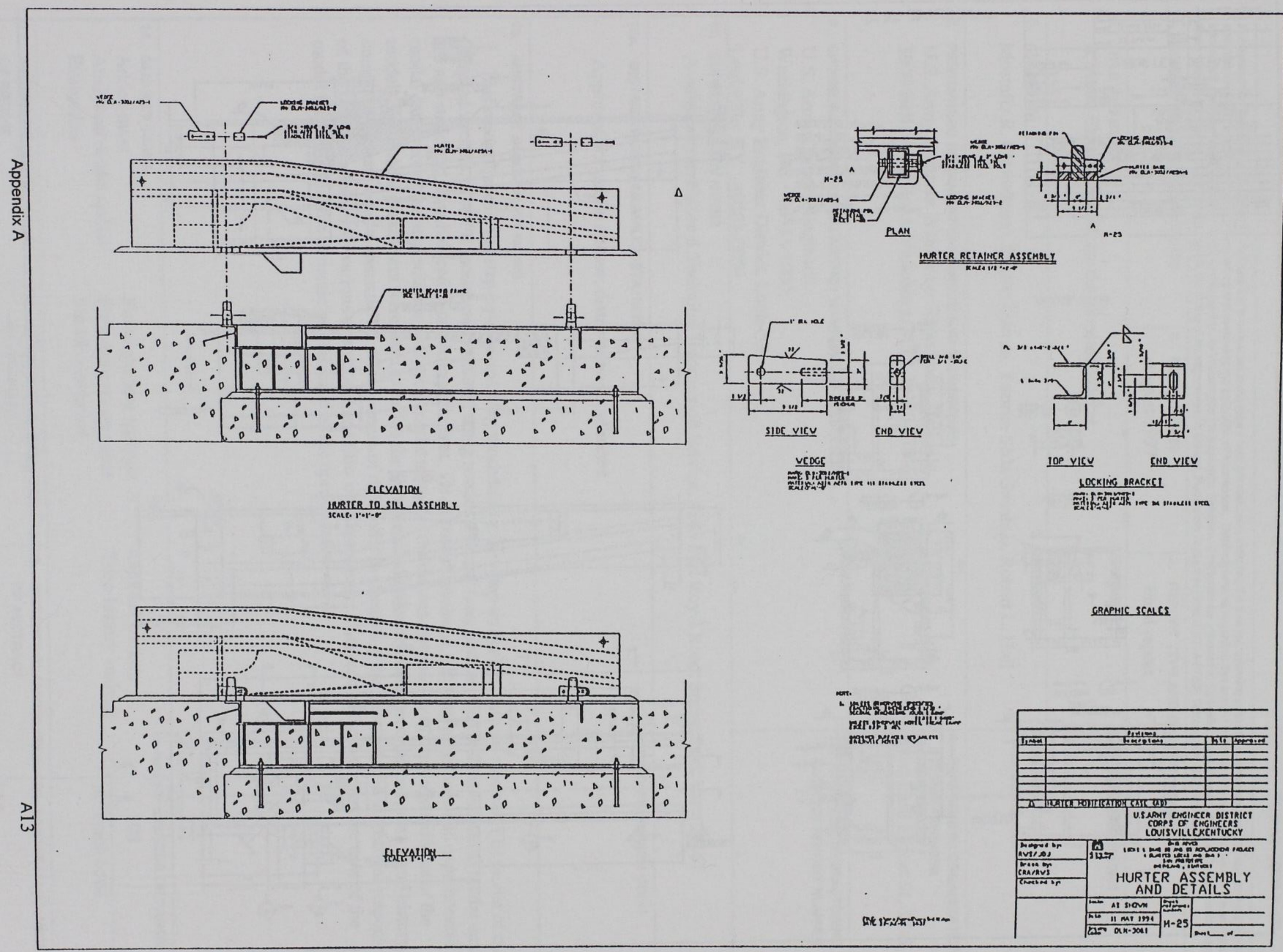




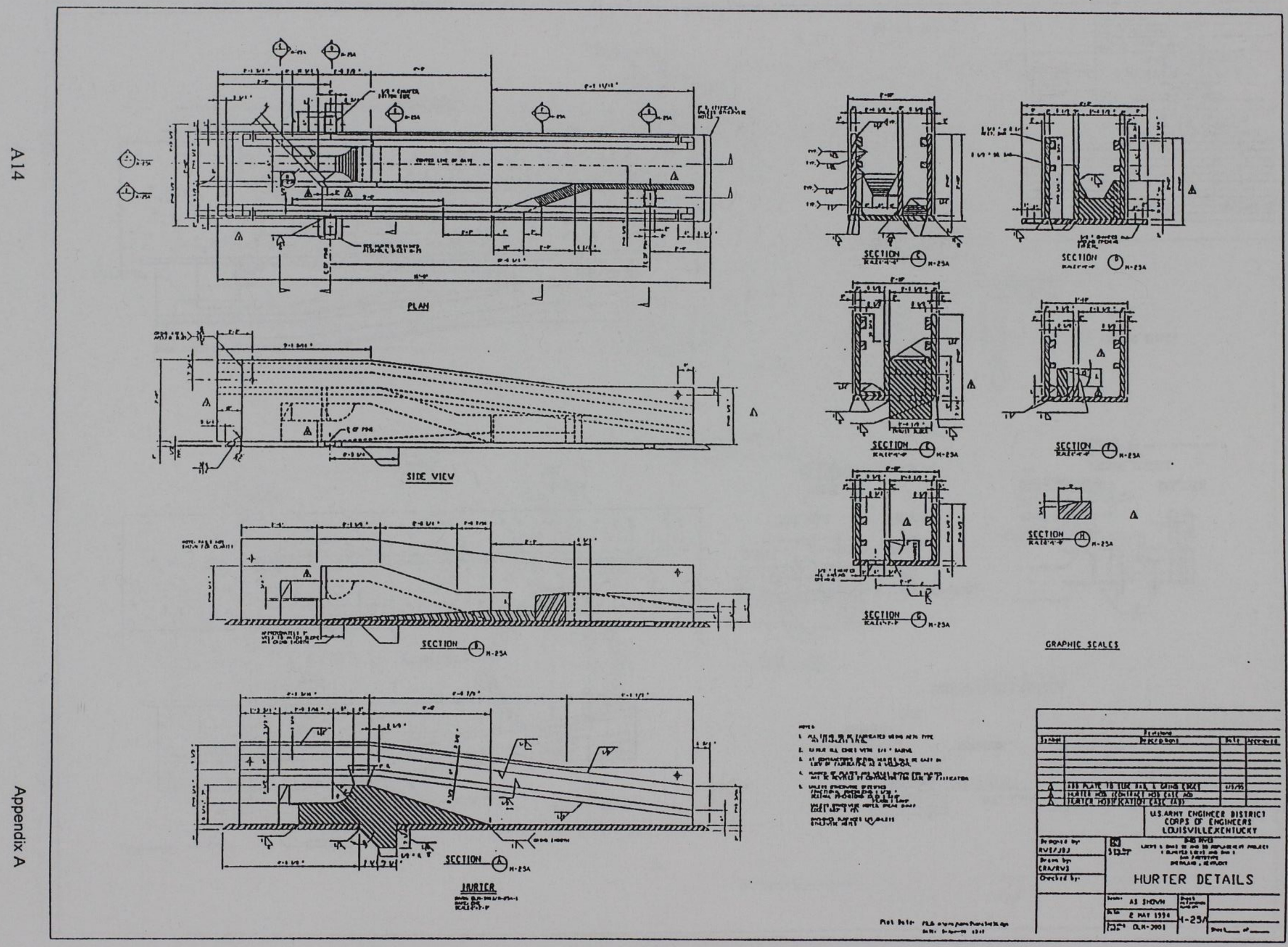


Public reporting burden for this collection of information is estimated to average 1 hour per response, including the time for reviewing instructions, searching existing data sources, gathering and maintaining the data needed, and completing and reviewing the collection of information. Send comments regarding this burden estimate or any other aspect of this collection of information, including suggestions for reducing this burden, to Washington Headquarters Services, Directorate for Information Operations and Reports, 1215 Jefferson Davis Highway, Suite 1204, Arlington, VA 22202-4302, and to the Office of Management and Budget, Paperwork Reduction Project (0704-0188), Washington, DC 20503.

\begin{tabular}{|l|l|l|}
\hline 1. AGENCY USE ONLY (Leave blank) & $\begin{array}{c}\text { 2. REPORT DATE } \\
\text { August } 1997\end{array}$ & $\begin{array}{l}\text { 3. REPORT TYPE AND DATES COVERED } \\
\text { Final report }\end{array}$ \\
\hline
\end{tabular}

\section{TITLE AND SUBTIILE}

A Finite-Element Model for the Olmsted Wicket

5. FÛNDING NUMBERS

\section{AUTHOR(S)}

Mostafiz R. Chowdhury; Sharon Garner, Yazmin Seda-Sanabria, Robert L. Hall

7. PERforming organization NAME(S) AND ADDRESS(ES)

U.S. Army Engineer Waterways Experiment Station

3909 Halls Ferry Road, Vicksburg, MS 39180-6199
8. PERFORMING ORGANIZATION REPORT NUMBER

Technical Report SL-97-6

9. SPONSORINGMONTORING AGENCY NAME(S) AND ADDRESS(ES)

U.S. Army Corps of Engineers

10. SPONSORINGMONITORING AGENCY REPORT NUMBER

Washington, DC 20314-1000;

U.S. Army Engineer District, Louisville

Louisville, KY 40201-0059

\section{SUPPLEMENTARY NOTES}

Available from National Technical Information Service, 5285 Port Royal Road, Springfield, VA 22161.

\section{2a. DISTRIBUTIONAVAILABILTY STATEMENT}

12b. DISTRIBUTION CODE

Approved for public release; distribution is unlimited.

\section{ABSTRACT (Maximum 200 words)}

This report presents the step-by-step updating procedures to develop an analytical finite element (FE) model of the Olmsted wickets. The FE model was validated using results obtained from both dry and wet experimental modal analyses and static and flow-induced dynamic experiments. Geometric dimensions, physical properties, and experimental modal data were correlated with the analytical model to ensure the correct distribution of mass and stiffness of the model. Wet modal parameters were used to define the added mass distribution of the operational gate. Time-history comparisons were used to measure the effectiveness of the model in simulating the flow-induced vibrational response of the Olmsted wickets for various operational and flow comfigurations. This report also describes the uses of the model for evaluating the dynamic performance of the operational wicket.

14. SUBJECT TERMS Added-mass Analytical model update Evaluation
Finite-element analysis Flow-induced response Modal correlation
Olmsted wickets

Time-history analysis
15. NUMBER OF PAGES 108

16. PRICE CODE

20. LMITATION OF ABSTRACT

17. SECURTY CLASSIFICATION OF REPORT UNCLASSIFIED
18. SECURTY CLASSIFICATION OF THIS PAGE UNCLASSIFIED
19. SECURITY CLASSIFICATION OF ABSTRACT 